UNIVERSIDADE DE SÃO PAULO

FACULDADE DE MEDICINA DE RIBEIRÃO PRETO

PÓS-GRADUAÇÃO EM IMUNOLOGIA BÁSICA E APLICADA

$O$ receptor NLRP1 atua como um regulador do perfil de resposta Th17 em modelos experimentais e em humanos com diabetes tipo 1

Frederico Ribeiro Campos Costa

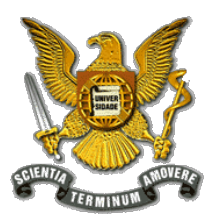

Ribeirão Preto - SP 
FREDERICO RIBEIRO CAMPOS COSTA

$O$ receptor NLRP1 atua como um regulador do perfil de resposta Th17 em modelos experimentais e em humanos com diabetes tipo 1

Tese apresentada ao curso de Pós-graduação em Imunologia Básica e Aplicada da Faculdade de Medicina de Ribeirão Preto da Universidade de São Paulo para obtenção do grau de Doutor em Ciências - Área de concentração: Imunologia Básica e Aplicada.

Orientação: Dra ${ }^{\mathrm{a}}$. Daniela Carlos Sartori 
AUTORIZO A REPRODUÇÃO E DIVULGAÇÃO TOTAL OU PARCIAL DESTE

TRABALHO, POR QUALQUER MEIO CONVENCIONAL OU ELETRÔNICO, PARA FINS DE ESTUDO E PESQUISA, DESDE QUE CITADA A FONTE.

\section{FICHA CATALOGRÁFICA}

Costa, Frederico Ribeiro Campos

O receptor NLRP1 atua como um regulador do perfil de resposta

Th17 em modelos experimentais e em humanos com diabetes tipo 1.

Ribeirão Preto, 2018. 143p.; Il.; 30cm

Tese de Doutorado apresentada à Faculdade de Medicina de Ribeirão Preto/USP. Área de concentração: Imunologia Básica e Aplicada.

Orientador(a): Sartori, Daniela Carlos.

1. Diabetes tipo 1. 2. NLRP1. 3.Resposta imune inata. 4. Microbiota intestinal. 5. Th17 


\section{FOLHA DE APROVAÇÃO}

\section{Frederico Ribeiro Campos Costa}

O receptor NLRP1 atua como um regulador do perfil de resposta Th17 em modelos experimentais e em humanos com diabetes tipo 1

Tese de Doutorado apresentada à Faculdade de Medicina de Ribeirão Preto da Universidade de São Paulo para obtenção do título de Doutor em Ciências. Área de concentração: Imunologia Básica e Aplicada

Aprovado em:

\section{Banca Examinadora}

Dr$^{\mathrm{a}}$. Daniela Carlos Sartori

Instituição: FMRP-USP

Assinatura:

Prof $^{\mathrm{a}}$. Dr ${ }^{\mathrm{a}}$. Maria Cristina Foss de Freitas

Instituição: FMRP-USP Assinatura:

Prof $^{\mathrm{a}}$. Dr ${ }^{\mathrm{a}}$. Alexandra Ivo de Medeiros

Instituição: FCFAr-UNESP

Assinatura:

Prof ${ }^{\mathrm{a}}$. Dr ${ }^{\mathrm{a}}$. Alessandra Pontillo

Instituição: ICB-USP

Assinatura:

Prof. Dr. Niels Olsen Saraiva Câmara

Instituição: ICB-USP

Assinatura:

Trabalho realizado no Laboratório de Imunoparasitologia, Departamento de Bioquímica e Imunologia da Faculdade de Medicina de Ribeirão Preto da Universidade de São Paulo, com auxílio Financeiro da Capes, CRID, NAP-Din, CNPq e FAPESP 
Dedico este trabalho aos meus pais, Arlete e Epaminondas. Vocês são o meu alicerce.

Amo vocês. 


\section{AGRADECIMENTOS}

Aos meus pais, Arlete e Epaminondas, minha irmã Raquel e minha namorada Bruna, muito obrigado por compartilharem comigo os momentos felizes, pelo incentivo nos momentos difíceis e pelo conforto e carinho que sempre estão à minha espera quando chego em Uberlândia. Sem vocês, nada seria possível.

Ao prof. Dr. João Santana, apesar de não “estar no papel”, eu me considero como um aluno do senhor. Muito obrigado pelos ensinamentos e por ceder o seu laboratório de Imunoparasitologia para a pesquisa de uma doença autoimune. Serei eternamente grato ao senhor.

À Dr. ${ }^{a}$ Daniela Carlos, muito obrigado pela orientação ao longo desses seis anos (dois de mestrado e quatro de doutorado), pela confiança no meu trabalho e pelas oportunidades.

Aos colegas do laboratório de Imunoparasitologia e do programa de pós-graduação em Imunologia Básica e Aplicada, obrigado pela parceria ao longo desses seis anos.

À Dr. ${ }^{a}$ Diane Meyre Rassi, muito obrigado por toda a ajuda na coleta das amostras de pacientes no HC. Seja magrinha ou com um barrigão carregando o filhão, seu sorriso e disposição para as coletas sempre continuaram os mesmos. Obrigado pela parceria e amizade.

À prof. Dr. ${ }^{a}$ Maria Cristina Foss de Freitas e à toda equipe da Endocrinologia do HC da FMRP-USP, obrigado pela atenção, apoio e colaboração, desde a submissão do projeto com humanos ao Comitê de Ética do HC até o momento da coleta de amostras de pacientes. 
Ao apoio técnico, Rubilan, vulgo “Rubs”, Dener Reis, Wander Ribeiro, Cristiane Milanezi

e Denise Ferraz, obrigado pelo auxílio na execução dos experimentos da presente tese; e à Ana Cristine, muito obrigado pelo profissionalismo, amizade e ajuda durante meu doutorado.

Aos meus queridos amigos de Uberlândia: Leandro Pedreiro Carneiro, Gustavo Bambu Freitas, Patrício da Silva Cardoso Black, “Dr.” Guilherme de Queiroz, Prof. Dr. Silas Silva Santana e Zezé Machado, obrigado pela amizade, incentivo e parceria.

À FAPESP, CAPES e CNPq pela concessão da bolsa, permitindo a realização deste trabalho. 
"Uma carreira acadêmica em que a pessoa é forçada a produzir textos científicos em grande quantidade gera o risco da superficialidade intelectual" Albert Einstein 


\section{ÍNDICE}

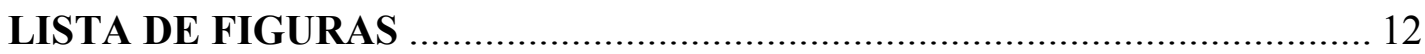

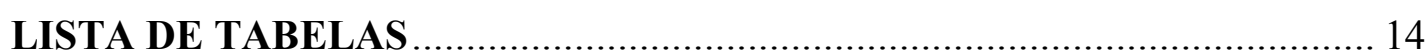

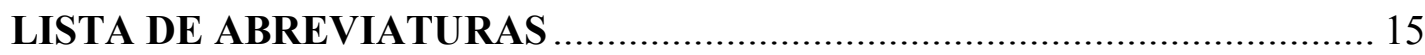

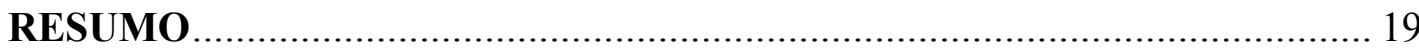

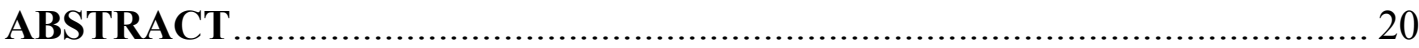

Introdução .......................................................................................................................... 21

1.1 Os principais eventos na história do diabetes mellitus ................................... 22

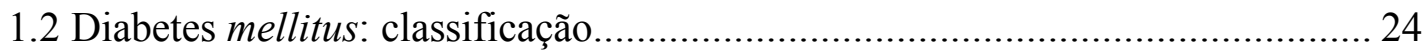

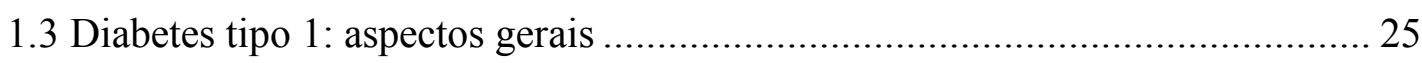

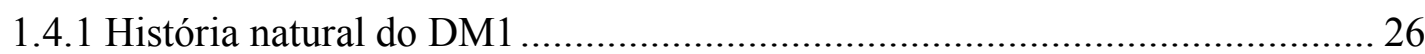

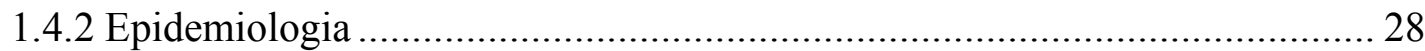

1.4.3 Suscetibilidade genética ao DM1 _........................................................ 29

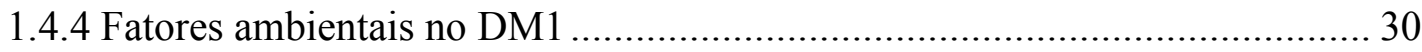

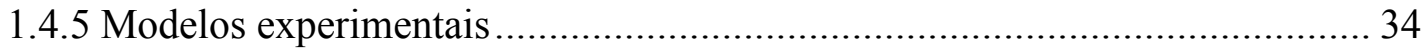

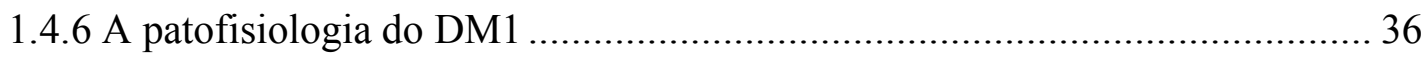

1.4.7 Células Th1 estão envolvidas no DM1 .................................................... 38

1.4.8 Células Th1 não estão envolvidas no DM1 ….............................................. 39

1.4.9 Células Th17 no DM1 ........................................................................... 40

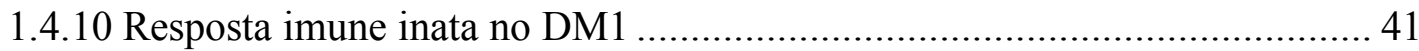

1.5 Resposta imune inata: o papel do complexo de proteínas inflamassoma........... 42

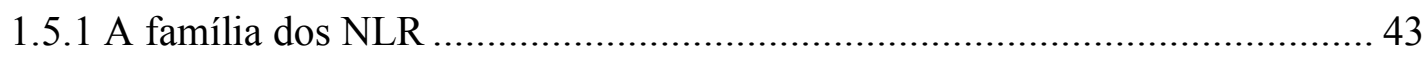

1.5.2 A ativação canônica e não-canônica do inflamassoma ................................ 45

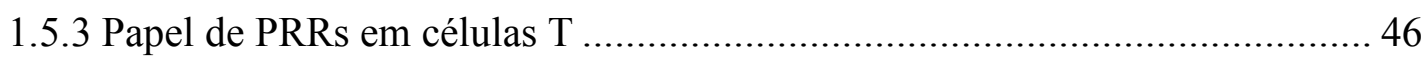

1.6 NLRP1: estrutura, função e evidências no DM1 ............................................ 47

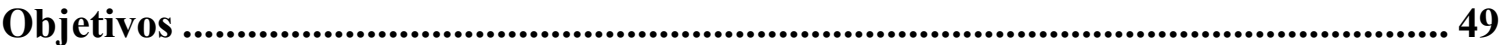

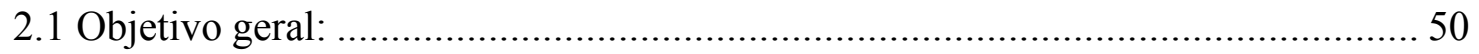

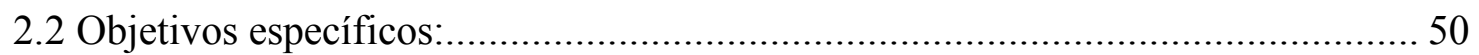




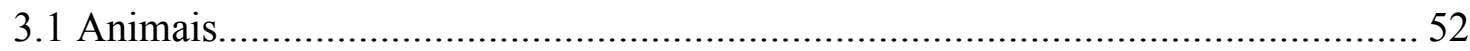

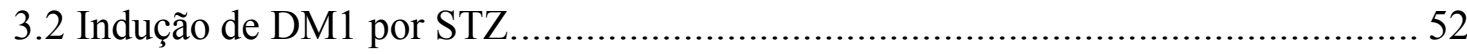

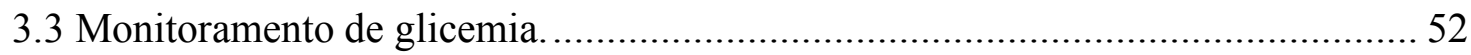

3.4 Avaliação de leucócitos por citometria de fluxo (FACS).................................. 52

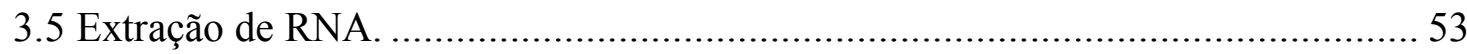

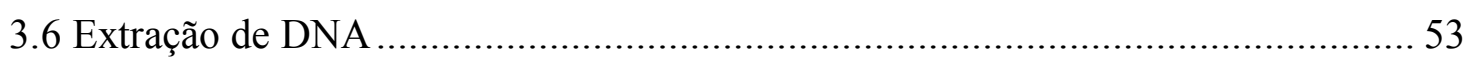

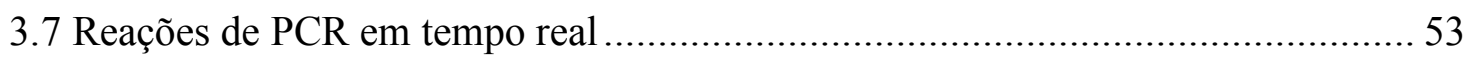

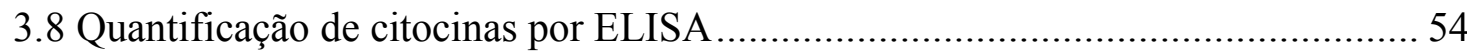

3.9 Pré-tratamento com antibióticos, transplante fecal e ensaio de translocação de

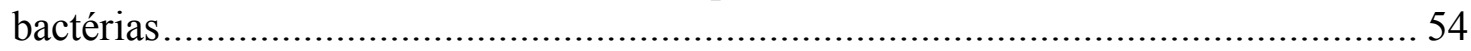

3.10 Obtenção de células dendríticas derivadas da medula óssea ............................ 55

3.11 Obtenção de células do sangue periférico de humanos e genotipagem do SNP

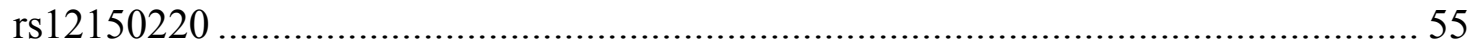

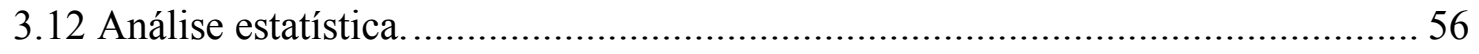

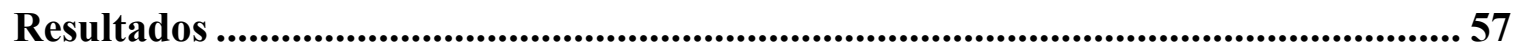

4.1 NLRP1 possui um papel protetor no diabetes tipo 1 induzido por STZ ............... 58

4.2 NLRP1 está envolvido na indução de células produtoras de IL-17 para os linfonodos pancreáticos durante o DM1 induzido por STZ .....................................61 61

4.3 A microbiota intestinal está envolvida no aumento da suscetibilidade de

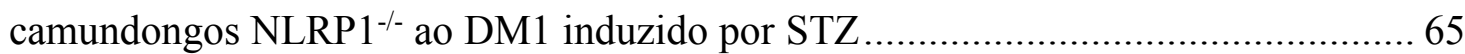

4.4 A suscetibilidade de camundongos NLRP1 ${ }^{-/}$ao DM1 induzido por STZ não se deve à ativação da maquinaria do inflamassoma....................................................... 72

4.5 A ativação do receptor NLRP1b em linfócitos é essencial para a indução de um

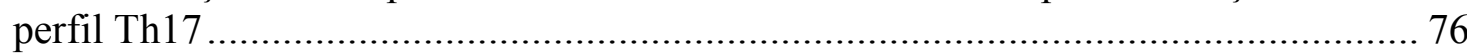

4.6 NLRP1 também está envolvido no modelo de diabetes autoimune espontâneo -

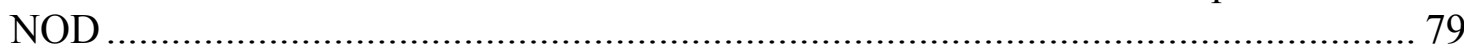

4.7 NLRP1 também está relacionado à produção de IL-17 em humanos com DM1 ... 81 
Discussão

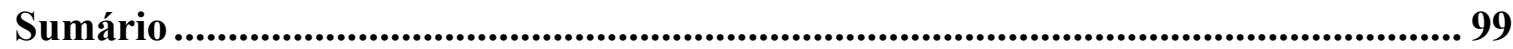

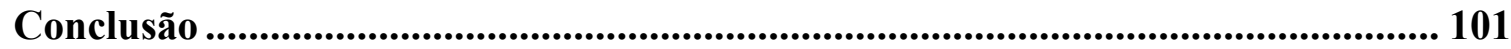

Referências bibliográficas...................................................................................... 103

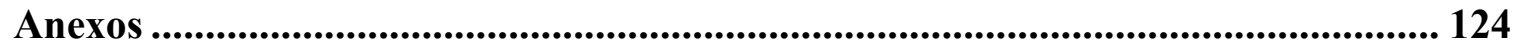




\section{LISTA DE FIGURAS}

Figura 1: A patogênese do DM1 é dividida em três estágios.

Figura 2: Possíveis eventos envolvidos no desenvolvimento ou prevenção do DM1 em indivíduos geneticamente suscetíveis. 38

Figura 3: Análise filogenética da família NLR. 44

Figura 4: Domínios do sensor intracelular NLRP1 de humanos, ratos e camundongos. 48

Figura 5: Análise do papel de NLRP1 na suscetibilidade/resistência ao DM1.... 59

Figura 6: Análise histopatológica de animais WT e NLRP1/-- após a indução de DM1 por STZ. 60

Figura 7: Células produtoras de IL-17 estão aumentadas nos estágios iniciais do DM1 induzido por STZ em animais NLRP1 ${ }^{-/}$.

Figura 8: Ausência de diferença nas distintas subpopulações de linfócitos $\mathrm{T}$ de animais WT e NLRP1 ${ }^{-/}$em estágios mais tardios do DM1 induzido por STZ. 64

Figura 9: IL-17 está intimamente relacionada à hiperglicemia de animais NLRP1 ${ }^{-/} \ldots . . .69$

Figura 10: NLRP1 não é um regulador negativo da produção de IL-6........................ 70

Figura 11: Análise do papel da microbiota intestinal no aumento da suscetibilidade de camundongos NLRP1 ${ }^{-/-}$ao DM1 induzido por STZ. 71

Figura 12: Análise da expressão dos genes Nlrpla e Nlrplb em diferentes subpopulaçõs celulares durante o desenvolvimento do DM1 induzido por STZ. 74

Figura 13: A maquinaria do inflamassoma não está envolvida no aumento da suscetibilidade de camundongos NLRP1 $1^{-/}$ao DM1 induzido por STZ. ........................ 75

Figura 14: Estratégia de gate utilizada para o isolamento de células T naive. ............... 77

Figura 15: Análise do papel de NLRP1 na diferenciação de células Th17 in vivo. ........ 78

Figura 16: Cinética da expressão de NLRP1 no modelo de diabetes autoimune espontâneo.

Figura 17: Genotipagem dos pacientes com DM1. 84

Figura 18: Fenotipagem dos pacientes com DM1 com e sem polimorfismos em NLRP1. 86

Figura 19: Estratégia de gate para a análise de linfócitos presentes no compartimento de memória. 87 
Figura 20: Células produtoras de IL-17 estão aumentadas em pacientes com

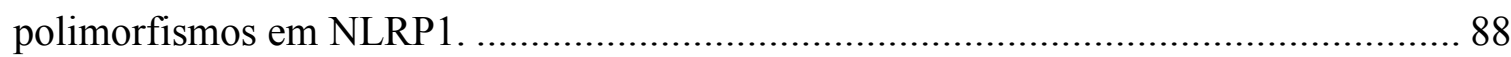

Figura 21: IL-17 está aumentada no soro de pacientes com polimorfismos em NLRP1.89 


\section{LISTA DE TABELAS}

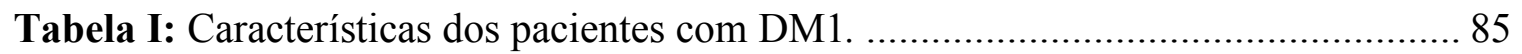




\section{LISTA DE ABREVIATURAS}

$\underline{\mathbf{A}}$

Abx - Antibióticos

APC - Células apresentadoras de antígeno

$\underline{\text { B }}$

BMDC - Células dendríticas derivadas de precursores da medula óssea

$\underline{\mathbf{C}}$

CAD - Cetoacidose diabética

CARD - Domínio de recrutamento e ativação de caspase

CD - Cluster de diferenciação

Células NK - Células Natural Killer

$\underline{\mathbf{D}}$

DC - Célula dendrítica

DM1 - Diabetes mellitus tipo 1

DNA - Ácido desoxirribonucleico

DP - Desvio padrão

$\underline{\mathbf{E}}$

EPM - Erro padrão da média 
FIIND - Domínio function to find

$\underline{\mathbf{G}}$

GAD - Descarboxilase do ácido glutâmico

$\underline{\mathbf{H}}$

HLA - Antígeno leucocitário humano

I

IFN- $\gamma$ - Interferon gama

IL - Interleucina

$\underline{\mathbf{L}}$

LNPs - Linfonodos pancreáticos

LPS - Lipopolissacarídeo

LRR - Repetições ricas em leucina

$\underline{\mathbf{M}}$

MHC-II - Complexo principal de histocompatibilidade - II

$\underline{\mathbf{N}}$

$\mathrm{NF}-\kappa \mathrm{B}$ - Fator nuclear $\kappa \mathrm{B}$ 
NLR - Receptor NOD-like

NLRP1 - NLR family pyrin domain containing 1

NOD - Camundongo diabético não obeso

NOR - Camundongo resistente não obeso

$\underline{\mathbf{P}}$

PAMPs - Padrões moleculares associados ao patógeno

PBMC - Células mononucleares de sangue periférico

PCR - Reação em cadeia da polimerase

PRR - Receptores de reconhecimento de padrões

PYD - Domínio pyrin

$\underline{\mathbf{R}}$

RNA - Ácido ribonucleico

$\underline{\mathbf{S}}$

sgRNA - Short-guide RNA

SNP - Polimorfismo de nucleotídeo único

STZ - Estreptozotocina

$\underline{\mathbf{T}}$

Th - Célula T helper

TLR - Receptor Toll-like 
TNF- $\alpha-$ Fator de necrose tumoral alfa

$\underline{\mathbf{W}}$

WT - Wild type 


\section{RESUMO}

O diabetes tipo 1 (DM1) é uma doença autoimune caracterizada pela destruição das células $\beta$ presentes nas ilhotas pancreáticas por linfócitos T auto-reativos, especialmente Th1 e Th17, levando o indivíduo a um estado de hiperglicemia. Embora existam diversos estudos que abordam a resposta imune adaptativa no contexto do DM1, poucos trabalhos tentaram elucidar o papel da resposta imune inata no desenvolvimento da doença. Neste contexto, avaliamos o perfil de expressão e o papel do receptor NLRP1 na patogênese do DM1 experimental e em humanos. Nossos dados apontam que no modelo de DM1 induzido por STZ, NLRP1 possui um papel protetor no desenvolvimento da doença de forma independente da ativação do inflamassoma, através da inibição da translocação de bactérias para os linfonodos pancreáticos (LNPs), além de reduzir a diferenciação de células Th17 e Tc17 nos LNPs, o que foi correlacionado à diminuição de IL-17 no pâncreas. Posteriormente, analisamos o papel de NLRP1 em outro modelo experimental, o NOD (nonobese diabetic), onde descrevemos que NLRP1 também é expresso no desenvolvimento da doença. Por fim, avaliamos o papel de NLRP1 em pacientes com DM1, através da genotipagem desses pacientes para um polimorfismo com ganho de função em NLRP1, o rs12150220. Ao contrário do que acontece em camundongos, NLRP1 em humanos parece ter um papel patogênico, uma vez que detectamos mais células T produtoras de IL-17 em células mononucleares do sangue periférico de indivíduos com o polimorfismo, além de níveis elevados da citocina no soro. Em suma, nossos dados apontam para papéis distintos de NLRP1 em camundongos e humanos com DM1, sugerindo cautela ao tentarmos transpor os achados sobre o receptor em camundongos para a clínica.

Palavras-chave: diabetes tipo 1, NLRP1, resposta imune inata, Th17, microbiota intestinal. 


\begin{abstract}
Type 1 diabetes (T1D) is an autoimmune disease that is caused by the destruction of the pancreatic $\beta$ cells by autoreactive T cells, especially Th1 and Th17, leading to a state of hyperglycemia. Even though there are several studies on the role of the adaptive immune response in T1D, little is known about the role of an innate immune response in the development of the disease. Thus, we investigated the role of NLRP1 in the pathogenesis of mouse and human T1D. Our data indicate that in STZ-induced T1D, NLRP1 exerts a protective role in the development of the disease in an inflammasome-independent pathway, through the inhibition of bacterial translocation to the pancreatic lymph nodes (PLNs), and inhibition of the differentiation of Th17 and Tc17 cells in the PLNs, which correlated with decreased levels of IL-17 in the pancreas. Then, we analyzed the role of NLRP1 in nonobese diabetic (NOD) mice. We demonstrate that NLRP1 is also expressed in the development of T1D in this murine model. Lastly, we evaluated the role of NLRP1 in T1D patients, by genotyping these individuals for a polymorphism with a gain-of-function in NLRP1, the rs12150220. Unlike murine NLRP1, NLRP1 in humans appears to be pathogenic, considering that we detected more IL-17-producing T cells in peripheral blood mononuclear cells in patients carrying the polymorphism, besides elevated levels of this cytokine in the serum. Overall, our data suggest distinct roles for murine and human NLRP1 in the context of T1D, suggesting carefulness when translating the findings from murine NLRP1 to the clinic.
\end{abstract}

Keywords: type 1 diabetes, NLRP1, innate immune response, Th17, intestinal microbiota. 


\section{Introdução}




\subsection{Os principais eventos na história do diabetes mellitus}

O diabetes é uma doença que envolve sede excessiva (polidipsia), urinação contínua (poliúria), severa perda de peso, e tem intrigado a medicina por cerca de três milênios. No entanto, infelizmente, até o começo do século XX, o prognóstico para um paciente com esta condição era o mesmo de um paciente que viveu há 3000 anos.

O Papiro de Ebers, que foi escrito por volta do ano 1500 a.C. no Egito descreve, entre várias outras doenças e suas medicações, uma condição de "grande extravasamento de urina" - referindo-se, possivelmente, ao diabetes. Acredita-se que esse seja o primeiro relato documentado da doença. Para o tratamento dessa condição, os médicos egípcios recomendavam consumir grãos de trigo, fruta e cerveja doce (PAPASPYROS, 1964).

Aproximadamente durante o mesmo período, médicos na Índia desenvolveram o que pode ser descrito como o primeiro teste clínico para diabetes. Eles observaram que a urina de pessoas com diabetes atraía formigas e mosquitos e resolveram, dessa forma, nomear a condição de "madhumeha" ou "urina de mel". Embora a poliúria associada ao diabetes fosse bem reconhecida, os clínicos dessa época não eram capazes de distinguir a poliúria presente no que hoje chamamos de diabetes mellitus da poliúria oriunda de outras doenças (PAPASPYROS, 1964).

Por volta do ano 230 a.C., Apollonius de Mênfis foi o primeiro a utilizar o termo "diabetes", que do grego significa "sifão" ( principal sintoma identificado pelos médicos da época: o excesso de urina (poliúria). Ele e seus contemporâneos consideravam o diabetes uma doença dos rins e recomendavam, dentre outros tratamentos ineficazes, medidas como a punção sanguínea e desidratação (PORETSKY et al, 2004).

Aretaeus da Capadócia, um médico grego que praticou a medicina em Roma e Alexandria no século II d.C., foi o primeiro a distinguir as condições que hoje conhecemos como diabetes mellitus e diabetes insipidus (condição completamente distinta do diabetes mellitus, que envolve a deficiência do hormônio antidiurético ou a insensibilidade dos rins ao mesmo, levando o indivíduo a um quadro de poliúria). Em seu trabalho, descreveu o diabetes da seguinte forma: "Diabetes é uma condição aterrorizante, não muito frequente entre homens, sendo o derretimento da carne e membros em urina. Os pacientes nunca param de fazer água e ofluxo é incessante, como a abertura dos aquedutos. A vida é curta, 
desagradável e dolorosa, sede insaciável, bebendo quantidades excessivas e desproporcionais de água para a grande quantidade de urina, embora mais urina continue passando... Se por um momento param de beber, suas bocas ficam secas e seus corpos ressequidos; as vísceras parecem esquentadas, os pacientes são afetados por náusea, inquietação e sede excessiva, e depois de um curto período de tempo eles se estinguem” (MEDVEI, 1993a).

No século V d.C., Susruta e Charaka, dois clínicos indianos, foram os primeiros a diferenciar entre os dois tipos de diabetes (tipo 1 e 2), observando que diabéticos magros desenvolviam a condição mais jovens (tipo 1), enquanto que diabéticos obesos desenvolviam a doença de forma mais tardia e viviam mais (tipo 2) (MEDVEI, 1993b). Por fim, apenas em 1776, mais de 3000 anos após os relatos do Papiro de Ebers, o fisiologista britânico Matthew Dobson demonstrou que a urina desses pacientes, que possuía um gosto adocicado, possuía tal característica devido às altas concentrações de açúcar (glicosúria). Posteriormente, em 1788, surgiu a primeira associação entre pâncreas e diabetes, após Thomas Cawley observar que pessoas com dano pancreático desenvolviam diabetes (MEDVEI, 1993c). O termo mellitus (derivado da palavra grega para mel) foi adicionado a "diabetes" pelo cirurgião John Rollo para distinguir entre diabetes mellitus e insipidus.

O advento da insulina e seu uso na clínica: durante os anos que antecederam a descoberta da insulina, o tratamento do diabetes consistia basicamente em dietas de restrição calórica. Frederick Allen, um dos melhores diabetologistas americanos da época, acreditava que caso a quantidade de comida fosse limitada, haveria melhora no quadro da doença, uma vez que diabéticos não eram capazes de utilizar a comida de forma eficiente. A restrição calórica era pesada e a morte por inanição não era incomum em pacientes com diabetes tipo 1 (condição onde a obesidade não está relacionada). Por outro lado, atualmente é fácil entender o porquê das dietas com poucas calorias se demonstraram tão eficazes em pacientes com diabetes tipo 2 (condição onde a obesidade parece ter papel proeminente no desenvolvimento da doença). (MEDVEI, 1993d; BLISS, 2007).

Em 1869, o patologista alemão Paul Langerhans, durante sua tese de doutorado aos 22 anos, demonstrou pequenos agrupamentos de células pancreáticas que não eram drenadas pelo ducto pancreático. Em 1909, o clínico belga Jean de Mayer denominou a substância produzida pelas ilhotas de Langerhans de "insulina" (MEDVEI, 1993e). Foi apenas em 1921 que Frederick Banting e Charles Best foram capazes de coletar glândulas pancreáticas 
atrofiadas de cachorros, macerá-las, purificá-las e injetá-las na veia de cachorros pancreatomizados (diabéticos). Quando ficou claro que a condição do cachorro melhorou, eles repetiram os experimentos com outros cachorros diabéticos, com resultados bastante semelhantes. Um ano depois, em 11 de janeiro de 1922, Frederick Banting e Charles Best injetaram seu extrato em Leonard Thompson, um garoto de apenas 14 anos de idade que estava sendo tratado para diabetes tipo 1 no Toronto General Hospital. Na época, o peso de Leonard era de apenas $28 \mathrm{~kg}$. Após a injeção, Leonard teve uma forte reação, desenvolvendo um abscesso no sítio de injeção. Na segunda tentativa de injetar insulina dois dias depois, utilizando uma preparação melhorada, a glicemia do paciente caiu de 520 para 120 mg/dL nas 24 horas seguintes e Leonard começou a ganhar peso rapidamente. Em 1923, Frederick Banting e John MacLeod (supervisor de Banting) receberam o Prêmio Nobel pela descoberta da insulina. De fato, aqueles pacientes que durante três milênios estavam condenados à morte com a descoberta do diagnóstico de diabetes tipo 1 passaram a desfrutar de uma longa expectativa de vida. Por exemplo, Ted Ryder, uma das quatro primeiras crianças a receber insulina em 1922 em Toronto por Frederick Banting, morreu apenas aos 76 anos de idade, em 1993.

\subsection{Diabetes mellitus: classificação}

O diabetes mellitus pode ser dividido em 4 subtipos:

- Diabetes mellitus tipo 1 (DM1);

- Diabetes mellitus tipo 2 (DM2);

- Diabetes mellitus gestacional (DMG);

- Tipos específicos de diabetes devido a outras causas.

A seguir, o DM1 será abordado de forma detalhada. Para um maior detalhamento sobre DM2, DMG e tipos específicos de diabetes devido a outras causas, refira ao "Standards of Medical Care in Diabetes - 2017" da Associação Americana de Diabetes (do inglês, American Diabetes Association - ADA) (ADA, 2017). 


\subsection{Diabetes tipo 1: aspectos gerais}

O diabetes tipo 1 (DM1) é uma doença caracterizada pela destruição autoimune das células $\beta$ pancreáticas em indivíduos geneticamente suscetíveis, resultando em uma secreção severamente comprometida ou até mesmo ausente de insulina, obrigando o indivíduo acometido pela doença a tomar doses diárias deste hormônio pelo resto da vida para sobreviver. Essa doença é geralmente diagnosticada em crianças e adolescentes, que normalmente apresentam a clássica tríade de sintomas (polidipsia, polifagia e poliúria), além de um estado de hiperglicemia, podendo ou não apresentar um quadro de cetoacidose diabética. A cetoacidose diabética $(\mathrm{CAD})$ é uma condição potencialmente fatal que acomete principalmente indivíduos com DM1 com reduzido controle glicêmico. O mecanismo da CAD está diretamente relacionado à insulina. Uma das ações da insulina é inibir o processo de lipólise (quebra e liberação de ácidos graxos do tecido adiposo na circulação). Na ausência do hormônio, ocorre o processo de lipólise com consequente liberação de ácidos graxos, que por sua vez são convertidos no fígado em corpos cetônicos (acetoacetato e $\beta$ hidroxibutirato) por um processo conhecido como beta oxidação. Esses corpos cetônicos são um mecanismo de defesa do organismo, uma vez que eles servem como fonte de energia na ausência de glicose (sem a produção de insulina, o indivíduo não é capaz de transportar a glicose para dentro das células, entrando em um estado de starvation). Entretanto, o aumento desses corpos cetônicos no organismo leva à diminuição do pH sanguíneo (acidose), situação extremamente danosa ao organismo, podendo ser até fatal. Além disso, a CAD está intimamente relacionada à glicosúria, levando a um processo de diurese osmótica, com perda de água, sódio, potássio e outros eletrólitos, complicando ainda mais o estado geral clínico do paciente (KITABACHI et al., 2006). A confirmação do diagnóstico de DM1 é geralmente realizado com a combinação de resultados positivos para hiperglicemia (glicemia de jejum maior ou igual a $126 \mathrm{mg} / \mathrm{dL}$ ou glicemia em horário aleatório maior ou igual a $200 \mathrm{mg} / \mathrm{dL}$ ), e presença de auto-anticorpos (anti-GAD, anti-insulina, entre outros). Existem diversos genes de suscetibilidade relacionados à doença (abordado posteriormente), porém a genotipagem desses pacientes ainda não é realizada de forma corriqueira na clínica.

É importante salientar que vários aspectos etiológicos dessa doença ainda permanecem obscuros, gerando um grande debate na comunidade médica e científica. Dentre 
esses aspectos, temos questões relacionadas à real porcentagem de casos de DM1 na população. Apesar da doença ser característica de crianças e adolescentes, foi recentemente descoberto que adultos também podem manifestar essa forma de diabetes. Dessa forma, acredita-se que muitos pacientes com DM1 tenham sido erroneamente classificados como DM2. Tem sido proposto que aproximadamente 5-15\% dos adultos com DM2 tenham na verdade DM1 (PALMER et al., 2005). Caso seja verdade, a atual noção de que o DM1 corresponde a apenas $10 \%$ de todos os casos de diabetes é bastante subestimada. Tentativas de se diferenciar entre casos de DM1 e DM2 em adultos levaram a uma nova nomenclatura: diabetes autoimune latente do adulto (do inglês, latent autoimmune diabetes of the adult LADA), que seria uma forma mais branda de DM1 que acomete adultos, onde normalmente não há manifestação clínica de CAD e onde esses pacientes apresentam poucas complicações micro e macrovasculares (para uma revisão completa sobre LADA, refira a LESLIE et al., 2008). Além da falta de entendimento completo sobre a exata idade em que o DM1 é diagnosticado, outra faceta do DM1 que tem gerado bastante discussão envolve a heterogeneidade dessa doença. Conforme mencionado acima, o DM1 é considerado uma doença de natureza autoimune, indicando que esses pacientes apresentam uma resposta imunológica que contribui para o desenvolvimento da doença, como demonstrado na presença de auto-anticorpos circulantes, genes da resposta imune associados com a suscetibilidade à doença, entre outros. No entanto, nem todos os pacientes com DM1 apresentam essas características, gerando assim uma nova subdivisão: diabetes tipo 1A (de natureza autoimune), que corresponde a 70-90\% dos casos de DM1, e diabetes tipo 1B (idiopático) que representa os $10 \%$ restantes, cuja patogênese permanece desconhecida (IMAGAWA et al., 2000).

\subsubsection{História natural do DM1}

Com relação à progressão da doença, o acompanhamento de crianças que possuíam uma alta suscetibilidade genética ao DM1 revelou que aquelas que tiveram o aparecimento de dois ou mais auto-anticorpos contra as ilhotas pancreáticas apresentaram uma incidência de mais de $90 \%$, demonstrando o alto poder preditivo desses marcadores para o desenvolvimento da doença (ZIEGLER et al., 2013). O DM1 é, portanto, caracterizado pelo aparecimento de auto-anticorpos contra as células $\beta$, sendo que o primeiro deles normalmente é 
voltado contra insulina ou contra a enzima descarboxilase do ácido glutâmico (do inglês, glutamic acid decarboxilase - GAD), que é uma enzima expressa majoritariamente no pâncreas (POCIOT; LERNMARK, 2016). No entanto, esses auto-anticorpos aparecem muitos meses ou até mesmo muitos anos antes do início dos sintomas. Por isso, acreditase que esses anticorpos não sejam patogênicos, servindo apenas como marcadores de autoimunidade (KATSAROU et al., 2017). A comunidade científica normalmente divide a patogênese do DM1 em três estágios, que estão relacionados com a detecção de auto-anticorpos e progressão para a destruição das células $\beta$, disglicemia (alterações nos níveis de glicemia) e, finalmente, sintomas associados com a hiperglicemia (Figura 1).

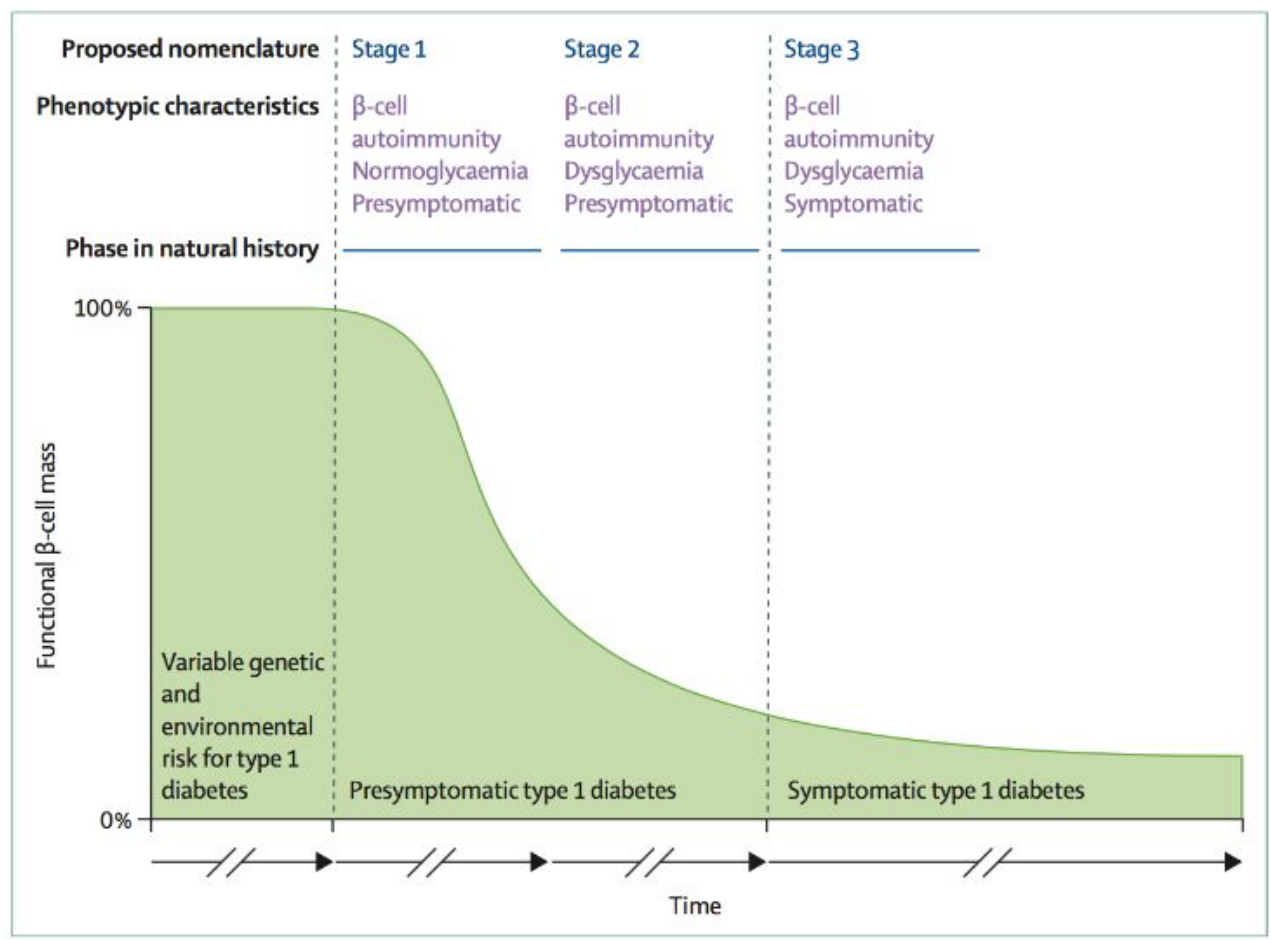

Figura 1: A patogênese do DM1 é dividida em três estágios. Estágio 1: auto-anticorpos contra as células $\beta$ são persistentes, a euglicemia prevalece, e nenhum sintoma está presente. Estágio 2: o número de autoanticorpos pode afetar a patogênese no sentido de induzir um quadro de disglicemia, mas nenhum dos sintomas do diabetes está presente ainda. Estágio 3: auto-anticorpos ainda prevalecem (alguns deles podem ter desaparecido) mas os sintomas do diabetes estão presentes. Figura extraída de POCIOT; LERNMARK, 2016. 


\subsubsection{Epidemiologia}

De acordo com a Federação Internacional de Diabetes (do inglês, International Diabetes Federation - IDF), 8,8\% da população adulta mundial possui diabetes (ATKINSON; EISENBARTH; MICHELS, 2014). De todos os indivíduos com diabetes, apenas $10-15 \%$ possuem DM1, enquanto que o DM2 é a forma mais comum da doença (lembrando que essa porcentagem pode ser subestimada, conforme discutido anteriormente). No entanto, o DM1 é a forma mais comum de diabetes em crianças ( $<15$ anos de idade), sendo que a estimativa é de que mais de 500.000 crianças no mundo vivam atualmente com essa doença (KATSAROU et al., 2017).

A incidência do DM1 tem aumentado globalmente e é estimado que aproximadamente 90.000 crianças são diagnosticadas a cada ano (DIAZ-VALENCIA; BOUGNÈRES; VALLERON, 2015). As taxas de incidência variam bastante entre países, sendo maiores nos países Escandinavos, seguido por países Europeus, América do Norte e Austrália. Em países Asiáticos, como China, Coréia e Japão, o DM1 é uma doença rara. As razões para essas variações permanecem desconhecidas mas podem estar relacionadas à suscetibilidade genética e fatores ambientais (KATSAROU et al., 2017). No Brasil, embora informações sobre a incidência de DM1 sejam escassas, estudos anteriores demonstraram uma ampla diferença da incidência da doença entre as regiões brasileiras: por exemplo, Campina Grande, na região nordeste, demonstrou uma incidência de 1,8 por 100.000 habitantes/ano; Bauru, na região sudeste, 10,4 por 100.000 habitantes/ano; e Londrina e Passo Fundo, ambos na região sul, 12,7 e 12 por 100.000 habitantes/ano, respectivamente (COUTINHO; SANTANA; JÚNIOR, 2015). O único estudo a fazer um acompanhamento longitudinal da incidência de DM1 no Brasil foi o realizado em Bauru (LISBÔA et al., 1998). A incidência estimada na população até 14 anos de idade morando na cidade e avaliada por um período de 21 anos (de 1986 a 2006, $n=1.673 .132$ ) foi de 13,7 por 100.000 habitantes/ano. Além disso, foi observado que houve um aumento de quase 10 vezes na incidência da doença entre 1987 e 2002, sendo que a idade média de diagnóstico foi de 8,6 $\pm 3,76$ anos (LISBÔA et al., 1998). No entanto, ainda não se sabe se esses resultados podem ser extrapolados para outras cidades de diferentes regiões do Brasil. 


\subsubsection{Suscetibilidade genética ao DM1}

A presença de auto-anticorpos contra as ilhotas de Langerhans no momento do diagnóstico do DM1 sempre foi associado com os haplótipos ou alelos $H L A-D R-D Q$ (GRAHAM et al., 2002; KNIP et al., 2002). Crianças homozigotas para HLA-DR3-DQ2 (do inglês, Human Leukocyte Antigen - HLA) possuíam anticorpos anti-GAD como primeiro auto-anticorpo (ILONEN et al., 2013; KRISCHER et al., 2015), enquanto que crianças com o haplótipo $H L A-D R 4-D Q 8$ tendiam a ter a insulina como primeiro alvo dos auto-anticorpos (ZIEGLER et al., 1991). A possibilidade de que outras moléculas do HLA classe II contribuam para o gatilho inicial da autoimunidade contra as células $\beta$ também não pode ser descartada, uma vez que tecnologias mais recentes como o sequenciamento de nova geração (do inglês, next generation sequencing - NGS) revelaram que HLA-DRB3, $H L A-D R B 4$, e $H L A-D R B 5$ podem estar associados com auto-anticorpos contra as células $\beta$ e aumento na suscetibilidade ao DM1 (ERLICH et al., 2013). No entanto, uma característica extremamente intrigante do DM1 reside no fato de que $85 \%$ dos novos casos de DM1 sejam de indivíduos com nenhum histórico familiar da doença (HAMALAINEN; KNIP, 2002). Outro ponto interessante é que as diferenças no risco de desenvolver o DM1 dependem de qual membro da família possui a doença: crianças com mães diabéticas possuem apenas $2 \%$ de chance de desenvolver DM1, enquanto que crianças de pais diabéticos apresentam um risco de 7\% (MELANITOU; FAIN; EISENBARTH, 2003).

Após décadas de esforços para desvendar o "enigma" da suscetibilidade genética ao DM1, aproximadamente 50 loci que estão associados com a suscetibilidade à doença foram identificados (COOPER et al., 2008; CONCANNON; RICH; NEPOM, 2009; POCIOT et al., 2010). Eles abrangem diversas moléculas, sendo que o primeiro locus identificado, o complexo HLA, já corresponde à aproximadamente $60 \%$ da contribuição genética à doença. De forma interessante, foi observado que além de polimorfismos no complexo HLA, diversos outros genes relacionados à resposta imune também foram identificados na suscetibilidade à doença, como Il2ra, Ptpn22, Ctla4, Il18rap, Ccr5, Cd226, Il2, Il17ra (ATKINSON, 2012), bem como Nlrp3 (PONTILLO et al., 2010) e Nlrp1 (MAGITTA et al., 2009).

De forma interessante, foi observado que a incidência do DM1 tem aumentado drasticamente nos últimos trinta anos (PATTERSON et al., 2009). Tal aumento só pode 
ser explicado por alterações no ambiente ou no estilo de vida (REWERS; LUDVIGSSON, 2016). Corroborando o papel desses fatores no risco de desenvolver a doença, foi demonstrado que migrantes tendem a ter o risco de desenvolver o DM1 alterado ao se mudarem de região, adquirindo o mesmo risco que a população local de sua nova área de residência (OILINKI et al., 2012; SÖDERSTRÖM; AMAN; HJERN, 2012). Além disso, outra forte evidência de que fatores ambientais estariam envolvidos no desencadeamento do DM1 provém de estudos utilizando taxas de concordância na incidência da doença, que é de $50 \%$ entre gêmeos monozigóticos, e de apenas $10 \%$ entre gêmeos dizigóticos (KYVIK; GREEN; BECK-NIELSEN, 1995), sugerindo um importante papel de fatores ambientais no desenvolvimento da doença. Neste contexto, diversos fatores ambientais foram propostos até o momento como sendo possíveis "gatilhos" da doença, por exemplo, infecções virais (FILIPPI; VON HERRATH, 2008) e a alteração na composição da microbiota intestinal (disbiose), com redução de bactérias produtoras de ácidos graxos de cadeia curta SCFAs (do inglês, Short Chain Fatty Acids - Vaarala et al., 2008). Dessa forma, um melhor entendimento sobre os fatores ambientais envolvidos no desencadeamento do diabetes tipo 1 são de suma importância, a fim de se retardar ou até mesmo prevenir o início da doença.

\subsubsection{Fatores ambientais no DM1}

- Infecções virais: estudos epidemiológicos (GAMBLE et al., 1969), estudos de casos (YOON et al., 1979), entre outros (GUNDERSEN, 1927) têm chamado a atenção para infecções virais como um potencial causador do DM1. Diversos vírus têm sido apontados, sendo que uma maior evidência de enterovírus tem sido encontrada em modelos experimentais (COPPIETERS et al., 2012) e em humanos (STENE; REWERS, 2012). Esses vírus possuem um tropismo por células pancreáticas humanas in vivo e in vitro (YOON et al., 1979; TRACY; DRESCHER; CHAPMAN, 2011) e já foram detectados no pâncreas de pacientes recém diagnosticados com DM1 (KROGVOLD et al., 2015). Neste contexto, os primeiros artigos sobre o assunto relacionavam infecções por coxsackievírus e DM1 baseando -se nos achados de altos níveis de anticorpos neutralizantes para o vírus no soro de pacientes com DM1 recém diagnosticados (GAMBLE et al., 1969). 
Alguns estudos também avaliaram anticorpos contra outros vírus em paralelo, porém coxsackievírus era normalmente o mais prevalente (BANATVALA et al., 1985). No entanto, o assunto permanece controverso. Em 1971, um estudo avaliou a incidência de DM1 após uma epidemia de coxsackievirus B4 (CVB4) nas isoladas Ilhas Pribilof. Após cinco anos do término da epidemia, a incidência de diabetes em indivíduos que foram infectados e aqueles que não foram infectados foi bastante similar, sugerindo nenhuma ligação entre CVB4 e DM1 (DIPPE et al., 1975).

- Hipótese da higiene: a hipótese da higiene postula que a incidência de doenças autoimunes pode estar aumentando devido à diminuição na frequência de infecções na infância, graças à melhora na higienização da população (BACH, 2002). No entanto, um estudo no Reino Unido demonstrou que infecções na infância, rotineiramente observadas por pediatras, não estavam associados com o subsequente desenvolvimento de DM1 na infância (CARDWELL; CARSON; PATTERSON, 2008). Já estudos longitudinais prospectivos têm reportado a correlação entre um aumento significativo no risco ao DM1 com a maior frequência de infecções respiratórias durante os 6 primeiros meses de vida, sendo que a associação foi menor para infecções entre 6-12 meses de vida e ausente naquelas depois de 1 ano de vida (BEYERLEIN et al., 2014). Por outro lado, um outro estudo demonstrou que existe uma associação entre DM1 e infecções gastrointestinais, mas não infecções respiratórias (STENE et al., 2010).

- Microbiota intestinal:

○ Evidências em modelos experimentais: o intestino é o maior órgão do sistema imune do corpo humano e é habitado por aproximadamente $10^{14}$ microorganismos de mais de 500 espécies diferentes (MOWAT; AGACE, 2014), vivendo em estável simbiose com o hospedeiro (LEY; PETERSON; GORDON, 2006). Um elemento de extrema importância que permite o mutualismo entre hospedeiro e bactérias comensais é a separação de micróbios do microambiente interno do hospedeiro por barreiras físicas, como as camadas 
epiteliais e de muco, e também através do sistema imune inato e adaptativo, que reconhece e elimina patógenos (SCHWABE; JOBIN, 2013).

Acredita-se que a perturbação destes mecanismos possa levar à inflamação e à autoimunidade (VAARALA, 2008), embora os mecanismos pelos quais a microbiota intestinal leve ao desencadeamento de doenças autoimunes permaneçam desconhecidos (SORINI; FALCONE, 2013). As maiores evidências da relação entre microbiota intestinal e DM1 são oriundas dos modelos experimentais. No entanto, se a microbiota possui um papel protetor ou patogênico na doença ainda permanece controverso. Tanto em modelos de DM1 com indução espontânea, como em ratos Biobreeding (BRUGMAN et al., 2006), ou com indução por reagentes químicos como com STZ (COSTA et al., 2016), a microbiota intestinal parece ter um papel patogênico, uma vez que o tratamento com antibióticos foi capaz de impedir o desenvolvimento da doença nesses animais. No entanto, em camundongos NOD (do inglês nonobese diabetic), a microbiota intestinal parece ter um papel protetor. Camundongos NOD selvagens, especialmente fêmeas, desenvolvem diabetes de forma espontânea e com alta frequência. A incidência de DM1 é similar em camundongos selvagens e germ-free (animais que não apresentam bactérias no organismo), embora camundongos NOD germ-free tenham um quadro de insulite (processo inflamatório nas ilhotas pancreáticas) mais agressivo. Além disso, comparado a camundongos NOD selvagens, animais NOD germ-free possuem maiores concentrações de IL-12 e IFN- $\gamma$ no soro (GREINER et al., 2014).

○ Evidências em humanos: atualmente, acredita-se que a dieta nos países desenvolvidos, que foi alterada para uma dieta rica em gordura, carboidrato e pobre em fibras ("Western Diet"), possa ter resultado em alterações funcionais na microbiota intestinal (disbiose - 
TURNBAUGH et al., 2006, 2008; HILDEBRANDT et al., 2009). Esse processo de disbiose causado pelas alterações na dieta poderiam participar no aumento da incidência de doenças imuno-mediadas e pró-inflamatórias dos países desenvolvidos, como obesidade, diabetes tipo 2 e doença inflamatória intestinal (DAVID et al., 2014). Ácidos graxos de cadeia curta (do inglês, short-chain fatty acids, SCFAs), como ácido butírico e ácido acético são produzidos pela fermentação por bactérias intestinais de fibras indigestíveis oriundas de plantas (BRESTOFF; ARTIS, 2013), sendo capazes de entrar na circulação (MORGAN et al., 2012) e regular o sistema imune inato e adaptativo, principalmente através de uma atividade anti-inflamatória (SMITH et al., 2013). Um número crescente de estudos apontam que o aumento na incidência do DM1 possa estar relacionado a alterações na microbiota intestinal, particularmente àquelas associadas com bactérias produtoras de SCFAs (VIJAY-KUMAR et al., 2010). Recentemente, foi realizado um estudo com amostras de fezes de 35 pacientes recém diagnosticados (até 6 meses após o diagnóstico de DM1), 21 parentes de primeiro grau de um indivíduo com DM1 (PPG) positivos para pelo menos um auto-anticorpo contra as ilhotas pancreáticas, 32 soro-negativos PPG e 23 indivíduos saudáveis, sem histórico de DM1 na família (ALKANANI et al., 2015). Foi demonstrado que não existe uma "assinatura microbiana" clara das comunidades de bactérias predominantes em indivíduos com DM1, anteriormente ou posteriormente ao diagnóstico da doença. No entanto, o microbioma de indivíduos soro-positivos e soronegativos de PPG apresentou uma similaridade entre si, mas foi distinto do microbioma de recém diagnosticados e indivíduos controles. Uma estratificação de indivíduos soro-positivos foi realizada baseada na expressão de um ou múltiplos auto-anticorpos e foi observado um aumento na abundância de Bacteroides, que tem sido relacionado a uma "Western diet", e uma diminuição de Prevotella e do 
filo Firmicutes no grupo com múltiplos auto-anticorpos. De forma interessante, foi observado que o aumento na abundância de Prevotella está associado a uma dieta rica em fibras oriundas de plantas (WU et al., 2011) e que bactérias do gênero Prevotella são capazes de digerir polissacarídeos oriundos de plantas (HOLMES et al., 2012) e promover a produção de SCFAs, que por sua vez possuem função anti-inflamatória (SMITH et al., 2013). No entanto, o mecanismo preciso pelo qual a microbiota intestinal promove a destruição autoimune das ilhotas pancreáticas ainda é incerto (NEEDELL; ZIPRIS, 2016), existindo apenas indícios de que ocorra um aumento na permeabilidade intestinal, mais conhecido como "leaky gut", antes do início da doença (BOSI et al., 2006).

Até o momento, apenas dois trabalhos na literatura procuraram elucidar tal mecanismo. Um deles sugere que a reatividade cruzada de células T entre antígenos das ilhotas pancreáticas e bactérias possa estar envolvido no processo de destruição das células $\beta$ (COLE et al., 2016). E o outro trabalho é o do nosso grupo de pesquisa, onde demonstramos que bactérias presentes na microbiota intestinal são capazes de translocar para os linfonodos pancreáticos de camundongos diabéticos e ativar o receptor nucleotide-binding oligomerization domain containing 2 (NOD2), induzindo uma resposta imune pró-inflamatória, que por sua vez contribui para o desenvolvimento do DM1 (Anexos I e II - COSTA et al., 2016).

\subsubsection{Modelos experimentais}

Modelos animais têm contribuído enormemente para o entendimento dos processos que levam ao desencadeamento do DM1. O DM1 pode ser induzido experimentalmente em animais de laboratórios com reagentes químicos (como estreptozotocina - STZ, ciclofosfamida e aloxano em linhagens geneticamente suscetíveis) ou através de manipulação genética, por exemplo, utilizando-se animais transgênicos. Além disso, dois modelos espontâneos em roedores têm sido utilizados extensivamente na tentativa de se entender a 
patofisiologia do DM1: ratos biobreeding (BB) e camundongos diabéticos não-obesos (NOD). Em ratos BB, não existe diferença na incidência de diabetes entre os gêneros. No entanto, fêmeas NOD desenvolvem diabetes a uma incidência maior que camundongos NOD machos. Além dessas diferenças, ambos os modelos se assemelham ao DM1 em humanos, incluindo a presença de células $\mathrm{T}_{\mathrm{CD}} 4^{+}$e $\mathrm{T} \mathrm{CD} 8^{+}$antígeno-específicas e um envolvimento genético no desenvolvimento da doença (LEHUEN et al., 2010).

Camundongos NOD: Makino e colaboradores (MAKINO et al., 1980; KIKUTANI; MAKINO, 1992) desenvolveram o camundongo NOD durante a seleção de uma linhagem suscetível à catarata derivada de uma linhagem outbred denominada JCl:ICR. Durante os experimentos, eles observaram que alguns camundongos obtidos dos cruzamentos apresentaram glicosúria e hiperglicemia. Dessa forma, a linhagem NOD foi estabelecida através de sucessivos acasalamentos entre irmãos. A incidência de diabetes em camundongos NOD é de 60-80\% em fêmeas e 20-30\% em machos (KIKUTANI; MAKINO, 1992; BACH, 1994). Esses animais apresentam diversas falhas na tolerância central e periférica, além de diversas mutações que conferem suscetibilidade à doença (revisado em ANDERSON; BLUESTONE, 2005). O início do diabetes nesses animais normalmente ocorre entre 12 e 14 semanas de idade em fêmeas e um pouco depois em camundongos machos. Estudos histológicos demonstraram que poucos infiltrados de células do sistema imune são encontrados até aproximadamente 3 a 4 semanas de idade. A partir desse momento, machos e fêmeas começam a apresentar infiltrados de células mononucleares que circundam as ilhotas pancreáticas (peri-insulite). Esses infiltrados progridem e invadem as ilhotas (insulite), sendo que a maioria dos animais já demonstram insulite severa com 10 semanas de idade. A maioria das células encontradas nesses infiltrados são T CD4 ${ }^{+}$ e T CD8 ${ }^{+}$, e embora células NK, linfócitos $\mathrm{B}$, células dendríticas e macrófagos sejam também identificados nas lesões (MAKINO et al., 1980; KIKUTANI; MAKINO, 1992), o desenvolvimento do DM1 em camundongos NOD depende majoritariamente de células T $\mathrm{CD}^{+}$e T CD8 $^{+}$(WICKER; MILLER; MULLEN, 1986; BENDELAC et al., 1987; BACH, 1994).

DM1 induzido por STZ: embora o DM1 em camundongos NOD seja similar ao DM1 em humanos, a maioria, se não todos, os ensaios clínicos em pacientes com DM1 baseados em terapias utilizadas em camundongos NOD tiveram resultados insatisfatórios 
(REED; HEROLD, 2015), demonstrando a necessidade de estudos em outros modelos experimentais. Neste contexto, o modelo de DM1 induzido por estreptozotocina (STZ) aparece como uma excelente alternativa, uma vez que, além de ser semelhante ao DM1 em humanos (LIKE; ROSSINI, 1976), também representa uma forma de diabetes induzida por uma resposta imune pró-inflamatória. O STZ (2-deoxy-(3-metil-3-nitrosureia)-1-D-glicopiranose) é um composto natural produzido pela bactéria do solo Streptomyces achromogenes, que possui propriedades antibacterianas (DOLAN, 1997). Ele é um análogo tóxico da glicose e N-acetil glicosamina, que é preferencialmente acumulado em células $\beta$ pancreática através do transportador de glicose GLUT-2 (VENTURA-SOBREVILLA et al., 2011). A partir do momento em que entra nas células pancreáticas, o STZ é capaz de gerar apoptose/necrose nessas células devido às suas propriedades químicas (porção citotóxica de nitrosureia e capacidade alquilante - revisado em (ELEAZU et al., 2013). No entanto, caso o STZ seja administrado em 5 pequenas doses $(40 \mathrm{mg} / \mathrm{kg} / \mathrm{dia})$, a atividade citotóxica da droga por si só não é suficiente para levar ao desencadeamento da doença. Acredita-se que a resposta imune tenha um papel fundamental nesse tipo de indução. Neste sentido, foi demonstrado que camundongos atímicos não desenvolvem diabetes quando tratados com 5 doses baixas de STZ. No entanto, quando eles são tratados com uma única dose alta de $200 \mathrm{mg} / \mathrm{kg}$, mesmo na ausência de linfócitos esses animais atímicos desenvolvem a doença normalmente (PAIK; FLEISCHER; SHIN, 1980). Portanto, acredita-se que nesse modelo de indução com 5 doses baixas, tanto a resposta imune, como a atividade citotóxica do STZ atuem em sinergismo para levar à morte das células $\beta$ pancreáticas, com consequente desenvolvimento do DM1. Com relação ao perfil da resposta, tem sido demonstrado um papel fundamental de células Th1 e Th17 no desenvolvimento da doença nesses animais (MENSAH-BROWN et al., 2006; YAOCHITE et al., 2012).

\subsubsection{A patofisiologia do DM1}

A suscetibilidade genética, alinhada a um fator ambiental, dão início ao desenvolvimento do DM1. A fase inicial da doença acontece no pâncreas, onde células dendríticas convencionais $(\mathrm{cDCs})$ capturam e processam antígenos oriundos de células $\beta$. $\mathrm{O}$ dano às células $\beta$ pode ocorrer por apoptose "natural” (potencializada pela suscetibilidade genética) ou após infecções virais (Figura 2). Células natural killer invariantes naturais (iNKT) e 
células dendríticas plasmocitóides (pDCs) controlam a replicação viral, prevenindo uma inflamação subsequente e desenvolvimento do DM1. cDCs ativadas ao migrarem para os linfonodos pancreáticos deparam-se com um ambiente pró-inflamatório gerado por um fator ambiental, levando à ativação de células $\mathrm{T}$ patogênicas antígeno-específicas, que será potencializada por macrófagos através da produção de IL-12. Células B apresentam antígenos de células $\beta$ para células T diabetogênicas (auto-reativas) e secretam auto-anticorpos (não mostrado na figura). A ativação de células $\mathrm{T}$ específicas para antígenos das ilhotas pancreáticas pode ser inibida por cDCs através de diversos mecanismos, como o engajamento de PDL1 (do inglês, programmed cell death ligand 1). Células iNKT promovem o recrutamento de cDCs e pDCs tolerogênicas que podem expandir células T reguladoras (Treg) através da produção de indoleamina 2,3-dioxigenase (IDO), IL-10, TGF- $\beta$ (do inglês, transforming growth factor- $\alpha$ ) e ICOSL (do inglês, inducible T cell co-stimulator ligand). No pâncreas, células $\beta$ podem ser destruídas por células T diabetogênicas (Th1 e Th17) e células NK através da liberação de IFN- $\gamma$, granzimas e perforinas, assim como por macrófagos através da produção de TNF- $\alpha$ (do inglês, tumour necrosis factor $\alpha$ ), IL-1 $\beta$ e óxido nítrico. IL-12 produzida por cDCs mantém as funções efetoras de células T diabetogênicas ativadas e células NK (não demonstrado na figura). $O$ dano às células $\beta$ pode ser inibido por células Treg que por sua vez inibem células $T$ diabetogênicas e células do sistema imune inato através da produção de IL-10 e TGF- $\beta$. pDCs tolerogênicas estimuladas por células iNKT também poderiam estar associadas ao controle de células T diabetogênicas através da produção de IDO. Por fim, células $\beta$ podem inibir células T diabetogênicas através da expressão de PDL1. Essa complexa interação entre células do sistema imune inato e adaptativo resulta no desenvolvimento ou prevenção do DM1. 


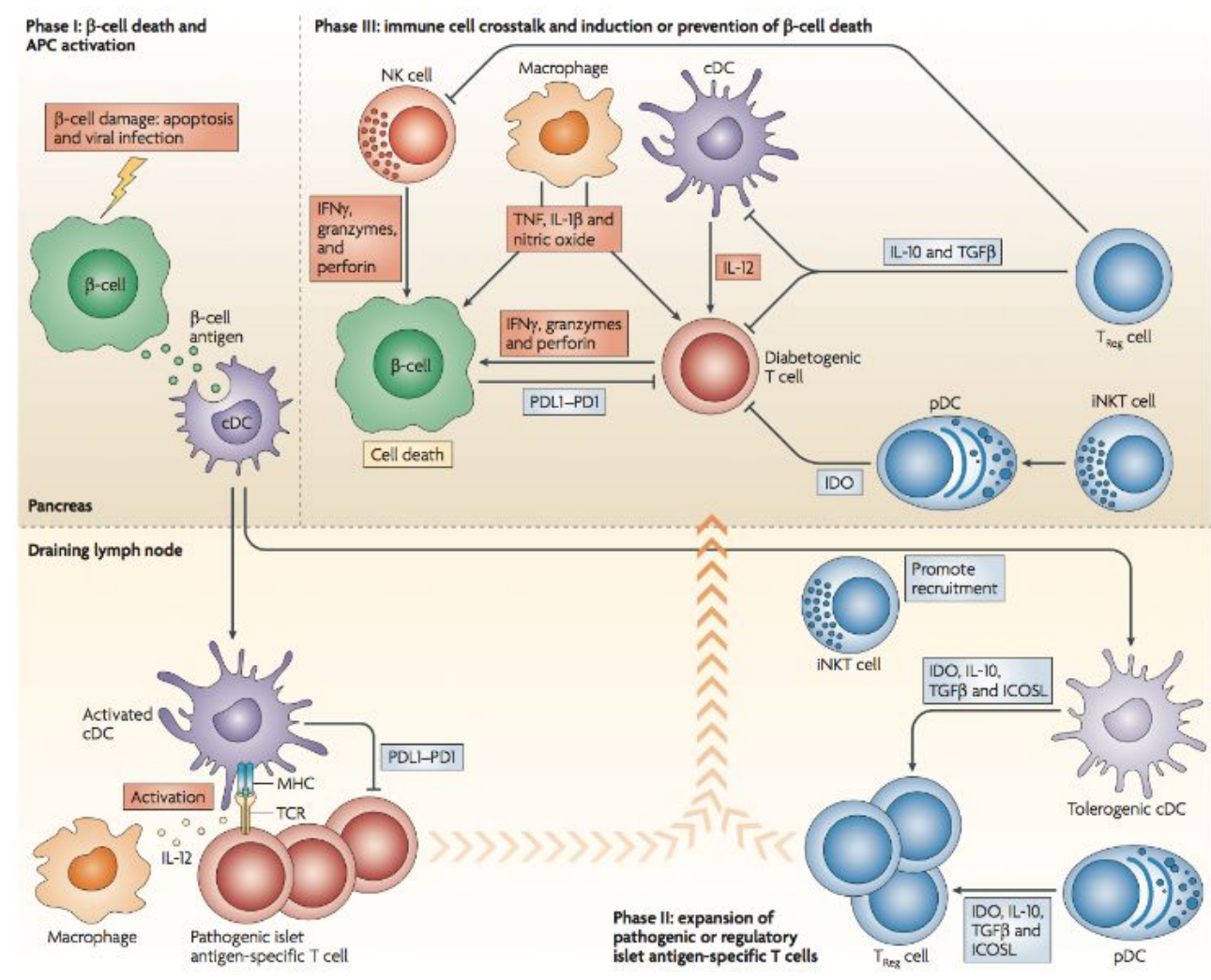

Figura 2: Possíveis eventos envolvidos no desenvolvimento ou prevenção do DM1 em indivíduos geneticamente suscetíveis. Figura extraída de LEHUEN et al., 2010.

1.4.7 Células Th1 estão envolvidas no DM1: modelos antigos de diferenciação de células $\mathrm{T} \mathrm{CD}^{+}$eram baseados na simples dicotomia entre respostas Th1 produtoras de IFN- $\gamma$ e respostas Th2 produtoras de IL-4. Células Th1 podem ser induzidas por IL-12 e são importantes para a ativação de macrófagos, enquanto que células Th2 são responsáveis pela defesa contra infecções helmínticas, além de estarem associadas com doenças alérgicas (por exemplo, asma, rinite e eczema) (WALKER, 2015). Visto sob essa perspectiva, o diabetes autoimune parecia estar firmemente associado ao padrão Th1, com um importante estudo por Katz e colaboradores demonstrando que células T expressando um TCR patogênico levavam ao desenvolvimento do DM1 em camundongos NOD neonatais quando diferenciados para um perfil Th1, mas não Th2 (KATZ; BENOIST; MATHIS, 1995). Corroborando essa ideia, foi demonstrado que níveis crescentes de IFN- $\gamma$ estavam 
correlacionados com a progressão do diabetes em camundongos NOD (RABINOVITCH, 1994) e que IFN- $\gamma$ era necessário para a indução de diabetes em um modelo de DM1 induzido por vírus (VON HERRATH; OLDSTONE, 1997). Existem diversas formas com que o IFN- $\gamma$ poderia estar contribuindo para o processo da doença, como o aumento da expressão das moléculas de MHC - classe I e II, facilitando a ativação de macrófagos e aumentando o extravasamento de leucócitos através da indução de moléculas de adesão e quimiocinas (revisado em SCHRODER et al., 2004). Além disso, tem-se atribuído ao IFN- $\gamma$ o papel de promover a migração de células T diabetogênicas para as ilhotas pancreáticas em camundongos NOD (SAVINOV; WONG; CHERVONSKY, 2001). Por fim, o IFN- $\gamma$ também tem sido associado à morte direta das células $\beta$. Neste contexto, foi demonstrado que ilhotas pancreáticas deficientes para o receptor de IFN- $\gamma\left(\mathrm{IFN}_{\gamma \mathrm{R}^{-/-}}\right.$- YI et al., 2012) são mortas com menos eficiência in vitro por citocinas como IFN- $\gamma$, TNF- $\alpha$ e IL- $1 \beta$, destacando a capacidade do IFN- $\gamma$ em sensibilizar as células $\beta$ para múltiplos gatilhos tóxicos.

O papel de células Th1 também tem sido estudado extensivamente em DM1 em humanos. A análise das células $\mathrm{T}$ do sangue periférico de adultos recém diagnosticados (idade média de 29 anos, com duração da doença de aproximadamente 5 semanas) demonstrou que o balanço entre IFN- $\gamma$ e IL-10 estava alterado em pacientes com DM1 quando comparado a indivíduos controle. Neste contexto, foi demonstrado que pacientes com DM1 possuíam mais células T auto-antígeno-específicas produzindo IFN- $\gamma$, enquanto que indivíduos sem a doença demonstraram um aumento em células produtoras de IL-10 (ARIF et al., 2011). De forma interessante, dois outros artigos também demonstraram resultados semelhantes, com um aumento da resposta do perfil Th1 em indivíduos recém diagnosticados com DM1 (PETRICH DE MARQUESINI et al., 2010; HAN et al., 2011).

1.4.8 Células Th1 não estão envolvidas no DM1: embora diversos estudos suportem um papel patogênico de células Th1 no DM1, nem todas as evidências são consistentes com essa conclusão. $\mathrm{O}$ achado de que camundongos NOD IFN $\gamma \mathrm{R}^{-/-}$exibiram uma alta taxa de resistência ao diabetes (WANG et al., 1997) parecia ser conclusivo para o papel patogênico desse subtipo celular. No entanto, essa proteção foi depois atribuída a um gene de resistência do cromossomo 10 que foi carregado do background 129 para o NOD 
durante os acasalamentos (KANAGAWA et al., 2000; SERREZE et al., 2000). De fato, a deficiência de IFN- $\gamma$ (HULTGREN et al., 1996) leva a apenas um modesto atraso no desenvolvimento da doença. Além disso, a injeção de IFN- $\gamma$ recombinante não acelerou o desenvolvimento do DM1 (SATOH et al., 1989), podendo até, de forma interessante, inibir o progresso da doença (FOUSTERI et al., 2010). Coletivamente, esses resultados questionam a visão tradicional de que o DM1 seja causado por células Th1 produtoras de IFN- $\gamma$, sugerindo que exista uma interação mais complexa no desenvolvimento da doença.

Em humanos, dados conflitantes com a visão patogênica de Th1 envolvem achados de que células $\mathrm{T}$ auto-reativas para insulina clonadas dos linfonodos pancreáticos de indivíduos com DM1 de longa duração expressaram IL-13, mas não IFN- $\gamma$ em resposta a estímulos (KENT et al., 2005). Além disso, outros estudos demonstraram que IFN- $\gamma$ estava, de fato, aumentado em pacientes recém diagnosticados com DM1. No entanto, outras citocinas do perfil Th2 como IL-4 e IL-5 também estavam aumentados (CHATZIGEORGIOU et al., 2010).

\subsubsection{Células Th17 no DM1}

O descobrimento de células Th17 (HARRINGTON et al., 2005; PARK et al., 2005) levou a uma intensa revisão do paradigma Th1/Th2 (STEINMAN, 2007) e levantou a possibilidade de que a autoimunidade tecido-específica pudesse ser gerada por células $\mathrm{T}$ produtoras de IL-17 ao invés de células Th1. No entanto, o papel de células Th17 no DM1 ainda permanece controverso. Os primeiros trabalhos em camundongos demonstraram o papel patogênico da IL-17 (JAIN et al., 2008; EMAMAULLEE et al., 2009a). No entanto, foi demonstrado posteriormente que o silenciamento da expressão de IL-17 não protegeu camundongos NOD do desenvolvimento do DM1 (JOSEPH et al., 2012b). Além disso, células Th17 purificadas de um camundongo que possui o TCR específico para antígenos das ilhotas pancreáticas (células T BDC2.5) foram capazes de induzir diabetes em um modelo de transferência adotiva, apesar de que a conversão para um perfil Th1 foi necessário para se alcançar esse fenótipo (BENDING et al., 2009; MARTIN-OROZCO et al., 2009).

Em humanos, a maioria dos trabalhos aponta para um papel patogênico de células Th17 no desenvolvimento do DM1. Crianças recém-diagnosticadas ou com longa duração da doença (média de idade: 8,7 anos) apresentaram mais células T positivas para IL-17 no 
sangue periférico quando comparadas com crianças controles (sem diabetes HONKANEN et al., 2010). Além disso, foi demonstrado por Ferraro e colaboradores que há um aumento de células Th17 inclusive nos linfonodos pancreáticos de indivíduos com DM1 quando comparado com os controles (FERRARO et al., 2011). Dessa forma, diversas evidências apontam para um aumento da produção de IL-17 no desenvolvimento do DM1.

\subsubsection{Resposta imune inata no DM1}

Macrófagos: estudos pioneiros com macrófagos descreveram a presença dessas células no infiltrado inflamatório das ilhotas pancreáticas (insulite) em camundongos NOD, e demonstraram que a inibição do influxo desses macrófagos para o pâncreas, através do bloqueio de um receptor de adesão nessas células inibiu o desenvolvimento do DM1 (HUTCHINGS et al., 1990). Estudos in vitro e in vivo em camundongos e ratos demonstraram que o efeito deletério de macrófagos nas células $\beta$ é mediado pela produção de TNF$\alpha$ e IL-1 $\beta$ (ARNUSH et al., 1998; DAHLÉN et al., 1998). Em humanos, macrófagos foram observados na insulite de pacientes com DM1 recém diagnosticados (UNO et al., 2007), demonstrando um papel patogênico desse subtipo celular tanto nas fases iniciais como nas fases tardias de destruição das células $\beta$ pancreáticas no DM1.

Células NK: células NK são tanto citotóxicas como produtoras de citocinas, especialmente IFN- $\gamma$. Dessa forma, células NK poderiam contribuir direta e indiretamente para a destruição das células $\beta$. Células NK foram detectadas no pâncreas de pacientes com DM1 e em diversos modelos experimentais de DM1 (POIROT; BENOIST; MATHIS, 2004; DOTTA et al., 2007; BRAUNER et al., 2010). De forma interessante, foi observado que células NK isoladas do pâncreas de camundongos NOD possuem um fenótipo mais ativado do que aquelas isoladas do baço e linfonodos pancreáticos, com maior expressão de CD25, CD69, PD-1 e KLRG1 (BRAUNER et al., 2010). Elas também proliferam mais e produzem maiores níveis de IFN- $\gamma$, além de expressarem CD107a na sua superfície (marcador de citotoxicidade) (GUR et al., 2010).

Células dendríticas (DCs): estudos iniciais demonstraram a presença de células apresentadoras de antígenos (do inglês, Antigen Presenting Cells - APCs) em ilhotas pancreáticas transplantadas (LACEY; DAVIE; FINKE, 1979) e observaram que a depleção 
dessas células facilitou a sobrevivência do enxerto em animais (FAUSTMAN et al., 1984). Esses dados sugeriam que APCs poderiam capturar e processar antígenos derivados das células $\beta$ e iniciar a resposta diabetogênica. Estudos posteriores demonstraram que células dendríticas convencionais (cDCs) poderiam capturar antígenos liberados por células $\beta$ em apoptose nas ilhotas pancreáticas e apresentá-los a células $\mathrm{T}$ antígeno-específicas nos linfonodos pancreáticos onde a resposta autoimune é iniciada (TURLEY et al., 2003; MARLEAU; SUMMERS; SINGH, 2008). Diversos estudos têm sugerido que cDCs de camundongos NOD são capazes de ativar células T através de uma elevada produção de IL-12, além da expressão de moléculas co-estimuladoras (POLIGONE et al., 2002; STEPTOE; RITCHIE; HARRISON, 2002).

De forma interessante, apesar de diversos estudos terem demonstrado a presença e função de células do sistema imune inato na patogênese do DM1, a forma com que receptores de reconhecimento de padrões (do inglês, Pattern Recognition Receptors - PRRs) são ativados nessas células e como eles dão início a todo o processo de destruição das células $\beta$ pancreáticas no DM1 ainda permanece pouco conhecido. Neste sentido, foi demonstrado por Hu e colaboradores, bem como pelo nosso grupo de pesquisa que a ausência de NLRP3 protege animais contra o DM1 no camundongo NOD e em C57BL/6 injetado com STZ, respectivamente (HU et al., 2015a; CARLOS et al., 2017). Além disso, um outro trabalho demonstrou que TLR2 também possui um papel patogênico na doença, através da produção de citocinas pró-inflamatórias como IL-1 $\beta$, IL-12p70 e óxido nítrico (KIM et al., 2007). Neste sentido, um melhor entendimento sobre o papel dos PRRs no contexto da autoimunidade se faz essencial a fim de se encontrar novas abordagens terapêuticas no contexto do DM1.

\subsection{Resposta imune inata: o papel do complexo de proteínas inflamassoma}

Tradicionalmente, a imunidade inata é vista como a primeira linha de defesa que discrimina o "próprio" (por exemplo, proteínas do hospedeiro) do não-próprio (por exemplo, microorganismos). No entanto, estudos posteriores têm sugerido que a imunidade inata atua na verdade como um sofisticado sistema que reconhece sinais de "perigo", como micróbios patogênicos ou sinais de estresse celular derivados do hospedeiro, enquanto 
permanece irrespondível a estímulos não perigosos, como moléculas normais do hospedeiro, antígenos da dieta, ou a microbiota intestinal (MATZINGER, 1994).

O sistema imune inato utiliza dos PRRs para detectar elementos invariáveis de micróbios. Os PRRs são expressos por células da linha de frente de defesa contra infecções, incluindo macrófagos, monócitos, DCs, neutrófilos e células epiteliais, assim como células do sistema imune adaptativo. Os PRRs incluem os TLRs (do inglês, toll-like receptors) e lectinas do tipo $\mathrm{C}$, que procuram no ambiente extracelular e compartimentos endossomais padrões moleculares associados a patógenos (do inglês, pathogen-associated molecular patterns - PAMPs). PRRs intracelulares incluem aqueles que reconhecem RNA, como RLHs (do inglês, RNA-sensing-RIG-like helicases), RIG-I e MD5; e os sensores de DNA, como DAI e AIM2 (SCHRODER; TSCHOPP, 2010). No entanto, existe ainda um outro conjunto de PRRs intracelulares, distinto desses descritos acima, chamado NLR (do inglês, NOD-like receptors), que são importantes na montagem do chamado complexo inflamassoma.

No ano de 2017, completou-se o marco de 15 anos do descobrimento dessa plataforma molecular denominada inflamassoma. Quinze anos atrás, Martinon, Burns e Tschopp publicaram um trabalho na revista Molecular Cell (MARTINON; BURNS; TSCHOPP, 2002) que resolveu o enigma de como um componente-chave da inflamação é ativado. A caspase-1 é um membro de uma família extremamente conservada evolutivamente de enzimas proteases que clivam proteínas reguladoras da morte celular e inflamação. Martinon e colaboradores descobriram que um complexo multi-protéico é necessário para ativar a caspase-1, e eles nomearam esse complexo de inflamassoma. Esse estudo deu início a um novo campo de pesquisa em inflamação, que continua a mapear a regulação das caspases inflamatórias, além de investigar seus papéis biológicos (LAMKANFI; DIXIT, 2017).

\subsubsection{A família dos NLR}

Os NOD-like receptors (NLRs) são constituídos por 22 genes humanos e muito mais genes murinos devido à expansão gênica desde o último ancestral comum. A família NLR é caracterizada por um domínio central de oligomerização e ligação à nucleotídeos (do inglês, nucleotide-binding and oligomerization - NACHT), que é comumente flanqueado por repetições ricas em leucinas (do inglês, leucine-rich repeats - LRRs) e domínios 
de recrutamento de caspase (do inglês, caspase recruitment and activation domain CARD) ou domínios pyrin - PYD. Acredita-se que os LRRs funcionem através da interação com o ligante e auto-regulação, enquanto que os domínios CARD e PYD realizem interações homotípicas proteína-proteína para que a sinalização downstream seja ativada. O domínio NACHT, que é o único domínio comum a todos os membros da família NLR, permite a ativação do complexo de sinalização através da oligomerização dependente de ATP (SCHRODER; TSCHOPP, 2010). Análises filogenéticas da família NLR revelaram 3 subfamílias distintas: os NODs (NOD1-2, NOD3/NLRC3, NOD4/NLRC5, NOD5/NLRX1, CIITA), os NLRPs (NLRP1-14) e a subfamília IPAF, que é formada por IPAF (NLRC4) e NAIP (Figura 3).

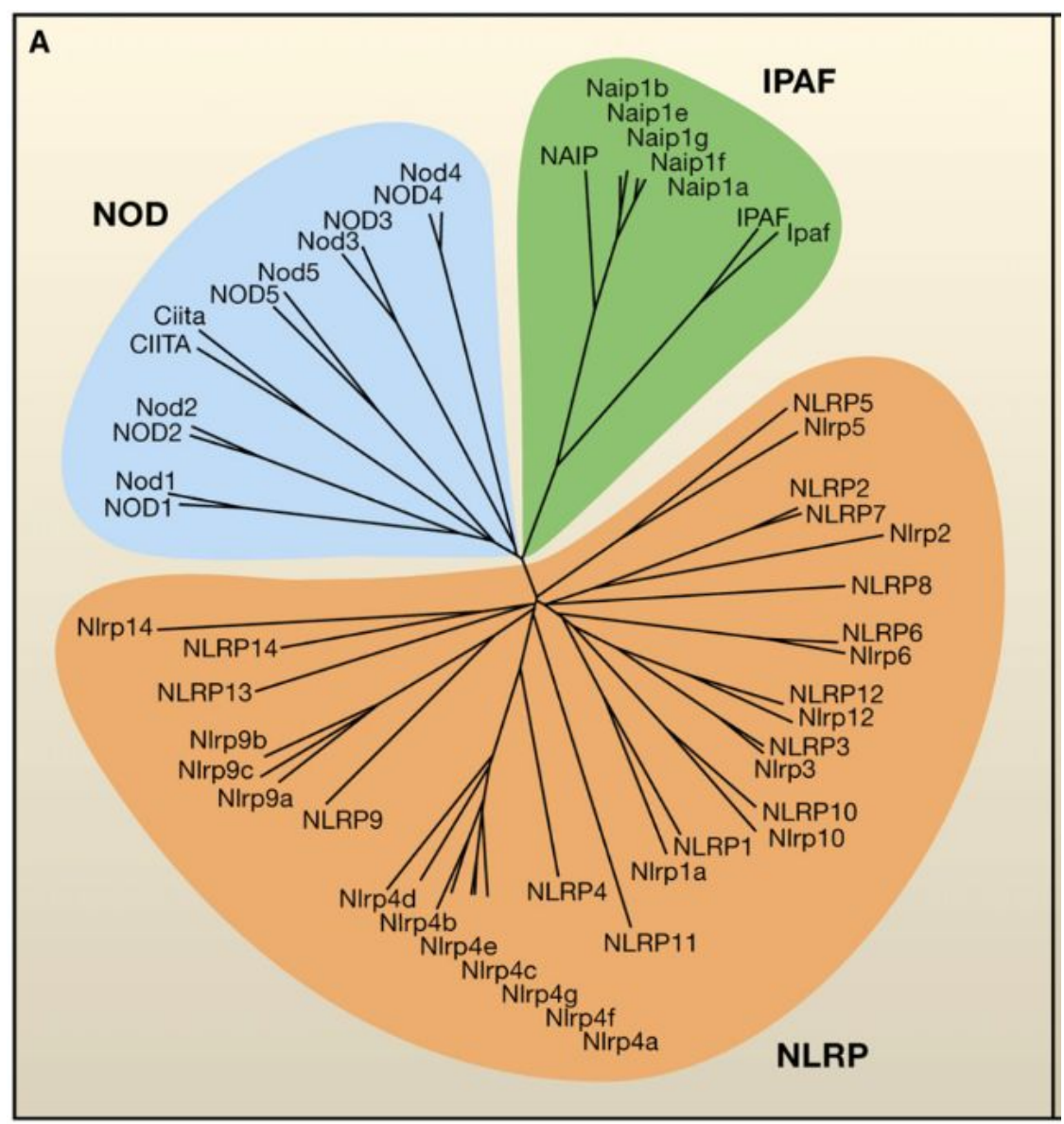

Figura 3: Análise filogenética da família NLR. Relações filogenéticas entre os domínios NACHT de cada proteína NLR de humanos (maiúsculo) e murino (minúsculo) demonstram três subfamílias distintas: NOD, NLRP e IPAF. Figura extraída de SCHRODER; TSCHOPP, 2010. 


\subsubsection{A ativação canônica e não-canônica do inflamassoma}

A ativação do inflamassoma NLRP3 é atualmente a mais bem caracterizada. Acredita-se que o NLRP3 deva ser "primado" antes de sua ativação. Esse priming envolve duas etapas distintas. Na ativação canônica do inflamassoma NLRP3, primeiramente, um estímulo como LPS se ligando a TLR4 induz o aumento na expressão de Nlrp3, levando ao aumento na expressão da proteína NLRP3. Posteriormente, um segundo estímulo diferente (existem diversos segundos sinais descritos até o momento, como realocação do NLRP3 para a mitocôndria, efluxo de potássio através de canais iônicos, liberação de catepsinas, entre outros) ativam o receptor, levando à formação do complexo inflamassoma (GUO; CALLAWAY; TING, 2015). Após a ativação, a oligomerização de NLRP3 leva à formação de um agregado de domínios PYD e consequente interações homotípicas com a molécula adaptadora ASC, que possui domínios PYD (ligando-se ao PYD de NLRP3) e domínios CARD, que por sua vez irão se ligar a domínios CARD presentes em pró-caspase-1. O agregado de pró-caspase-1 permite que ela seja auto-clivada e forme caspase-1 ativa (tetrâmero p10/p20), que irá, por sua vez, processar as pró-formas de citocinas (como próIL-1 $\beta$ e pró-IL-18) em suas formas maduras (SCHRODER; TSCHOPP, 2010). Além disso, caspase-1 ativa também é capaz de induzir um tipo de morte celular conhecida como piroptose (WEN; MIAO; TING, 2013; LAMKANFI; DIXIT, 2014; VANAJA; RATHINAM; FITZGERALD, 2015). Com relação à ativação não-canônica de NLRP3, estudos têm demonstrado que a pró-caspase-11 em camundongos e pró-caspases-4 e -5 em humanos podem se ligar diretamente à LPS intracelular e ativar o inflamassoma não-canônico de NLRP3. Essa ativação leva à oligomerização e consequente ativação dessas prócaspases, sendo suficiente para induzir piroptose, mas não o processamento de pró-IL-1 $\beta$ e pró-IL-18 (GUO; CALLAWAY; TING, 2015). De forma interessante, tem sido demonstrado que a caspase- 8 também possui papel crucial na ativação do inflamassoma e processamento das pró-formas de IL-1 $\beta$ e IL-18. A caspase-8 é uma protease pró-apoptótica que inicia a via de sinalização da apoptose em resposta a estímulos externos, como FasL e TNF, e protege contra uma forma inflamatória de morte celular denominada necroptose (SALVESEN; WALSH, 2014). Acredita-se que a caspase-8 seja importante tanto para o priming transcricional quanto para a ativação das vias canônica e não-canônica do inflamassoma NLRP3 em camundongos, em resposta a estímulos patogênicos e ligantes que 
estimulam diversos TLRs (ALLAM et al., 2014; GANESAN et al., 2014; GURUNG et al., 2014). Dessa forma, doenças inflamatórias onde os ligantes de TLRs são gerados poderiam levar ao priming ou ativação de NLRP3 mediado por caspase-8 (GUO; CALLAWAY; TING, 2015).

\subsubsection{Papel de PRRs em células T}

No presente momento, a biologia dos PRRs tem sido descrita principalmente em células mielóides, onde há uma alta expressão da maioria desses receptores. No entanto, novos estudos têm sugerido que a expressão de PRRs, como NLRP3 e NOD2, acontece não só em células mielóides, como em células epiteliais (FERON et al., 1990; ANDERSON; FINKELSTEIN; SHIMA, 2013) e células linfóides (SGOUROUDIS; ALBANESE; PICCIRILLO, 2008; SHAW et al., 2009; BRUCHARD et al., 2015; ARBORE et al., 2016). Neste sentido, foi demonstrado, por exemplo, que camundongos deficientes em NOD2 especificamente em células T infectados com Toxoplasma gondii possuíram menor diferenciação para o perfil Th1, o que foi associado com uma menor produção de IL-2 e menor acúmulo nuclear do fator de transcrição c-Rel (SHAW et al., 2009). No entanto, vale ressaltar que um estudo posterior não conseguiu encontrar tal associação (CAETANO et al., 2011). Com relação ao receptor NLRP3, foi observado que este possui papel importante em células linfóides, tanto na diferenciação para o perfil Th1 (ARBORE et al., 2016), quanto para o perfil Th2 (BRUCHARD et al., 2015). Com relação ao mecanismo, foi demonstrado que células $\mathrm{T} \mathrm{CD}^{+}{ }^{+}$humanas expressam o componente da via do complemento C5, que pode ser estimulado pela ativação do TCR e co-estimulação autócrina via CD46. A ativação intracelular subsequente de C5aR1 por C5a induziu a geração de ROS e a inesperada montagem do inflamassoma NLRP3 em células T CD4 ${ }^{+}$, sendo este último processo essencial para a produção de IFN- $\gamma$ por células T (ARBORE et al., 2016). Já com relação ao papel de NLRP3 na diferenciação de um perfil Th2, foi demonstrado que NLRP3 atua como um fator de transcrição, se ligando ao promotor do gene Il4 e o ativando juntamente com o fator de transcrição IRF4. Além disso, foi observado que apenas NLRP3, mas não os outros componentes do inflamassoma, como ASC ou caspase-1, estavam relacionados com a diferenciação para o perfil Th2 (BRUCHARD et al., 
2015). Dessa forma, é de suma importância a análise do papel de PRRs, como os membros da família NLR, tanto no compartimento mielóide, como no linfóide.

\subsection{NLRP1: estrutura, função e evidências no DM1}

O inflamassoma NLRP1 foi o primeiro a ser descrito (SCHRODER; TSCHOPP, 2010). Nlrpl humano possui três genes parálogos em camundongos (Nlrpla-c) que são extremamente polimórficos entre linhagens isogênicas distintas (BOYDEN; DIETRICH, 2006). Essa variação entre as linhagens no locus Nlrplb parece ser a responsável pelas diferentes respostas obtidas frente ao estímulo com a toxina letal do Bacillus anthracis, uma vez que macrófagos de uma linhagem de camundongos suscetíveis, mas não resistentes, são capazes de ativar caspase-1 após a exposição à toxina (BOYDEN; DIETRICH, 2006). De forma interessante, foi demonstrado que o inflamassoma NLRP1 também é capaz de ser ativado por MDP (FAUSTIN et al., 2007).

Com relação à sua estrutura, NLRP1 contém uma extensão C-terminal que abriga o domínio CARD, que por sua vez é capaz de interagir diretamente com a pró-caspase-1, sem a necessidade da molécula adaptadora ASC, embora a inclusão de ASC ao complexo seja capaz de aumentar a atividade do inflamassoma NLRP1 humano (FAUSTIN et al., 2007). Ao contrário do NLRP1 humano, o ortólogo NLRP1 murino não possui domínios PYD funcionais e parece ser incapaz de interagir com ASC (Figura 4). De fato, foi observado que ASC é dispensável para a ativação de caspase-1 por Nlrplb em macrófagos murinos (HSU et al., 2008). Recentemente, foi desenvolvida uma linhagem de camundongo deficiente para os três genes parálogos de NLRP1 (NLRPla, $\left.b, c^{-/}\right)$. Foi demonstrado que a montagem do inflamassoma NLRP1 após o estímulo com a toxina letal do Bacillus anthracis leva à ativação de caspase-1 e produção de IL-1 $\beta$. De forma interessante, foi demonstrado que a presença de caspase-1, mas não a produção de IL-1 $\beta$, está diretamente relacionada à morte celular, que por sua vez é responsável por gerar um dano agudo nos pulmões e morte desses animais após o estímulo com a toxina (KOVAROVA et al., 2012). Posteriormente, dois outros artigos demonstraram papéis diferentes para a proteína NLRP1. Williams e colaboradores demonstraram que $N l r p l b$ é importante para atenuar a inflamação intestinal e tumorigênese através de sua expressão no compartimento não hematopoiético (WILLIAMS et al., 2015). Além disso, foi demonstrado que Nlrpla é capaz de induzir 
piroptose em células progenitoras hematopoiéticas de forma dependente de caspase-1, gerando uma severa pancitopenia, que por sua vez leva a um quadro de imunossupressão em camundongos com Nlrpla ativado (MASTERS et al., 2012a). Coletivamente, esses dados demonstram funções distintas para NLRP1 dependendo do contexto, tornando necessário uma melhor caracterização da função dessa proteína frente à estímulos endógenos e exógenos.

Já com relação ao papel do receptor NLRP1 no DM1, existem apenas relatos na literatura que relacionam a presença de polimorfismos no gene Nlrpl com o desenvolvimento do DM1 (MAGITTA et al., 2009; TANG et al., 2013) ou com a proteção da nefropatia diabética em pacientes com DM1 (SOARES et al., 2017). Todavia, a importância deste receptor, assim como das citocinas produzidas em decorrência da sua ativação na indução da resposta inflamatória e polarização da resposta imune celular no modelo de DM1, ainda não foi investigada. Portanto, avaliamos na presente tese o papel do receptor NLRP1, bem como o das citocinas IL-1 $\beta$ e IL-18 na patogênese do DM1 em camundongos e em humanos, com ênfase na regulação da resposta mediada por linfócitos Th1 e Th17.

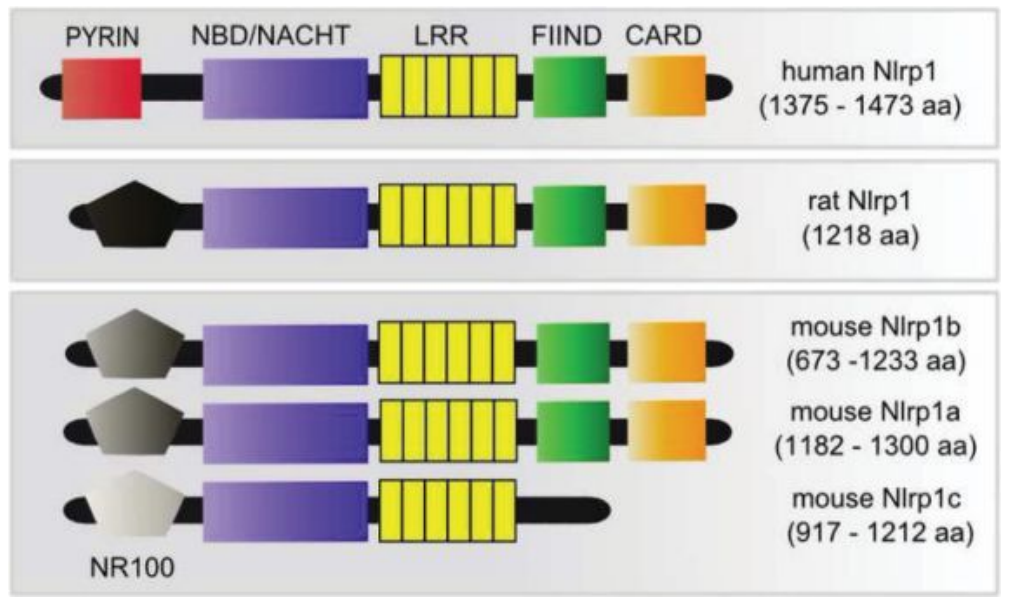

Figura 4: Domínios do sensor intracelular NLRP1 de humanos, ratos e camundongos. Os genomas de camundongos contêm três genes Nlrpl parálogos no cromossomo 11 (Nlrpla, Nlrplb e Nlrplc) e diferentes linhagens de camundongos expressam duas ou três dessas proteínas, assim como diferentes variantes do splicing. NLRP1 humano contém um domínio pyrin (capaz de interagir com ASC) que é ausente em roedores. NLRP1 de roedores possui uma região N-terminal (NR100) sem nenhuma sequência homóloga encontrada em NLRP1 humano, além de uma homologia limitada entre espécies de roedores e parálogos, conforme indicado pelo sombreamento na figura. Outros domínios demonstrados são: NBD/NACHT, nucleotide-binding ATPase domain; LRR, leucine-rich repeats; FIIND, function-to-find domain; CARD, caspase-1 recruitment domain. Figura extraída de SASTALLA; LEPPLA; MOYAERI, 2012. 
Objetivos 


\subsection{Objetivo geral:}

Avaliar a ativação e a contribuição do receptor NLRP1 na modulação da resposta imune celular durante a progressão do DM1 em modelos experimentais, bem como na modulação da resposta imune em pacientes com DM1.

\subsection{Objetivos específicos:}

Para isso, estabelecemos os seguintes objetivos específicos:

1. Correlacionar a expressão do receptor NLRP1, bem como a expressão de moléculas associadas a esse receptor com o perfil de resposta Th1 e Th17 no DM1;

2. Determinar o papel do receptor NLRP1 na polarização/reprogramação de linfócitos Th1 e Th17 no DM1;

3. Identificar a população celular (mielóide ou linfóide) que expressa o receptor NLRP1 nos linfonodos pancreáticos (LNP) de animais diabéticos e qual o papel dessa expressão na geração de uma resposta imune pró- ou antiinflamatória;

4. Investigar o envolvimento direto do receptor NLRP1 na diferenciação de linfócitos Th1 e/ou Th17;

5. Averiguar o possível papel de NLRP1 na estabilidade da barreira epitelial intestinal, composição da microbiota intestinal e translocação de bactérias para os LNP em modelos experimentais de DM1;

6. Avaliar os parâmetros clínicos e imunológicos relacionados ao DM1 em camundongos NOD, bem como gerar camundongos $\mathrm{NLRP}^{-/}$nesse background (NOD.NLRP1/-/)

7. Correlacionar polimorfismos do receptor NLRP1 com a regulação de uma resposta Th1 ou Th17 em pacientes com DM1. 
Metodologia 
3.1 Animais. Foram utilizados camundongos C57BL/6 machos selvagens (wild type - WT) e deficientes de NLRP1, ASC, IL-1R e caspase-1/11 entre 8 a 10 semanas de idade, pesando entre 20 e 25 gramas. Foram divididos da seguinte forma: grupo I ( $n=4)$, animais controles WT, sem indução de DM1; grupo II $(\mathrm{n}=4)$, animais controles knockouts, sem indução de DM1; grupo III $(n=6)$, camundongos WT com DM1, e grupo IV $(n=6)$, animais knockouts, com DM1. Todos os procedimentos realizados estão de acordo com os princípios propostos pelo Colégio Brasileiro de Experimentação Animal (COBEA) e foram submetidos à análise e aprovação pelo Comitê de Ética em Experimentação Animal (CETEA) da Universidade de São Paulo (nº 139/2012 - Anexo III).

3.2 Indução de DM1 por STZ. Os animais receberam cinco injeções i.p. diárias de STZ na concentração final de $40 \mathrm{mg} / \mathrm{Kg}$ de peso do animal em solução de citrato de sódio 25 $\mathrm{mM}, \mathrm{pH}=4,0$.

3.3 Monitoramento de glicemia. A glicemia foi avaliada em camundongos WT C57BL/6 ou deficientes para moléculas de interesse semanalmente a partir da primeira dose de STZ. Para isso, uma gota de sangue foi retirada da base da cauda de cada animal e a taxa de glicose foi quantificada no aparelho Accu Chek Nano (Accu Chek $\left.{ }^{\circledR}\right)$.

3.4 Avaliação de leucócitos por citometria de fluxo (FACS). A análise fenotípica de células extraídas dos LNP e de PBMCs (do inglês, peripheral blood mononuclear cells) de pacientes com DM1 foi realizada por citometria de fluxo. Para a detecção de Th17/Tc17 e Th1/Tc1, a expressão de IL-17 e IFN- $\gamma$ em células $\mathrm{CD}^{+}$e $\mathrm{CD} 8^{+}$foi determinada após cultivo dos leucócitos dos linfonodos, in vitro, com forbol-miristato-acetato (PMA) e ionomicina, e subsequentemente brefeldina. Além disso, o infiltrado celular nos tecidos coletados foi também analisado para quantificação das células $\mathrm{CD} 11 \mathrm{~b}^{+} \mathrm{CD} 11 \mathrm{c}^{+}$(células dendríticas). As células foram lavadas e ressuspendidas em Fc block (para bloquear ligações inespecíficas) por 30 minutos a $4^{\circ} \mathrm{C}$ e em seguida com $1.0 \mu \mathrm{g}$ de anticorpos monoclonais específicos aos marcadores determinados acima, conjugados com FITC, PE, PECy7, APC$\mathrm{Cy} 7$, PerCP ou APC por 30 minutos à $4^{\circ} \mathrm{C}$. Após incubação com os anticorpos, as amostras foram lavadas 2 vezes com PBS-BSA e centrifugadas a 250 x g por 10 minutos. Os 
leucócitos foram adquiridos em FACSCanto II (Becton \& Dickson ${ }^{\circledR}$, San Jose, CA, USA) e as análises feitas usando o software FlowJo (Treestar $\left.{ }^{\circledR}\right)$. Para realizar o sorting das populações celulares de interesse, consideramos células mielóides como sendo CD11b $\mathrm{b}^{+}$e células linfóides como $\mathrm{CD}^{+}$. Para a análise das células produtoras de IL-17 e IFN- $\gamma$ no compartimento de memória em humanos, após estímulo com PMA, ionomicina e brefeldina, avaliamos a expressão de IL-17 e IFN- $\gamma$ em células $\mathrm{CD}^{2} 5 \mathrm{RA}^{-} \mathrm{CD} 45 \mathrm{RO}^{+} \mathrm{CD}^{+} \mathrm{CD}^{+}$(ou $\left.\mathrm{CD}^{+}\right)$.

3.5 Extração de RNA. A extração do RNA das amostras dos LNP ou PBMCs foi realizada utilizando-se o kit de extração de RNA (Promega) de acordo com as recomendações do fabricante. As amostras de RNA foram suspensas em $40 \mu 1$ de água deionizada e livre de Rnase, sendo então armazenadas a $-80^{\circ} \mathrm{C}$. A concentração de RNA foi determinada utilizando-se o aparelho NanoDrop 2000 (Thermo Fisher Scientific, EUA).

3.6 Extração de DNA. A extração de DNA dos PBMCs de pacientes com DM1 foi realizada com o kit DNeasy Blood \& Tissue ${ }^{\circledR}$ (Qiagen, EUA), de acordo com as recomendações do fabricante. Já para a extração de DNA das fezes de animais utilizamos o kit DNeasy Power Soil ${ }^{\circledR}$ (Qiagen, EUA), conforme as especificações do fabricante. O DNA foi ressuspendido em um volume final de $40 \mu \mathrm{l}$ e armazenado a $-80^{\circ} \mathrm{C}$. Para a quantificação das amostras, utilizamos o equipamento NanoDrop $2000^{\circledR}$ (Thermo Fisher Scientific, EUA).

3.7 Reações de PCR em tempo real. A expressão relativa dos genes das moléculas Nlrpla, Nlrp1b, Ifn $\gamma$, Il17 e Nlrpl (humano) foi analisada através de reações de PCR em tempo real, utilizando-se os sistemas SYBR Green em um aparelho Step One Plus ${ }^{\circledR}$ (Applied Biosystems, EUA). O DNA complementar sintetizado a partir do RNA mensageiro foi utilizado juntamente com reagente SYBR Green, conforme determinado pelo fabricante. A reação básica de amplificação foi de 2 minutos a $50^{\circ} \mathrm{C}, 10$ minutos a $95^{\circ} \mathrm{C}$, e quarenta ciclos de 15 segundos a $95^{\circ} \mathrm{C}, 30$ segundos a $59^{\circ} \mathrm{C}$ e trinta segundos a $72^{\circ} \mathrm{C}$, além de um ciclo final de vinte minutos, com temperatura crescente de 60 a $95^{\circ} \mathrm{C}$, que foi empregada para a obtenção da curva de dissociação dos produtos da reação. Os resultados foram analisados com base no valor de CT (cycle threshold - ou ciclo limiar), sendo este 
o ponto correspondente ao número de ciclos onde a amplificação atinge um dado limiar que permite a análise quantitativa da expressão do fator avaliado. Para a análise da microbiota intestinal, 20ng de DNA das fezes de camundongos foram utilizados para a análise dos filos de bactéria Verrucomicrobia, Actinobacteria, Firmicutes e Bacteroidetes, utilizando os mesmos tempos e temperaturas da reação de PCR em tempo real. Já para a genotipagem, 20ng de DNA obtidos de PBMCs de pacientes com DM1 foram utilizados. A reação de amplificação utilizada foi de 30 segundos a $60^{\circ} \mathrm{C}$, dez minutos a $95^{\circ} \mathrm{C}$ e 50 ciclos de quinze segundos a $92^{\circ} \mathrm{C}$ e um minuto a $60^{\circ} \mathrm{C}$. Posteriormente, foi realizada uma curva de dissociação, com temperaturas crescentes de $60-95^{\circ} \mathrm{C}$ no período de trinta minutos. A análise de discriminação alélica foi realizada pelo próprio software do equipamento StepOnePlus ${ }^{\circledR}$.

3.8 Quantificação de citocinas por ELISA. A produção de citocinas (IFN- $\gamma$, IL-6, IL-17, IL-1 $\beta$, IL-18 e IL-1 $\alpha$ ) nos tecidos pancreáticos de camundongos; ou IFN- $\gamma$ e IL-17 no soro de pacientes com DM1 foi quantificada pela técnica de ELISA. A quantificação foi realizada em homogenato dos tecidos em solução contendo inibidores de protease, utilizando kits específicos para essas dosagens, conforme as recomendações do fabricante (Kits R\&D System).

\subsection{Pré-tratamento com antibióticos, transplante fecal e ensaio de translocação de}

bactérias. Um coquetel de antibióticos $(\mathrm{Abx})$ contendo Vancomicina $(0,96 \mathrm{mg})$, Neomicina (1.86mg), Metronidazol (1.86mg) e Ampicilina (1.86mg) foi administrado por gavagem para os camundongos por três semanas para a depleção da microbiota. Alternadamente, camundongos $\mathrm{NLRP}^{-/-}$foram tratados com Abx por 3 semanas e depois receberam por gavagem $200 \mu \mathrm{l}$ de amostra fecal de animais WT diluído em PBS. Dez dias depois, período necessário para a colonização da microbiota WT no hospedeiro deficiente para NLRP1, esses camundongos (designados NLRP1 $1^{--}(\mathrm{WT})$ ) foram injetados com 5 doses de STZ e tiveram a glicemia analisada 10 dias depois. Para o ensaio de translocação bacteriana, duas abordagens foram utilizadas: os LNPs foram macerados e plaqueados em cultura em meio BHI-ágar por até 5 dias em uma estufa a $37^{\circ} \mathrm{C}$ para a quantificação de bactérias por CFU (do inglês, colony-forming unit); ou, alternadamente, os LNPs foram macerados 
e posteriormente $100 \mu \mathrm{l}$ do macerado foram pipetados em tubos de ensaio contendo meio BHI líquido para posterior cultura em um shaker com rotação a 200 r.p.m. a $37^{\circ} \mathrm{C}$. Para a análise de bactérias anaeróbicas, foi utilizado o sistema GasPack ${ }^{\circledR}$ (BD Biosciences, EUA).

\subsection{Obtenção de células dendríticas derivadas da medula óssea.}

Para a geração de células dendríticas in vitro foram utilizados precursores da medula óssea (BMDC) de camundongos WT ou NLRP1 $1^{-/}$. Brevemente, as células foram distribuídas em placas de Petri em uma concentração de $1 \times 10^{6}$ células/placa e cultivadas com meio completo (RPMI 1640 suplementado com 10\% de SBF, 2Mm de L-glutamina, 100U/ml de penicilina, $100 \mu \mathrm{g} / \mathrm{ml}$ de estreptomicina, $0,05 \mathrm{mM}$ de 2-ME) sendo posteriormente adicionado $20 \mathrm{ng} / \mathrm{ml}$ de rGM-CSF murino (Sigma-Aldrich). No $3^{\circ}$ dia de cultura, outros $20 \mathrm{ng} / \mathrm{ml}$ de rGM-CSF foram adicionados na cultura e cultivadas por mais 3 dias. Em seguida, BMDCs foram ressuspendidas a uma concentração de $2 \times 10^{6}$ células em $200 \mu 1$ de meio incompleto e injetadas via intravenosa em camundongos WT previamente anestesiados.

\subsection{Obtenção de células do sangue periférico de humanos e genotipagem do SNP} rs12150220. Quarenta mililitros $(40 \mathrm{~mL})$ de sangue foram coletados no Hospital das Clínicas da USP de Ribeirão Preto, utilizando-se o sistema a vácuo. O sangue foi diluído em PBS pH 7,2 na proporção 1:1 e transferido para tubos cônicos contendo Ficoll-Hypaque (GE Healthcare), também na proporção 1:1. Após uma centrifugação a 2000 r.p.m. por 30 minutos a $25^{\circ} \mathrm{C}$, a camada de PBMC obtida entre a mistura de Ficoll-Hypaque e o plasma foi removida, depositada em novos tubos cônicos e lavada com $20 \mathrm{ml}$ de PBS. Depois de nova centrifugação a $500 \mathrm{Xg}$ por 10 minutos a $25^{\circ} \mathrm{C}$, o sobrenadante foi descartado e o sedimento ressuspendido em $10 \mathrm{ml}$ de PBS (pH 7,2) e novamente centrifugado a $500 \mathrm{Xg}$, durante o mesmo tempo e mesma temperatura. Depois do descarte do sobrenadante, o sedimento composto de PBMC foi ressuspendido em meio de cultura X-Vivo ${ }^{\mathrm{TM}}$ (Lonza). Uma alíquota da suspensão celular foi então removida, diluída 1:10 em azul de trypan (Sigma) e quantificada em câmara de Neubauer. Para a genotipagem de polimorfismos no gene Nlrpl (rs12150220), foi realizada a extração do DNA das amostras de PBMCs provenientes dos pacientes conforme descrito no item 3.6 e posteriormente foi realizada a 
análise de polimorfismos através do kit Taqman SNP Genotyping Assay (Applied Biosystems, EUA), de acordo com as recomendações do fabricante.

3.12 Análise estatística. A análise estatística foi realizada por meio do programa Graphpad Prism (Versão 6.0). Em todas as variáveis foram testadas a distribuição normal e a variância homogênea. Quando a distribuição foi considerada normal e com variância homogênea foram utilizados testes paramétricos. Quando a variância foi estatisticamente diferente, utilizamos o teste de $t$ não pareado com a correção de Welch. Os resultados foram expressos em média \pm erro padrão da média. As diferenças observadas foram consideradas significantes quando $\mathrm{p}<0,05$. 
Resultados 


\subsection{NLRP1 possui um papel protetor no diabetes tipo 1 induzido por STZ}

Existem estudos que demonstram polimorfismos no gene Nlrpl em pacientes com diabetes tipo 1 (DM1), sugerindo um possível papel do receptor na patogênese da doença (MAGITTA et al., 2009; TANG et al., 2013). Dessa forma, para se investigar o possível papel do receptor NLRP1 no DM1, camundongos selvagens (wild-type - WT) ou deficientes para os três genes parálogos do receptor NLRP1 (NLRP1a,b, $c^{-/}$) foram injetados com 5 doses de STZ e tiveram a glicemia analisada nos dias 10 e 15 após a primeira dose (Figura 5A). De forma interessante, observamos que animais $\mathrm{NLRP}^{-/}$injetados com STZ apresentaram níveis maiores de glicemia nos dias 10 e 15 quando comparado a animais WT injetados com STZ (Figura 5B e 5C, respectivamente). Pode-se observar que animais $\mathrm{NLRP}^{-/}$começam a ficar diabéticos (glicemia acima de $200 \mathrm{mg} / \mathrm{dL}$ ) já a partir do dia 10 , enquanto que o pico da incidência da doença em animais WT ocorre apenas no dia 15, o que sugere um papel protetor deste receptor no desenvolvimento do DM1 experimental. Além disso, analisamos dados histopatológicos desses animais e observamos um aumento no infiltrado inflamatório nas ilhotas pancreáticas de animais NLRP1 ${ }^{-/-}$quando comparados a animais WT, já a partir do dia 10 após as doses de STZ (Figura 6). 

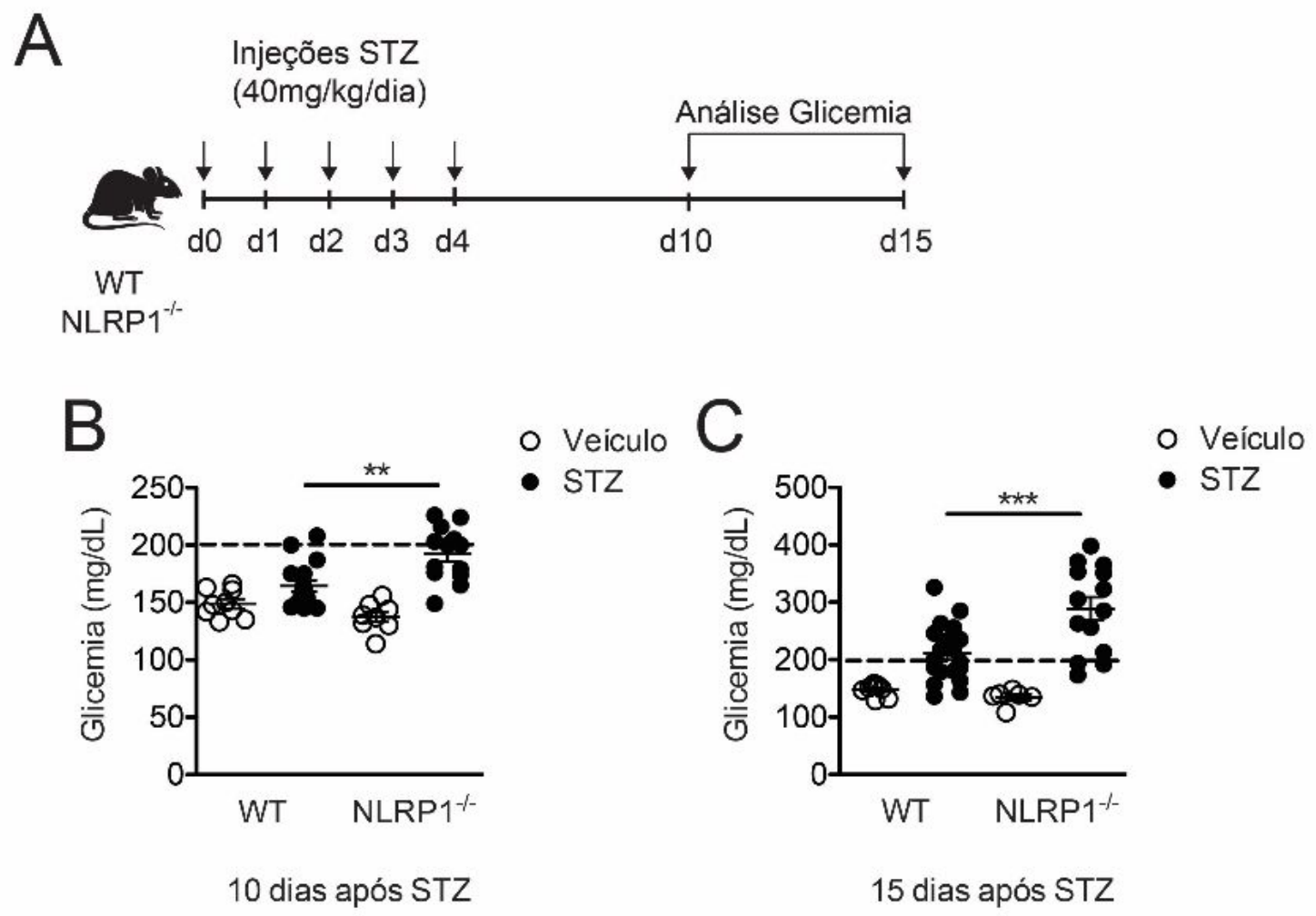

Figura 5: Análise do papel de NLRP1 na suscetibilidade/resistência ao DM1. Camundongos selvagens (wild-type WT) ou NLRP1 ${ }^{-1-}$ foram injetados com 5 doses de STZ $(40 \mathrm{mg} / \mathrm{kg} / \mathrm{dia})$ ou solução veículo (controles) (A). Esses animais tiveram a glicemia analisada nos dias 10 (B) e 15 (C) após a administração das doses de STZ. Os resultados são um compilado de três experimentos independentes e foram expressos em Média \pm Erro Padrão da Média. $\mathrm{P} \leq 0.05$ foi considerado estatisticamente significativo. 

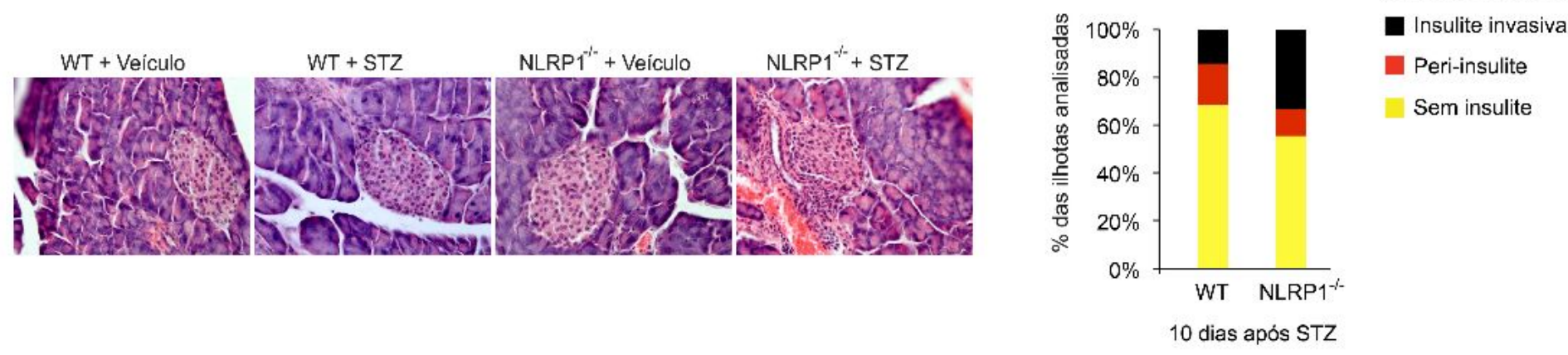

Figura 6: Análise histopatológica de animais WT e NLRP1 ${ }^{--}$após a indução de DM1 por STZ. Camundongos WT ou NLRP1 $1^{--}$foram injetados com 5 doses de STZ $(40 \mathrm{mg} / \mathrm{kg} / \mathrm{dia})$ ou solução veículo. Esses animais foram sacrificados e tiveram o pâncreas coletado para a análise histopatológica no dia 10 após a primeira dose de STZ. Os resultados foram expressos em Média \pm Erro Padrão da Média. $\mathrm{P} \leq 0.05$ foi considerado estatisticamente significativo. 


\subsection{NLRP1 está envolvido na indução de células produtoras de IL-17 para os linfo- nodos pancreáticos durante o DM1 induzido por STZ}

Com o intuito de se investigar os mecanismos imunológicos envolvidos no aumento da suscetibilidade ao DM1 por animais $\mathrm{NLRP}^{-/}$, a frequência e número absoluto de células Th1, Tc1, Th17 e Tc17 foram analisados nos linfonodos pancreáticos (LNPs) de animais WT e NLRP1 $1^{-/-}$tratados ou não com STZ, nos dias 10 e 15 após a primeira administração de STZ. Foi observado que 10 dias após a primeira dose de STZ não existe diferença na indução de células Th1 e Tc1 entre os grupos experimentais (Figura 7A e 7B). No entanto, foi observado um aumento no número de células Th17 e Tc17 nos LNPs de animais $\mathrm{NLRP}^{-/}$tratados com STZ quando comparados a animais WT (Figura 7A e 7B), indicando um possível papel de células produtoras de IL-17 no aumento da suscetibilidade de animais NLRP1/- ao DM1.

Já no dia 15 após as doses de STZ, observamos que em animais WT ocorre o aumento de células Th1, Tc1, Th17 e Tc17 nos LNPs (Figura 8A e 8B), o que coincide com o pico da doença nesses animais (Figura 5B e 5C). De forma interessante, observamos que em animais $\mathrm{NLRP}^{-/-}$injetados com STZ também ocorre a indução de células Th1 e Tc1 e que aquela diferença inicial no aumento de células produtoras de IL-17 é perdida no dia 15 após a administração de STZ (Figura 7A e 7B), sugerindo que a importância de células produtoras de IL-17 no aumento da suscetibilidade ao DM1 em animais NLRP1 ${ }^{-/}$está relacionada a estágios mais iniciais da doença. O próximo passo foi investigar como estavam os níveis das citocinas pró-inflamatórias no pâncreas, órgão alvo da doença, nesses animais. Primeiramente, observamos que, de fato, as citocinas IL-17 e IFN- $\gamma$ estão intimamente relacionadas com a destruição das células produtoras de insulina, com consequente quadro de hiperglicemia. Conforme observado na Figura 9A, existe uma forte correlação positiva entre os níveis de IFN- $\gamma$ e IL-17 no pâncreas e os níveis de glicemia em animais tratados com STZ. Ao analisarmos os níveis de IFN- $\gamma$ no pâncreas nos dias 10 e 15, não observamos diferenças entre animais NLRP1 ${ }^{-/-}$e animais WT (Figura 9B e 9C, respectivamente). Já em relação à IL-17, observamos que no dia 10 também não existe diferença entre os grupos tratados com STZ (Figura 9B). No entanto, de forma interessante, se dividirmos o grupo dos animais NLRP1 $1^{-/}$tratados com STZ em diabéticos (círculos vermelhos) 
e não-diabéticos (círculos pretos - vale ressaltar que no dia 10 a incidência da doença ainda é de apenas 50\% nesses animais) observamos uma diferença estatística na produção de IL17 entre os animais NLRP1 ${ }^{-/-}$que já se encontram em um estado de hiperglicemia, comparado a animais WT tratados com STZ, indicando o papel proeminente da citocina IL-17 na destruição das células $\beta$ (Figura 9B). Já no dia 15, apesar do aumento nos níveis de IL-17 quando comparado ao dia 10 (os níveis vão de $\sim 3 \mathrm{ng} / \mathrm{g}$ de tecido no dia 10 para $\sim 6 \mathrm{ng} / \mathrm{g}$ de tecido no dia 15 em ambos os grupos), já não observamos mais uma diferença entre animais $\mathrm{NLRP}^{-/-}$e WT, o que corrobora os dados encontrados nos LNPs (Figuras 7 e 8) e reforça a hipótese de que o receptor NLRP1 seja protetor no DM1 em estágios iniciais da doença através da regulação negativa de células produtoras de IL-17. 


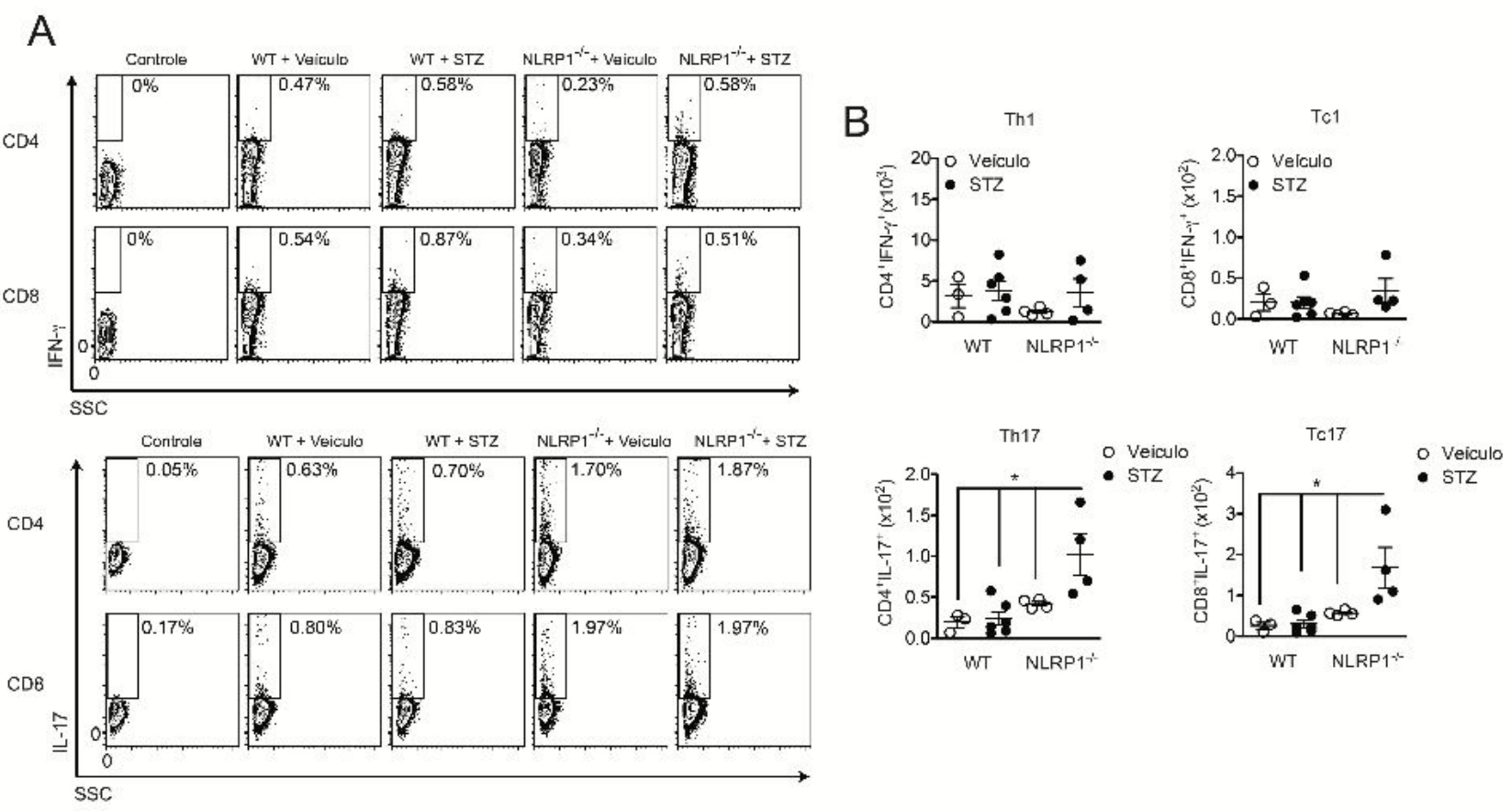

Figura 7: Células produtoras de IL-17 estão aumentadas nos estágios iniciais do DM1 induzido por STZ em animais NLRP1 ${ }^{-/}$. Camundongos WT ou NLRP1 ${ }^{-\digamma}$ foram injetados com 5 doses de STZ (40mg/kg/dia) ou solução veículo (controles). Esses animais tiveram os linfonodos pancreáticos coletados no dia 10 para a análise da frequência (A) e número absoluto (B) de células Th1 $\left(\mathrm{CD} 4^{+} \mathrm{IFN}-\gamma^{+}\right)$, Tc1 $\left(\mathrm{CD} 8^{+} \mathrm{IFN}-\gamma^{+}\right)$, Th17 $\left(\mathrm{CD} 4^{+} \mathrm{IL}-17^{+}\right)$e Tc17 (CD8 $\left.{ }^{+} \mathrm{IL}-17^{+}\right)$ por citometria de fluxo. As gates foram realizadas em células $\mathrm{CD}^{+}$, após exclusão dos doublets e delineamento da gate de linfócitos por FSC/SSC. Os resultados foram expressos em Média \pm Erro Padrão da Média. $\mathrm{P} \leq 0.05$ foi considerado estatisticamente significativo. 


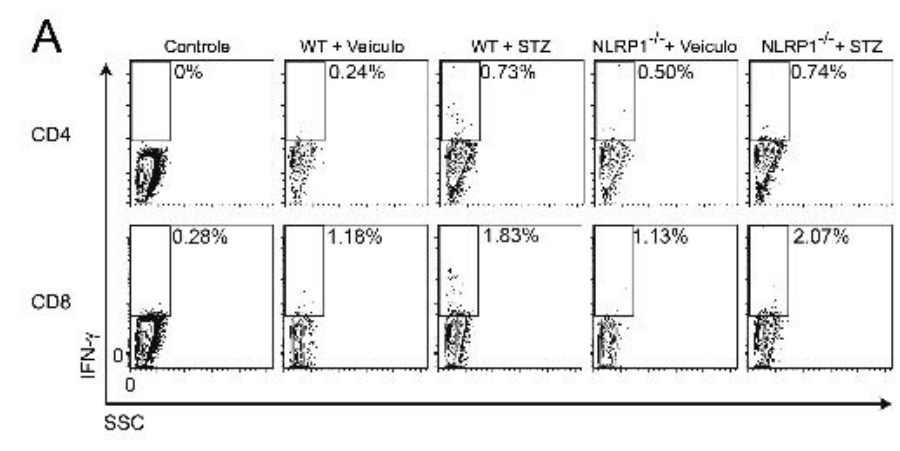

B
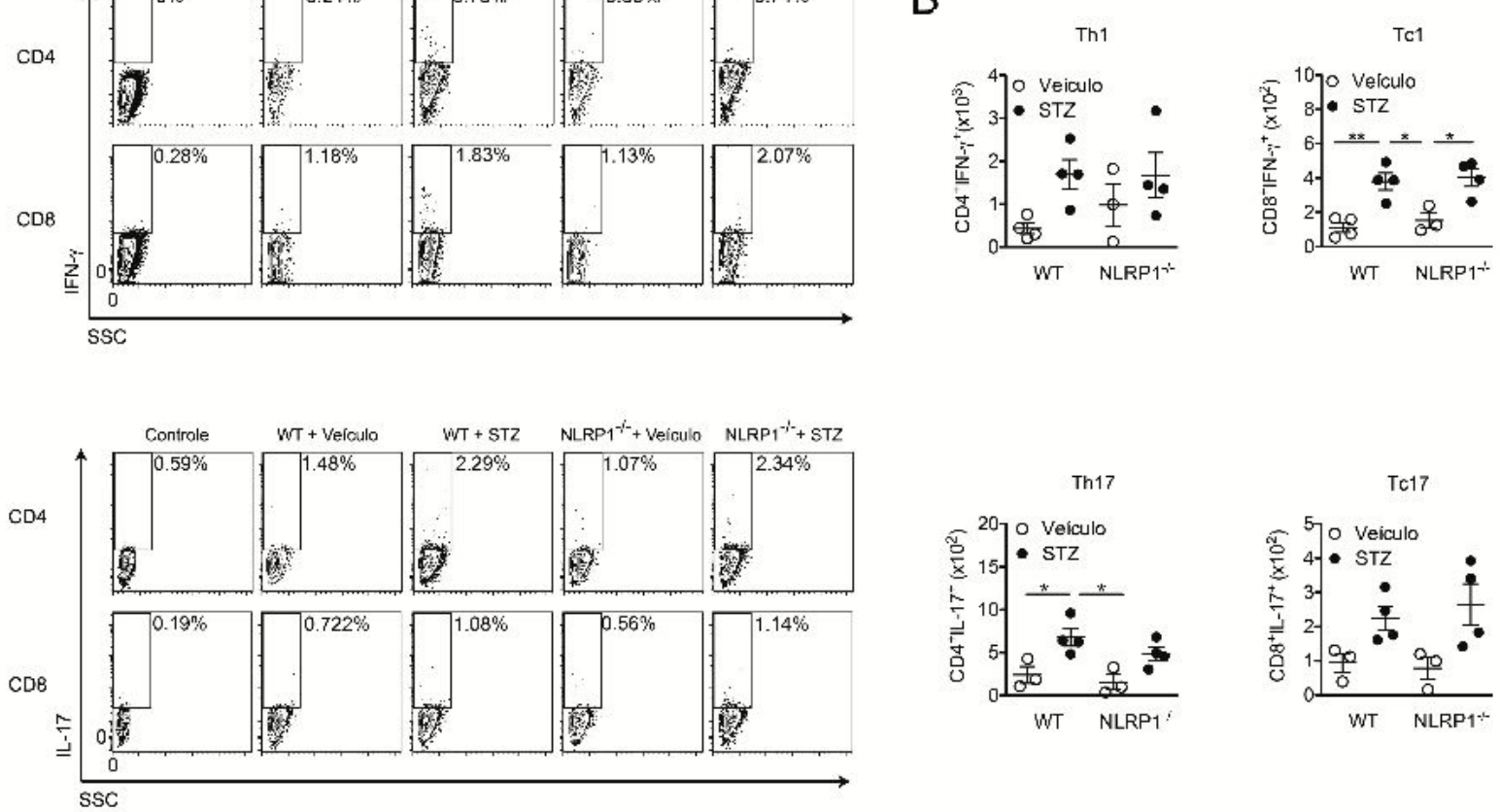

Figura 8: Ausência de diferença nas distintas subpopulações de linfócitos T de animais WT e NLRP1 ${ }^{-/-}$em estágios mais tardios do DM1 induzido por STZ. Camundongos WT ou NLRP1 ${ }^{-/}$foram injetados com 5 doses de STZ $(40 \mathrm{mg} / \mathrm{kg} / \mathrm{dia})$ ou solução veículo (controles). Esses animais tiveram os linfonodos pancreáticos coletados no dia 15 para a análise da frequência (A) e número absoluto (B) de células Th1 (CD4 ${ }^{+}$IFN- $\left.\gamma^{+}\right)$, Tc1 (CD8 ${ }^{+}$IFN- $\left.\gamma^{+}\right)$, Th17 (CD4 ${ }^{+}$IL$\left.17^{+}\right)$e Tc17 $\left(\mathrm{CD}^{+} \mathrm{IL}_{-1} 7^{+}\right)$por citometria de fluxo. As gates foram realizadas em células CD3 ${ }^{+}$, após exclusão dos doublets e delineamento da gate de linfócitos por FSC/SSC. Os resultados foram expressos em Média \pm Erro Padrão da Média. $\mathrm{P} \leq 0.05$ foi considerado estatisticamente significativo. 


\subsection{A microbiota intestinal está envolvida no aumento da suscetibilidade de camun- dongos NLRP1 ${ }^{-/-}$ao DM1 induzido por STZ}

Já é bem estabelecido que a citocina IL-6 possui um importante papel na diferenciação de células Th17. Portanto, decidimos avaliar a produção desta citocina por células da imunidade inata em camundongos NLRP1 ${ }^{-/-}$tratados com STZ. Para isso, analisamos a frequência e número absoluto de células dendríticas produtoras de IL-6 e IL-12p40 nos linfonodos pancreáticos de animais WT e NLRP1 $1^{-/}$tratados ou não com STZ. De forma interessante, observamos que no dia 10 após as doses de STZ, onde ocorre um pico em animais NLRP1 ${ }^{-/}$na indução de células Th17 (Figura 7A e 7B), mas não Th1, houve um aumento tanto em frequência como em número absoluto de células dendríticas produtoras de IL-6 (Figura 10A), mas não de IL-12p40 (Figura 10B), sugerindo que o aumento na produção de IL-6 por células dendríticas no dia 10 após as doses de STZ possa estar contribuindo na diferenciação de células Th17 em animais NLRP1 ${ }^{-/}$. Nosso próximo passo foi avaliar se a alta produção de IL-6 por células dendríticas de animais NLRP1/- ocorre pelo fato do receptor NLRP1 ser um regulador negativo da via de sinalização de IL-6 em células dendríticas. Portanto, células dendríticas derivadas da medula óssea de camundongos WT ou $\mathrm{NLRP}^{-/-}$foram transferidas para animais WT, que foram então injetados com 5 doses de STZ e tiveram a glicemia analisada 10 dias depois (Figura 10C). De forma interessante, observamos que animais WT transferidos com células dendríticas de animais NLRP1 ${ }^{-/-} \mathrm{e}$ tratados com STZ não tiveram o mesmo fenótipo que animais NLRP1/-- (Figura 10D). Além disso, não encontramos diferença na produção de IL-6 no pâncreas de animais WT transferidos com células dendríticas de animais WT ou NLRP1 ${ }^{-/-}$e tratados com STZ (Figura 10E). Esses resultados excluem a possibilidade de que NLRP1 seja um regulador negativo da sinalização de IL-6, indicando que outros fatores estão levando ao aumento na produção de mediadores pró-inflamatórios em animais NLRP1 ${ }^{-/}$quando tratados com STZ.

Nosso próximo passo foi investigar o que poderia estar levando ao aumento na resposta pró-inflamatória em animais $\mathrm{NLRP}^{-/}$, com consequente aumento na diferenciação de células Th17 e aumento na suscetibilidade ao DM1 induzido por STZ. Nosso grupo de pesquisa já demonstrou que a translocação de bactérias da microbiota intestinal para os 
LNPs é essencial para o desenvolvimento da doença (COSTA et al., 2016). Portanto, nós levantamos a hipótese de que o aumento no número de células Th17 e consequente aumento na suscetibilidade de camundongos NLRP1 ${ }^{-/-}$ao DM1 induzido por STZ se deve ao aumento na translocação de bactérias para os LNPs. Portanto, analisamos a presença de bactérias nos LNPs de animais WT ou NLRP1 ${ }^{-/}$, tratados ou não com STZ, pela técnica de CFU (do inglês, colony-forming unit). De forma interessante, observamos que tanto animais $\mathrm{NLRP}^{-/-}$tratados com solução veículo, como animais injetados com STZ apresentaram um aumento na translocação bacteriana para os LNPs nos dias 10 e 15, quando comparados com camundongos WT (injetados ou não com STZ), sugerindo que NLRP1 talvez possua um importante papel na manutenção da barreira epitelial intestinal (Figura 11A). Para comprovar o papel da microbiota intestinal no aumento da suscetibilidade de camundongos NLRP1 $1^{-/}$ao DM1, tratamos esses animais com um coquetel de antibióticos para diminuir ao máximo o número de bactérias presentes no trato gastrointestinal e posteriormente os submetemos às 5 injeções de STZ (Figura 11B). Alternadamente, um outro grupo de animais NLRP1 $1^{-/}$também foi submetido ao tratamento com antibióticos (Abx), no entanto, após este tratamento, foi submetido a um transplante fecal com fezes de camundongos WT (sendo designados (NLRP1 ${ }^{-/-}$(WT)). Dez dias após o transplante fecal, que é o período necessário para que haja a colonização das bactérias dos camundongos WT no hospedeiro deficiente para NLRP1, esses animais foram submetidos às injeções de STZ (Figura 11B). Surpreendentemente, observamos que o pré-tratamento com antibióticos foi capaz de inibir o aumento na suscetibilidade de camundongos NLRP1 ${ }^{-/-}$ao DM1 induzido por STZ, tornando-os resistentes à doença (Figura 11C). Além disso, observamos que este aumento na suscetibilidade ao DM1 por camundongos NLRP1 $1^{-/-}$se deve à quantidade $(\mathbf{F i}$ gura 11A), mas não à qualidade de bactérias (NLRP1 $1^{-/-}$(WT) - Figura 11C) presentes nos linfonodos pancreáticos, uma vez que, mesmo possuindo a microbiota de camundongos WT (devido ao transplante fecal), esses animais NLRP $1^{-/}$transplantados voltaram a desenvolver a doença, com 100\% de incidência já a partir do décimo dia após as doses de STZ (Figura 11C). Posteriormente, analisamos a composição da microbiota fecal para averiguar uma possível participação do receptor NLRP1 nesse contexto. De forma interessante, observamos que o tratamento com STZ em animais WT foi capaz de induzir um aumento de bactérias do filo Bacteroidetes e diminuição de bactérias do filo Firmicutes 
(Figura 11D). Além disso, foi observado que na ausência do receptor NLRP1, existe uma notável diferença na composição da microbiota intestinal de animais NLRP1 ${ }^{-/}$tratados com solução veículo, com aumento de bactérias do filo Verrucomicrobia e diminuição de bactérias dos filos Actinobacteria e Firmicutes, quando comparado com animais WT sem tratamento com STZ (Figura 11D). De forma interessante, demonstramos que o tratamento com STZ em animais NLRP1 $1^{-/}$foi capaz de induzir uma inibição quase que completa de bactérias do gênero Verrucomicrobia, com consequente aumento de bactérias dos demais filos analisados.

Alternadamente, resolvemos analisar dois fatores: primeiro, se o tratamento com antibióticos é capaz de eliminar por completo a microbiota intestinal; e segundo, se o transplante fecal de bactérias provenientes de animais WT em animais NLRP1/- é capaz de induzir uma microbiota intestinal semelhante à um animal WT convencional. Conforme observado na Figura 11E, o tratamento com Abx levou a uma diminuição de aproximadamente 20 vezes na quantidade de DNA encontrado nas fezes de animais deficientes para NLRP1. Além disso, ao analisarmos a expressão de um gene ubíquo do reino Eubacteria pela fórmula $2^{\wedge}$-СT (do inglês, cycle threshold), confirmamos que, de fato, houve um substancial decréscimo no número de bactérias presentes nas fezes de animais tratados com Abx (Figura 11E). Ao observamos a composição da microbiota intestinal, observamos que o tratamento com Abx praticamente eliminou bactérias de todos os filos, restando somente bactérias do filo Firmicutes. Além disso, foi observado que o transplante fecal foi capaz de restabelecer bactérias dos filos Actinobacteria e Bacteroidetes (Figura 11F). De forma geral, esses dados sugerem que a microbiota intestinal está envolvida no desenvolvimento de DM1 induzido por STZ em animais deficientes para NLRP1.

Posteriormente, para se avaliar o papel do receptor NLRP1 no intestino de animais diabéticos, animais WT foram tratados com STZ e posteriormente tiveram o íleo coletado para a análise da expressão dos genes Nlrpla e Nlrplb por RT-PCR (Figura 11G). Considerando que Nlrplc não possui os domínios FIIND e CARD (Figura 5 da introdução), este gene produz uma proteína truncada (SASTALLA et al., 2013), sendo considerado, portanto, um pseudogene. Por conseguinte, resolvemos não o adicionar as nossas análises. De forma interessante, observamos que a expressão de Nlrpla está aumentada no íleo de animais diabéticos, quando comparado a camundongos WT injetados com solução veículo, 
sugerindo um possível papel de NLRP1a na manutenção da integridade da barreira epitelial intestinal.

Por fim, investigamos se a microbiota intestinal seria importante na indução da resposta Th17 encontrada no dia 10 após as doses STZ em camundongos NLRP1 ${ }^{-/-}$(Figura 7). Surpreendentemente, quando analisamos o número absoluto de células Th17 nos LNPs de animais NLRP1 ${ }^{-/-}$tratados com Abx e submetidos às doses de STZ, observamos que a depleção da microbiota intestinal não foi capaz de reduzir o número de células produtoras de IL-17, indicando que existe um outro mecanismo responsável pelo aumento de IL-17 na ausência de NLRP1 (Figura 11H). 
A
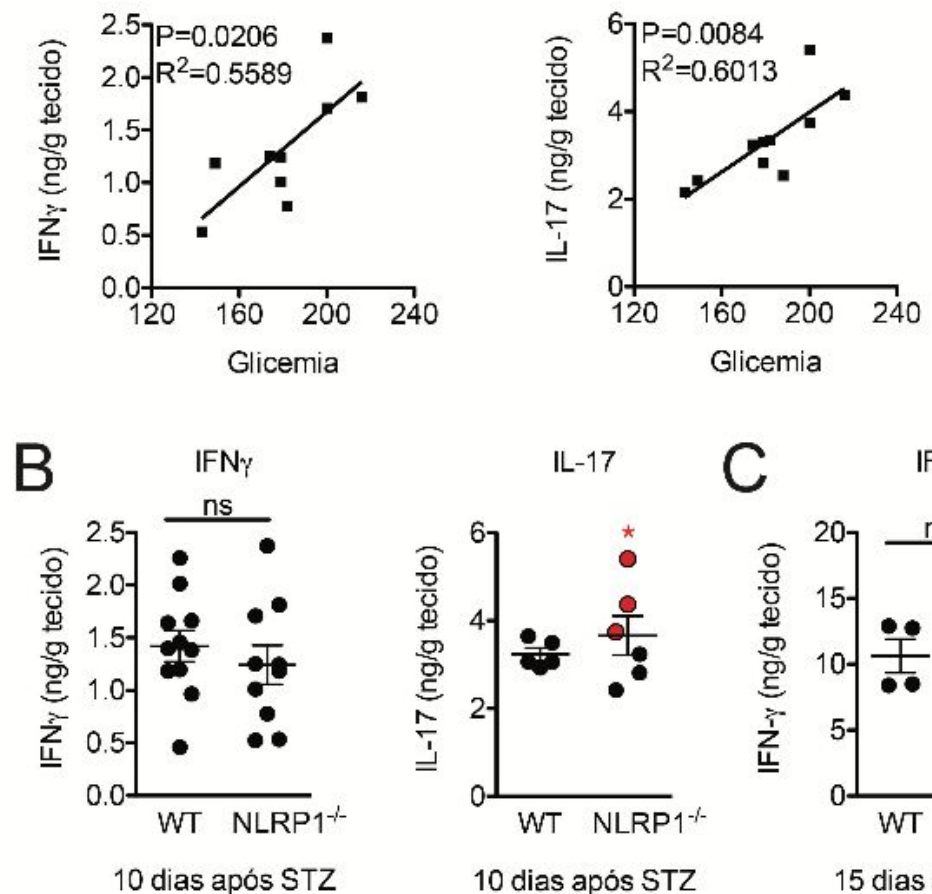

IFN $\gamma$

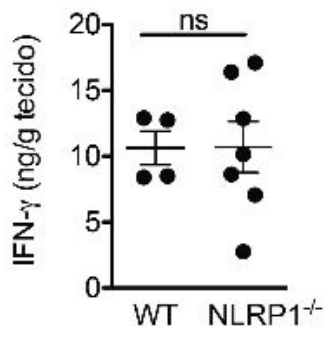

15 dias após STZ
$\mathrm{IL}-17$

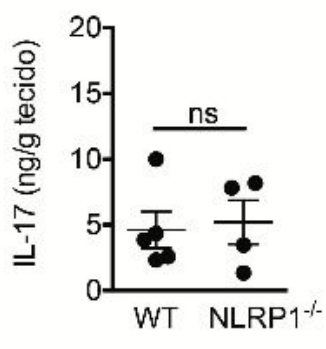

15 dias após STZ

Figura 9: IL-17 está intimamente relacionada à hiperglicemia de animais NLRP1 ${ }^{-/}$. Camundongos WT ou NLRP1I- foram injetados com 5 doses de STZ (40mg/kg/dia) ou solução veículo (controles). Esses animais tiveram a glicemia analisada, bem como o pâncreas coletado nos dias 10 e 15 para a análise da produção de citocinas pela técnica de ELISA. A glicemia foi correlacionada com a produção das citocinas IFN- $\gamma$ e IL-17 (A), enquanto que os dados referentes à produção das citocinas nos dias 10 e 15 após as injeções de STZ encontram-se em (B) e (C), respectivamente. Os resultados foram expressos em Média \pm Erro Padrão da Média. $\mathrm{P} \leq 0.05$ foi considerado estatisticamente significativo. 


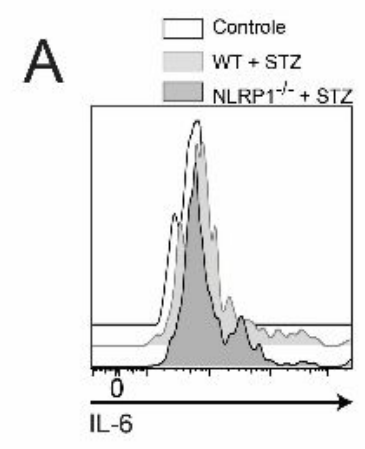

C

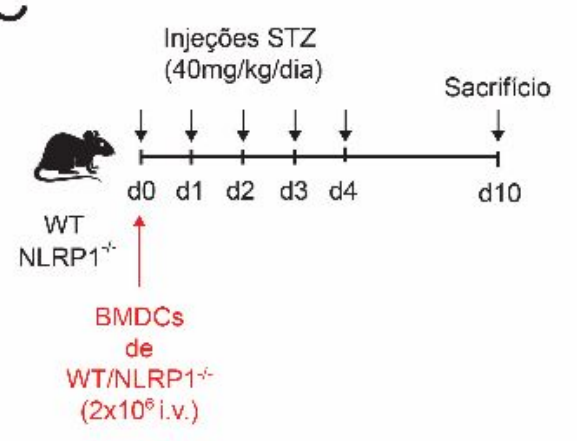

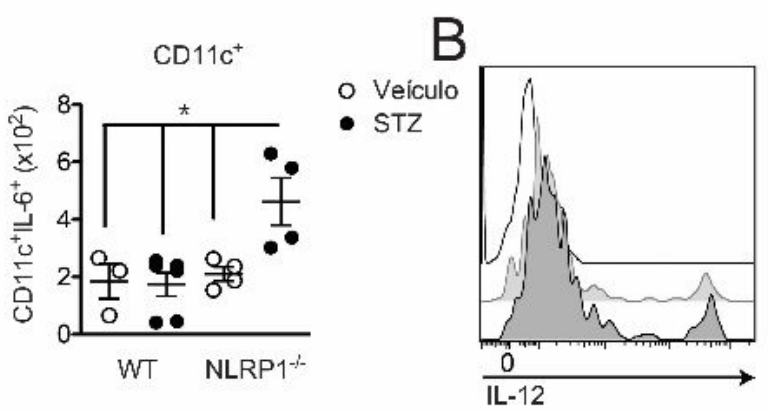

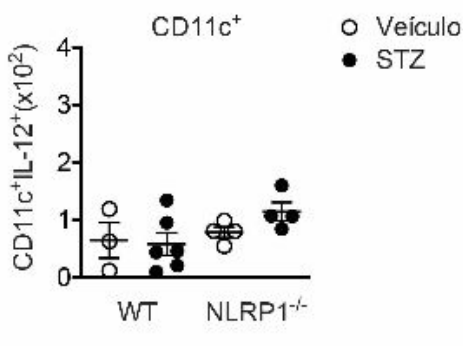

$\mathrm{D}$

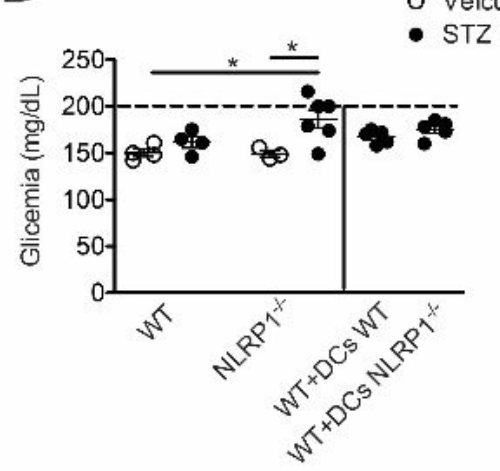

10 dias após STZ
$\mathrm{E}$

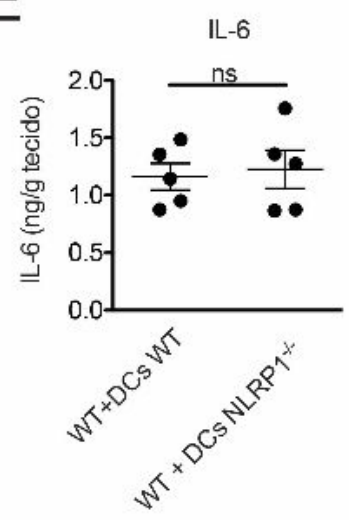

10 dias após STZ

Figura 10: NLRP1 não é um regulador negativo da produção de IL-6. Camundongos WT ou NLRP1 ${ }^{-/-}$foram tratados com 5 doses consecutivas de STZ (40mg/kg/dia) ou solução veículo (controles). Esses animais tiveram os linfonodos pancreáticos coletados 10 dias após as doses de STZ para a análise da frequência e número absoluto de células dendríticas produtoras de IL-6 (CD11 $\left.\mathrm{c}^{+} \mathrm{IL}-6^{+}\right)(\mathrm{A})$ ou IL-12p40 $\left(\mathrm{CD} 11 \mathrm{c}^{+} \mathrm{IL}-12^{+}\right)(\mathrm{B})$. Camundongos WT foram inoculados pela via intravenosa com $2 \times 10^{6}$ células dendríticas derivadas da medula óssea de camundongos WT ou NLRP1\%(C). Esses animais tiveram a glicemia analisada no dia 10 após as injeções de STZ (D) e tiveram o pâncreas coletado para a análise da produção de IL-6 pela técnica de ELISA (E). Os resultados foram expressos em Média \pm Erro Padrão da Média. $\mathrm{P} \leq 0.05$ foi considerado estatisticamente significativo. 

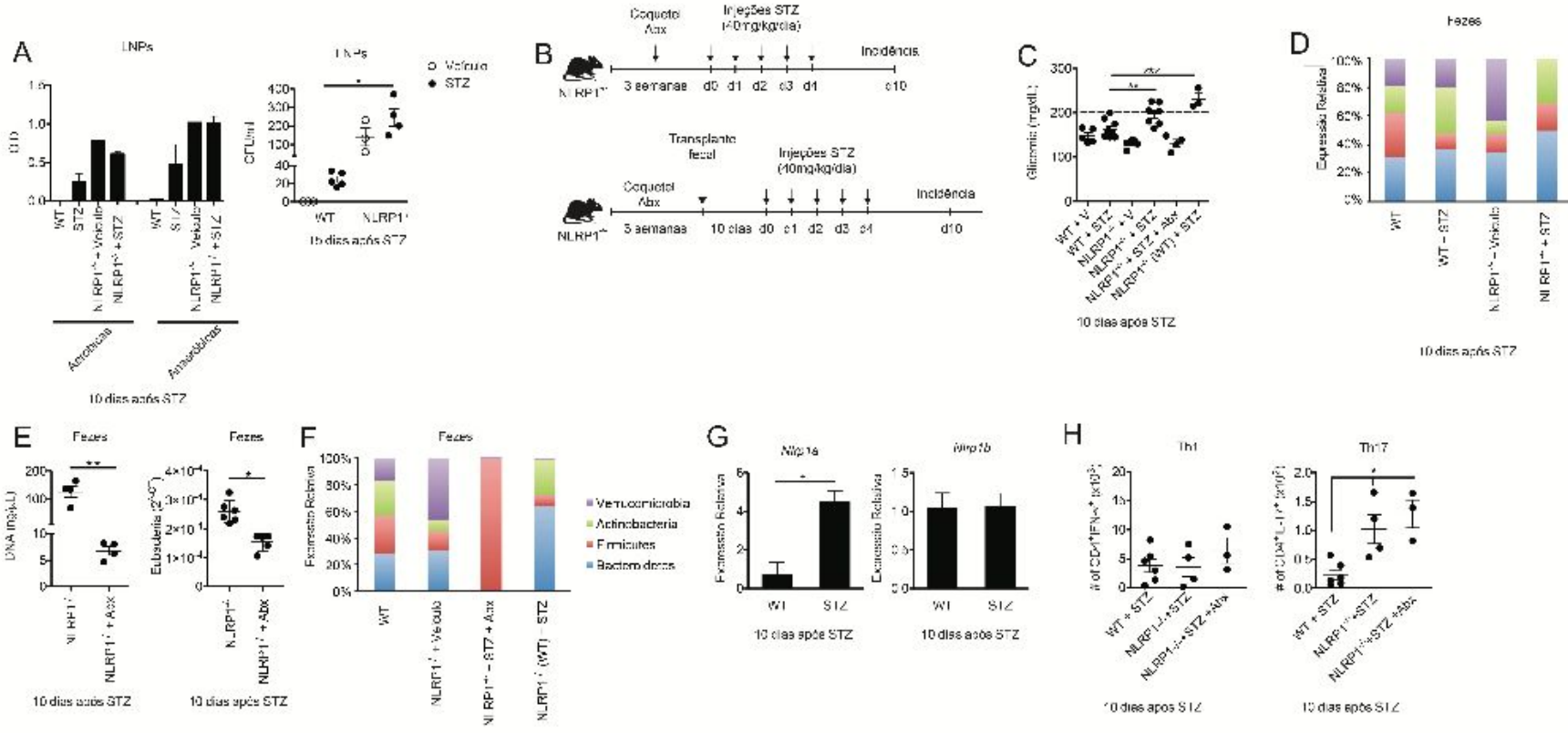

Figura 11: Análise do papel da microbiota intestinal no aumento da suscetibilidade de camundongos NLRP1 ${ }^{-1}$ ao DM1 induzido por STZ. Camundongos WT ou NLRP1 ${ }^{-1-}$ foram tratados com 5 doses consecutivas de STZ (40 mg $\left./ \mathrm{kg} / \mathrm{dia}\right)$ ou solução veículo (controles). Esses animais tiveram os linfonodos pancreáticos (LNPs) coletados 10 e 15 dias após as doses de STZ para a quantificação de bactérias pela técnica de CFU (do inglês, colony-forming unit) (A). Camundongos $\mathrm{NLRP}^{1-\text { f }}$ foram tratados com um coquetel de antibióticos (abx: ampicilina $1 \mathrm{~g} / \mathrm{L}$, metronidazol $1 \mathrm{~g} / \mathrm{L}$, neomicina $1 \mathrm{~g} / \mathrm{L}$ e vancomicina $0,5 \mathrm{~g} / \mathrm{L}$ ) por três semanas e foram submetidos ou não a um transplante fecal de fezes provenientes de camundongos WT. Esses animais foram então injetados com 5 doses consecutivas de STZ (40mg/kg/dia) (B). Posteriormente, esses animais tiveram a glicemia e as fezes analisadas no dia 10 após as injeções de STZ (C-F). O íleo de animais WT tratados ou não com 5 doses de STZ foi coletado e analisado para expressão gênica de Nlrpla e Nlrplb por RT-PCR (G). Os camundongos descritos em (C) tiveram os linfonodos pancreáticos coletados para a análise do número absoluto de células Th1 $\left(\mathrm{CD}^{+} \mathrm{IFN}-\gamma^{+}\right)$e Th17 $\left(\mathrm{CD} 4^{+} \mathrm{IL}-17^{+}\right)$por citometria de fluxo $(\mathrm{H})$. Os resultados foram expressos em Média \pm Erro Padrão da Média. $\mathrm{P} \leq 0.05$ foi considerado estatisticamente significativo. 


\subsection{A suscetibilidade de camundongos NLRP1-- ao DM1 induzido por STZ não se deve à ativação da maquinaria do inflamassoma}

Considerando-se que a expressão de receptores da imunidade inata em linfócitos $\mathrm{T}$ já foi documentada (abordado no item 1.5.3 da introdução), levantamos a hipótese de que o receptor NLRP1 seja expresso em células T, inibindo a diferenciação para um perfil Th17, explicando assim o aumento desse subtipo celular na ausência do receptor. A fim de testar tal hipótese, tratamos animais WT com STZ por 5 doses consecutivas e os sacrificamos nos dias 7, 10 e 15 para a análise da expressão dos genes Nlrpla e Nlrp1b em células linfóides $\left(\mathrm{CD}^{+}\right)$, mielóides $\left(\mathrm{CD} 11 \mathrm{~b}^{+}\right)$e demais subtipos celulares $\left(\mathrm{CD} 3^{-} \mathrm{CD} 11 \mathrm{~b}^{+}\right.$- Figura 12A e B). De forma interessante, observamos que Nlrpla, ao contrário do que acontece no íleo (Figura 11F), não é expresso nos LNPs durante a progressão da doença (Figura 12A). Surpreendentemente, observamos que Nlrp $1 b$ é altamente expresso, já a partir do dia $7 \mathrm{em}$ células linfóides, mantendo sua expressão constante durante o período analisado (Figura 12B). Além disso, demonstramos que Nlrp $1 b$ também é expresso em células mielóides no dia 10, indicando uma possível ativação da maquinaria do inflamassoma pelo receptor NLRP1, tendo sua expressão suprimida a níveis basais no décimo quinto dia.

Posteriormente, decidimos avaliar diversas moléculas associadas ao inflamassoma, a fim de validar ou excluir a hipótese de que a maquinaria do inflamassoma estaria associada ao aumento de células Th17 na ausência de NLRP1. Para isso, camundongos WT e $\mathrm{NLRP}^{-/-}$tratados ou não com STZ foram sacrificados 10 ou 15 dias após a administração da droga e tiveram o pâncreas coletado para a análise da produção de citocinas que utilizam da maquinaria do inflamassoma (IL-1 $\beta$ e IL-18) e uma citocina que não necessita da clivagem pela caspase-1, sendo encontrada diretamente em sua forma ativa, a IL-1 $\beta$ (Figura 13A e B). De forma interessante, foi observado que, de fato, na ausência do inflamassoma NLRP1 há um decréscimo na produção de IL-1 $\beta$ e IL-18, mas não de IL-1 $\beta$ no dia 10 após as injeções com STZ (Figura 13A), o que coincide com a expressão de Nlrplb em células mielóides no mesmo dia (Figura 12B). Já no dia 15, a expressão de Nlrp $1 b$ volta aos níveis basais (Figura 12), o que também é correlacionado com o desaparecimento na diferença encontrada nos níveis de IL-1 $\beta$ e IL-18 no pâncreas (Figura 13B). Esses dados indicam que mesmo na ausência de citocinas pró-inflamatórias como Il-1 $\beta$ e IL-18, animais NLRP1-

\footnotetext{
/- tratados com STZ são capazes de induzir uma potente resposta Th17, o que contribui para
} 
o desenvolvimento precoce do DM1 nesses animais. Posteriormente, para excluir de fato que a ativação do inflamassoma de NLRP1 esteja relacionado com o aumento da suscetibilidade ao DM1 induzido por STZ observado em camundongos NLRP1 ${ }^{-/}$, utilizamos esse modelo experimental em diversos camundongos deficientes para proteínas essenciais da maquinaria do inflamassoma, como caspase-1, caspase-11, ASC e IL-1R (Figura 13C). Corroborando nossa hipótese, nenhum desses animais apresentou o fenótipo de suscetibilidade que animais $\mathrm{NLRP}^{-/-}$apresentaram, demonstrando inclusive um quadro de resistência, como o que aconteceu em animais $\mathrm{ASC}^{-/-}$e IL-1R $\mathrm{R}^{-/-}$(Figura 13C). De forma geral, esses dados indicam que a ativação da maquinaria do inflamassoma pelo receptor NLRP1 não está relacionada com a proteção ao DM1 induzido por STZ. 
A

Nirp1a

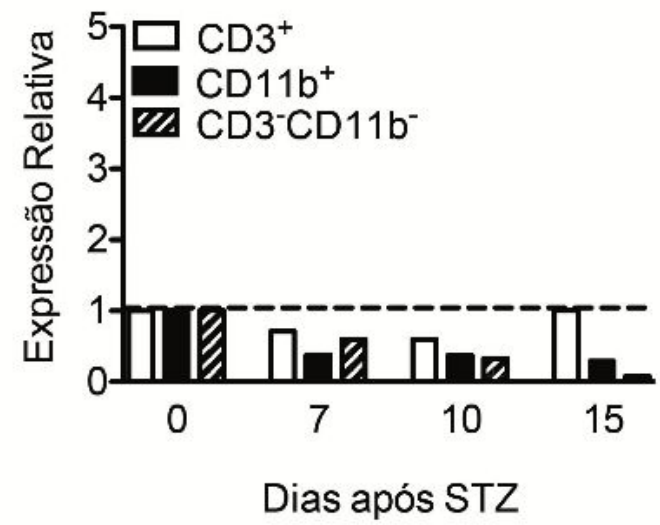

B

Nirp1b

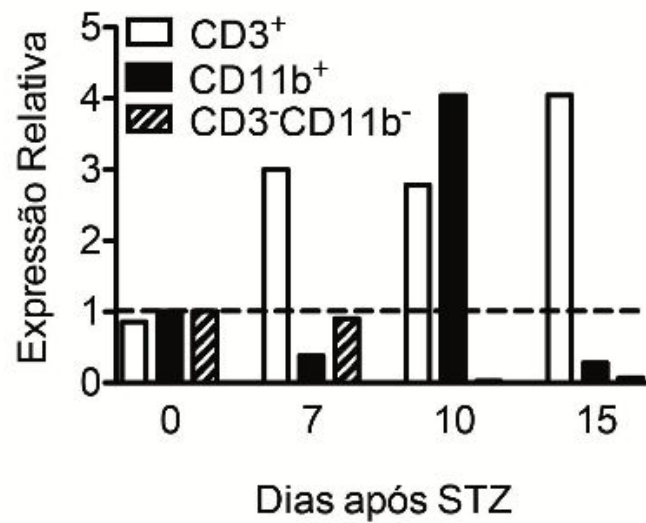

Figura 12: Análise da expressão dos genes Nlrpla e Nlrp1b em diferentes subpopulaçõs celulares durante o desenvolvimento do DM1 induzido por STZ. Camundongos WT tratados ou não com STZ por cinco dias (40mg/kg/dia) foram sacrificados nos dias 0, 7, 10 e 15 após as doses de STZ e tiveram os linfonodos pancreáticos coletados para o isolamento de células linfóides $\left(\mathrm{CD}^{+}\right)$, mielóides $\left(\mathrm{CD} 11 \mathrm{~b}^{+}\right)$e demais subtipos celulares $\left(\mathrm{CD}^{-} \mathrm{CD} 11 \mathrm{~b}^{-}\right)$por sorting. Posteriormente, foram analisados para a expressão de Nlrpla (A) e Nlrplb (B) pela técnica de RT-PCR. 
A

IL-1 $\beta$

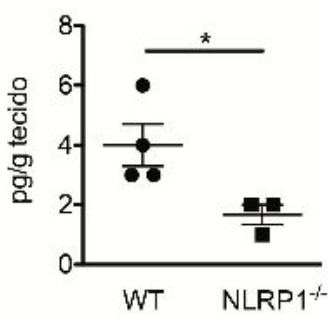

10 dias após STZ

B

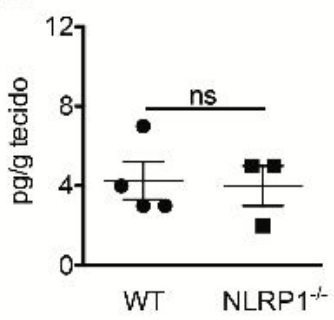

15 dias após STZ

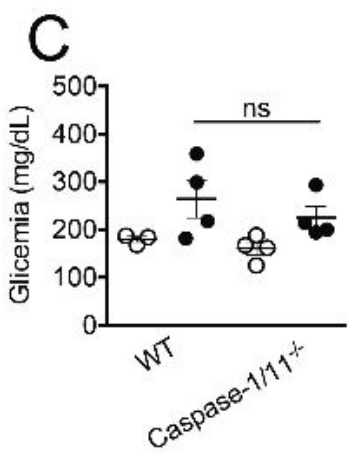

15 dias após STZ
$\mathrm{LL}-1 \alpha$.

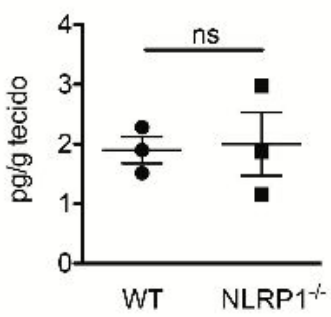

10 dias após STZ

IL-1 $\alpha$

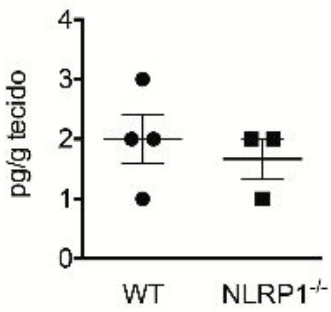

15 dias após STZ
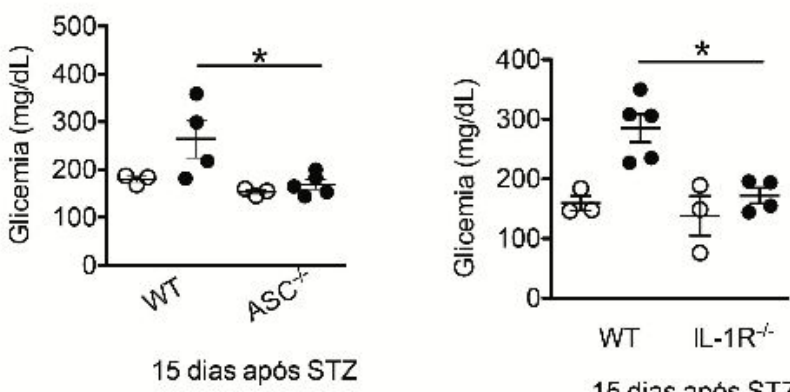

15 dias após STZ

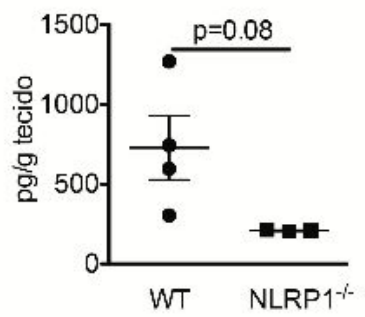

10 dias após STZ

|L-18

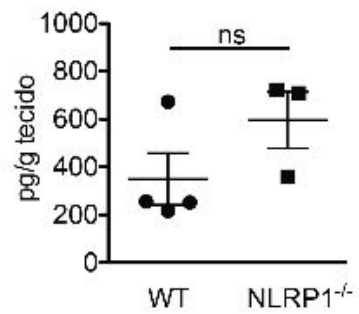

15 dias após STZ

- Veículo

- STZ

Figura 13: A maquinaria do inflamassoma não está envolvida no aumento da suscetibilidade de camundongos NLRP1 $^{-/-}$ao DM1 induzido por STZ. Camundongos WT ou NLRP1 ${ }^{-/}$tratados com STZ tiveram o pâncreas coletado no dia 10 (A) ou 15 (B) após as doses de STZ para a análise da produção de IL-1 $\beta$, IL-18 e IL-1 $\alpha$ por ELISA. Camundongos WT ou Caspase $1 / 11^{1--}$ foram tratados com 5 doses consecutivas de STZ $(40 \mathrm{mg} / \mathrm{kg} / \mathrm{dia})$ ou solução veículo (controles) e tiveram a glicemia analisada no dia 15 após a administração da droga (C). Os resultados foram expressos em Média \pm Erro Padrão da Média. $\mathrm{P} \leq 0.05$ foi considerado estatisticamente significativo; ns = não significativo. 


\subsection{A ativação do receptor NLRP1b em linfócitos é essencial para a indução de um perfil Th17}

Além de ser expresso em células mielóides, nós observamos também uma robusta expressão de Nlrplb em células linfóides (Figura 12B). Portanto, nosso próximo passo foi investigar se existe uma relação entre a expressão desse gene e a produção de IL-17. Para isso, foi realizado o isolamento de células $\mathrm{T} \mathrm{CD} 4^{+}$naive $\left(\mathrm{CD} 4^{+} \mathrm{CD} 62 \mathrm{~L}^{+}\right)$de animais WT ou NLRP1 ${ }^{-/-}$(Figura 14). Posteriormente, essas células foram transferidas para camundongos Rag $1^{-/}$, que por sua vez foram injetados com 5 doses de STZ (Figura 15A). Dez dias após a primeira dose de STZ, esses animais foram sacrificados e analisados para a presença de células produtoras de IL-17. Considerando que animais deficientes para Rag1 são incapazes de realizar a recombinação V(D)J, eles não apresentam linfócitos circulantes, fazendo com que todos os linfócitos analisados pela citometria de fluxo sejam provenientes da transferência adotiva (Figura 15B). De forma interessante, foi observado que células $T$ naive deficientes para NLRP1 geraram mais células produtoras de IL-17 após as injeções de STZ, quando comparado com animais WT (Figura 15B), sugerindo que NLRP1 seja um possível regulador negativo da diferenciação de Th17, através da expressão de Nlrplb em linfócitos. 
Pré-sorting
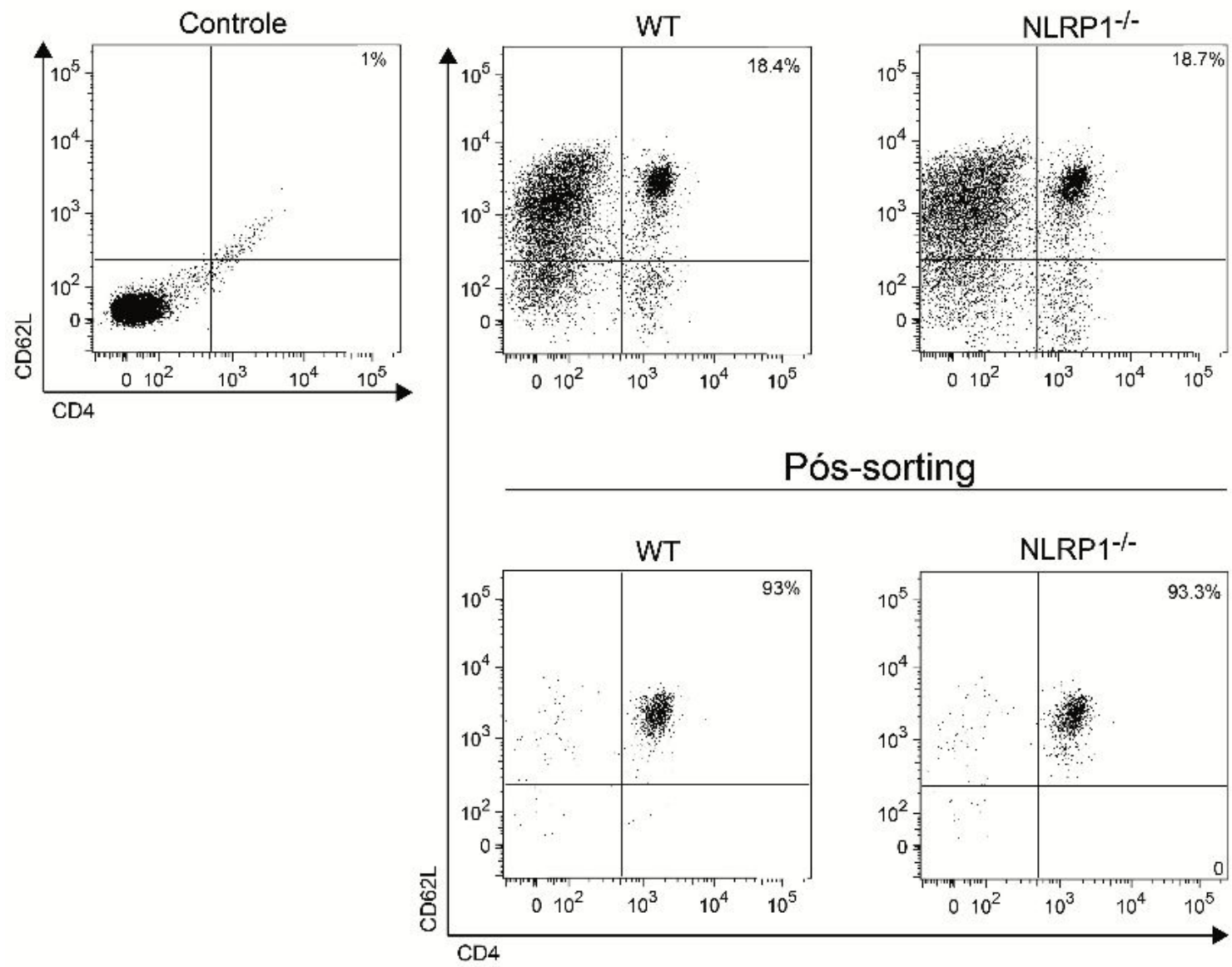

Figura 14: Estratégia de gate utilizada para o isolamento de células $\mathbf{T}$ naive. Camundongos WT ou NLRP1 $1^{\text {-r }}$ foram sacrificados e tiveram os baços coletados para o isolamento de células T naive $\left(\mathrm{CD}^{+} \mathrm{CD}^{+} \mathrm{CD}^{+} 2 \mathrm{~L}^{+}\right)$por sorting. Os dados demonstram a porcentagem de células T naive antes (pré-sorting) e após (pós-sorting) o sorting. 
A

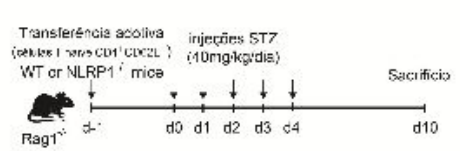

B
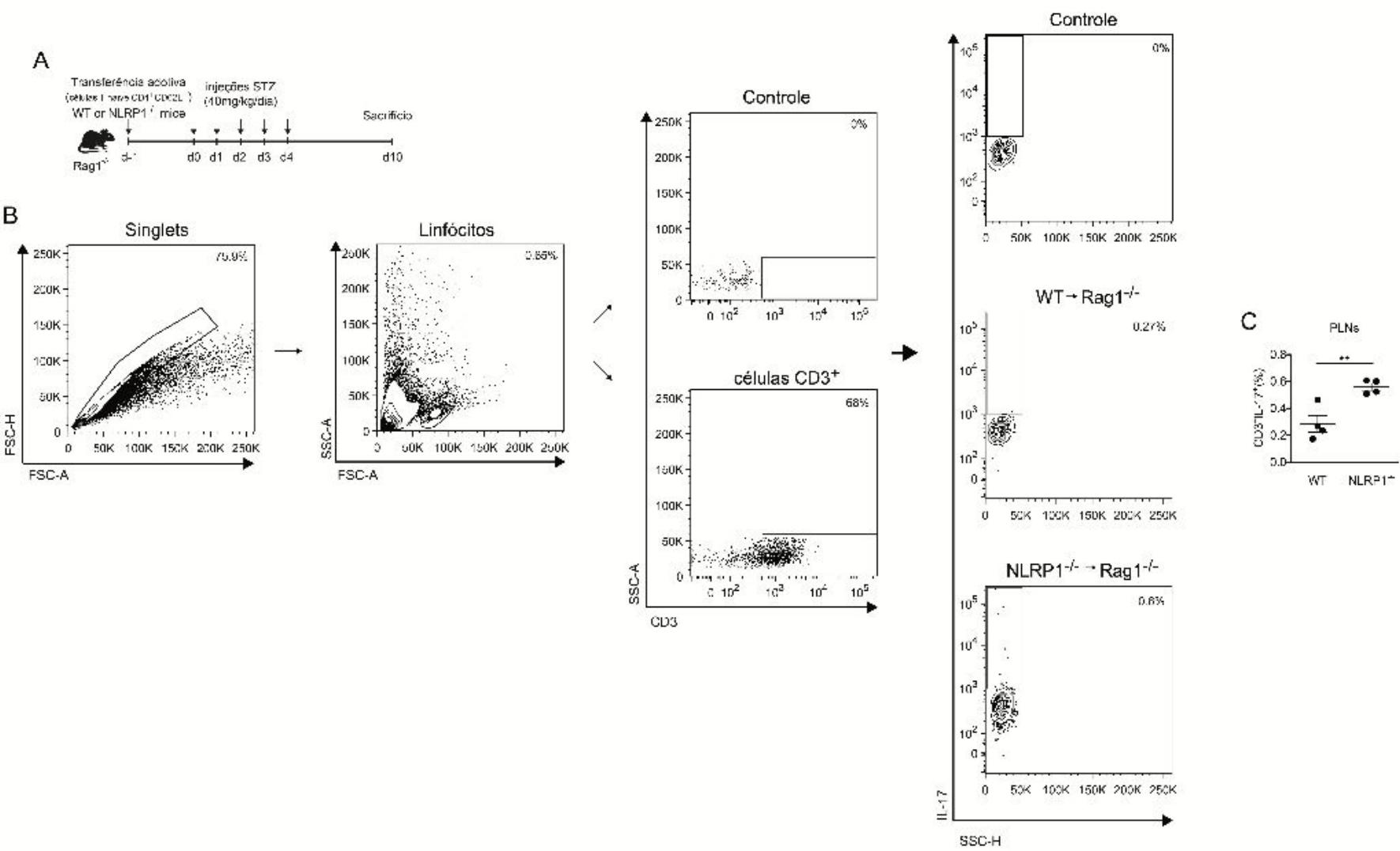

Figura 15: Análise do papel de NLRP1 na diferenciação de células Th17 in vivo. Células T naive $\left(\mathrm{CD}^{+} \mathrm{CD}^{+} \mathrm{CD} 62 \mathrm{~L}^{+}\right)$ de animais WT ou NLRP1 ${ }^{-/-}$isoladas conforme descrito na legenda da Figura 10 e foram transferidas para camundongos $\operatorname{Rag}^{1 /-}$ (A). Estes animais foram então injetados com 5 doses de STZ e sacrificados no dia 10 para a coleta dos linfonodos pancreáticos, que foram analisados para a presença de células Th17 $\left(\mathrm{CD} 3^{+} \mathrm{CD} 4^{+} \mathrm{IL}-17^{+}\right)$por citometria de fluxo (B-C). Os resultados foram expressos em Média \pm Erro Padrão da Média. $\mathrm{P} \leq 0.05$ foi considerado estatisticamente significativo. 


\subsection{NLRP1 também está envolvido no modelo de diabetes autoimune espontâneo - NOD}

Conforme discutido no item 1.6 da introdução, os genes Nlrpla-c são bastante polimórficos em linhagens isogênicas distintas, tornando-se necessário uma melhor caracterização da função desse receptor em outros modelos experimentais. Portanto, realizamos uma cinética da expressão dos genes Nlrpla-b, Ifn $\gamma$ e Ill 7 no background do NOD (Figura 17A). De forma interessante, observamos que, ao contrário do que ocorre no modelo com STZ, onde apenas Nlrp $1 b$ é expresso nos LNPs durante a progressão da doença, no modelo do NOD, tanto Nlrpla como Nlrplb aumentam sua expressão. Além disso, este aumento ocorre em fases mais tardias do desenvolvimento da doença, uma vez que apenas na vigésima semana fomos capazes de notar uma diferença estatística na expressão (Figura 16A). De forma interessante, observamos o mesmo resultado com a expressão de Ifn $\gamma$ que também se mostrou alterada apenas a partir da vigésima semana. Já com relação à IL-17, dois fatores nos chamaram a atenção: $I l 17$ foi expresso em fases mais iniciais da doença (décima semana, Figura 16A e B), corroborando dados da literatura (EMAMAULLEE et al., 2009b). Além disso, surpreendentemente, no pico da expressão dos genes Nlrpla e Nlrp1b, os níveis de IL-17 (RNA e proteico) retornaram ao estado basal, correlacionando-se aos achados em animais NLRP1 ${ }^{-/}$, onde há um aumento dessa citocina após as injeções com STZ (Figura 7). A fim de confirmar se os genes Nlrpla e Nlrplb possuem a mesma função observada no background do C57BL/6 em camundongos NOD, iniciamos a geração de duas novas linhagens através da técnica CRISPR/Cas9: camundongos NOD deficientes para Nlrpla e Nlrplb (NOD.NLRP1a ${ }^{-/-}$e NOD.NLRP1b ${ }^{-/}$, respectivamente). Os sgRNA (do inglês, short guide RNA) já estão prontos (Anexo IV), e a expectativa é que sejam injetados em embriões de fêmeas NOD até o mês de fevereiro de 2018. 
A

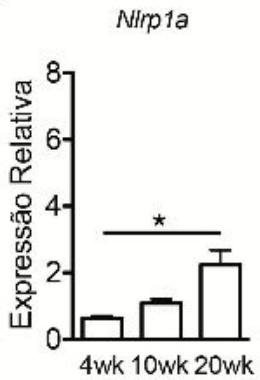

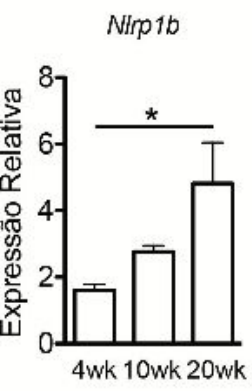
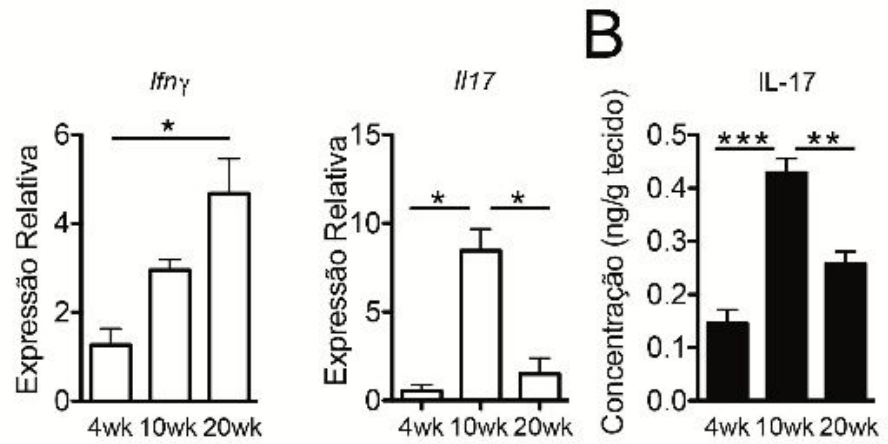

Figura 16: Cinética da expressão de NLRP1 no modelo de diabetes autoimune espontâneo. Camundongos NOD foram sacrificados com 4, 10 ou 20 semanas e tiveram o pâncreas coletado para a análise da expressão gênica de Nlrpla, Nlrp 1b, Ifn $\gamma$ e Ill7 pela técnica de RT-PCR (A). Alternadamente, esses animais tiveram o pâncreas coletado para a análise da produção de IL-17 pela técnica de ELISA (B). Os resultados foram expressos em Média \pm Erro Padrão da Média. $\mathrm{P} \leq$ 0.05 foi considerado estatisticamente significativo. 


\subsection{NLRP1 também está relacionado à produção de IL-17 em humanos com DM1}

Por fim, resolvemos avaliar o papel do receptor NLRP1 no DM1 em humanos. Para isso, resolvemos analisar um polimorfismo já descrito em NLRP1 (MAGITTA et al., 2009; TANG et al., 2013) que possui uma importante correlação com a suscetibilidade à doença: o SNP (do inglês, single nucleotide polymorphism) rs12150220, localizado no gene NLRP1, que por sua vez se encontra no cromossomo 17 em humanos. Esse polimorfismo resulta na possibilidade de um indivíduo possuir três genótipos: ser homozigoto para timina $(\mathrm{T} / \mathrm{T})$, homozigoto para adenina $(\mathrm{A} / \mathrm{A})$ ou ser heterozigoto $(\mathrm{A} / \mathrm{T})$. Foi demonstrado que a presença de adenina eleva o risco ao desenvolvimento da doença, sendo este risco maior, portanto, quando o indivíduo for A/A (MAGITTA et al., 2009). Funcionalmente, a troca de uma timina por uma adenina leva à uma modificação na sequência de aminoácidos da proteína NLRP1 na posição 155, onde ocorre a troca de uma leucina por uma histidina.

Nosso primeiro passo foi submeter o projeto ao Comitê de Ética em Pesquisa do Hospital das Clínicas da Faculdade de Medicina de Ribeirão Preto da USP (Anexos V e VI). Após aprovado, iniciamos a coleta do sangue de pacientes com diabetes tipo 1, isolamos o PBMC (do inglês, peripheral blood mononuclear cells) e soro desses pacientes, e genotipamos esses indivíduos a fim de investigar qual dos três possíveis genótipos do polimorfismo rs12150220 eles possuíam (Figura 17 e Tabela I). Resolvemos agrupar os pacientes de duas formas para as análises: na primeira, agrupamos os indivíduos em três grupos distintos (T/T, A/T ou A/A), e na segunda, dividimos esses mesmos pacientes em dois grupos (T/T: sem suscetibilidade aumentada ao DM1 - denominado grupo WT; e um grupo com os pacientes que possuíam pelo menos uma adenina em seus alelos, A/T e A/A, possuindo, portanto, um aumento na suscetibilidade à doença - denominado grupo rs12150220).

Iniciamos nossas análises com a expressão de Nlrpl nesses pacientes, a fim de se analisar se o polimorfismo seria capaz de alterar a expressão gênica do receptor. Conforme demonstrado nas Figura 18A e 18B, não houve alteração na expressão de Nlrpl em PBMCs desses indivíduos, seja agrupando em três (Figura 18A) ou dois grupos (Figura 18B). Posteriormente, analisamos a frequência de células $\mathrm{CD}^{+}, \mathrm{CD}^{+}$e $\mathrm{CD} 8^{+}$nas $\mathrm{PBMCs}$ desses indivíduos. Conforme esperado, não foi encontrada diferença entre os grupos, seja agrupando em três ou dois grupos. Por fim, analisamos o perfil de resposta de células Th1 
$\left(\mathrm{CD}^{+} \mathrm{CD}^{+} \mathrm{IFN}_{-} \gamma^{+}\right)$e Th17 $\left(\mathrm{CD}^{+} \mathrm{CD}^{+} \mathrm{IL}^{-17^{+}}\right)$. De forma interessante, não observamos nenhuma diferença nesses subtipos celulares em nenhuma das duas formas de análise (Figura 18A e 18B). Considerando que os indivíduos da nossa coorte possuem, em média, mais de 15 anos de doença (Tabela 1), acreditamos que a maior parte da resposta imune efetora auto-reativa se encontre no compartimento de memória. Portanto, nosso próximo passo foi analisar a frequência de células $\mathrm{T}$ de memória $\left(\mathrm{CD} 45 \mathrm{RO}^{+} \mathrm{CD} 45 \mathrm{RA}^{-}\right)$produtoras de IL-17 e IFN- $\gamma$ (Figura 19). Ao analisarmos a subpopulação de células Th1 de memória, não encontramos nenhuma diferença significativa em nenhuma das formas analisadas (Figura 20A e B). De forma interessante, ao analisarmos células Tc1 de memória, observamos um aumento dessa subpopulação em indivíduos A/T (Figura 20A), o que justifica a diferença estatística encontrada no grupo rs 12150220 (Figura 20B). No entanto, vale ressaltar que esse aumento aparentemente não condiz com a presença do polimorfismo rs12150220, uma vez que o esperado seria encontrarmos um incremento dessa subpopulação no grupo $\mathrm{A} / \mathrm{T}$ comparado ao grupo T/T e um aumento máximo no grupo $\mathrm{A} / \mathrm{A}$, o que não aconteceu. Ademais, é importante salientar que ao contrário de camundongos isogênicos, os humanos analisados nesta pesquisa são provenientes dos mais distintos antecedentes genéticos, possuindo diversas alterações além do rs12150220. Dessa forma, nós acreditamos que o aumento de células Tc1 no grupo A/T se deva a outra alteração que não o SNP rs12150220, encontrada especificamente nesse grupo de indivíduos. Nosso próximo passo foi analisar células T de memória produtoras de IL-17. Surpreendentemente, observamos um aumento na população de células Th17 em pacientes com genótipo A/T quando comparado ao grupo $\mathrm{T} / \mathrm{T}$, e um incremento ainda maior em indivíduos com genótipo A/A, o que correlaciona com o perfil de suscetibilidade ao DM1, atribuído à presença de adenina (Figura 20A). Ao analisarmos todos os indivíduos que possuem pelo menos um alelo composto por adenina, também observamos um robusto incremento na população de células Th17 (grupo rs12150220 - Figura 20B). De forma interessante, observamos o mesmo fenótipo ao analisarmos células Tc17: um aumento dessa subpopulação em indivíduos A/T, um aumento ainda maior em indivíduos A/A (Figura 20A) e, por fim, um aumento substancial em indivíduos do grupo rs12150220, comparado ao grupo WT (T/T) (Figura 20B).

Avaliamos também a produção das citocinas IFN- $\gamma$ e IL-17 no soro desses indivíduos. Corroborando os dados encontrados no compartimento das células $\mathrm{T}$ de memória, 
não observamos diferenças na produção de IFN- $\gamma$ entre os grupos (Figura 21A e B), porém notamos um aumento na produção de IL-17 em indivíduos A/T comparado com indivíduos $\mathrm{T} / \mathrm{T}$, um aumento ainda maior em indivíduos $\mathrm{A} / \mathrm{A}$, o que foi refletido em um potente aumento na produção de IL-17 em indivíduos com o SNP rs12150220, quando comparado com indivíduos WT (T/T - Figura 21A e B). De forma geral, esses dados sugerem que o SNP rs12150220 encontrado em pacientes diabéticos está relacionado a um aumento na produção de IL-17 por células que já sofreram um estímulo antigênico (neste caso, um auto-antígeno). 


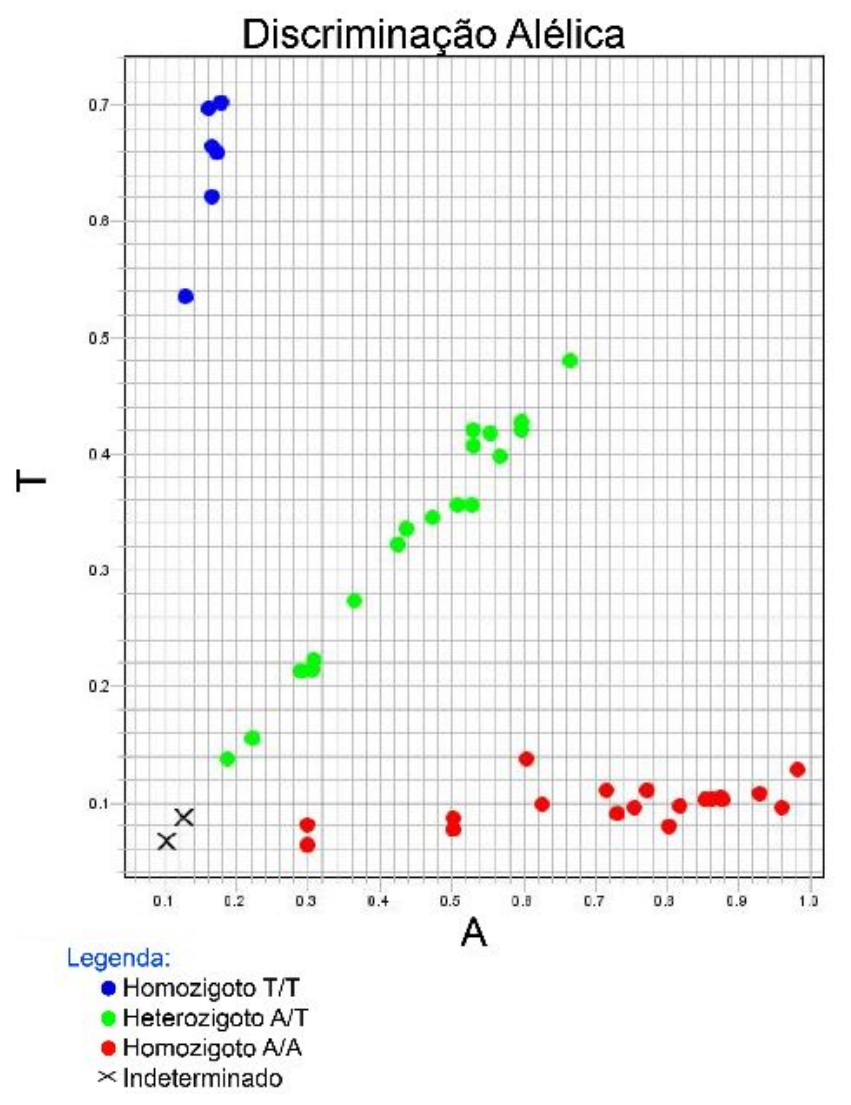

Figura 17: Genotipagem dos pacientes com DM1. O sangue de pacientes com DM1 foi coletado para o isolamento de PBMCs (do inglês, peripheral blood mononuclear cells), que por sua vez, foram utilizadas para a extração de DNA e posterior discriminação alélica baseada no SNP rs12150220 utilizando o SNP Genotyping Assay Kit. Os pacientes foram divididos em três grupos: Homozigoto para timina (azul), homozigoto para adenina (vermelho) e heterozigotos (verde). 
Tabela I: Características dos pacientes com DM1. Os indivíduos com DM1 foram divididos em três grupos, de acordo com seu genótipo (T/T: homozigoto para timina; A/T heterozigotos e A/A: homozigotos para adenina). A tabela demonstra dados como $\mathrm{n}$, frequência, porcentagem de indivíduos do sexo masculino e feminino $(\% \mathrm{M}$ e $\% \mathrm{~F}$, respectivamente $)$, idade e anos desde o diagnóstico da doença. D.P. = desvio padrão. 
A

Nirp1

Células T

Células T CD $4^{+}$

Células T CD8

Th1

Th17
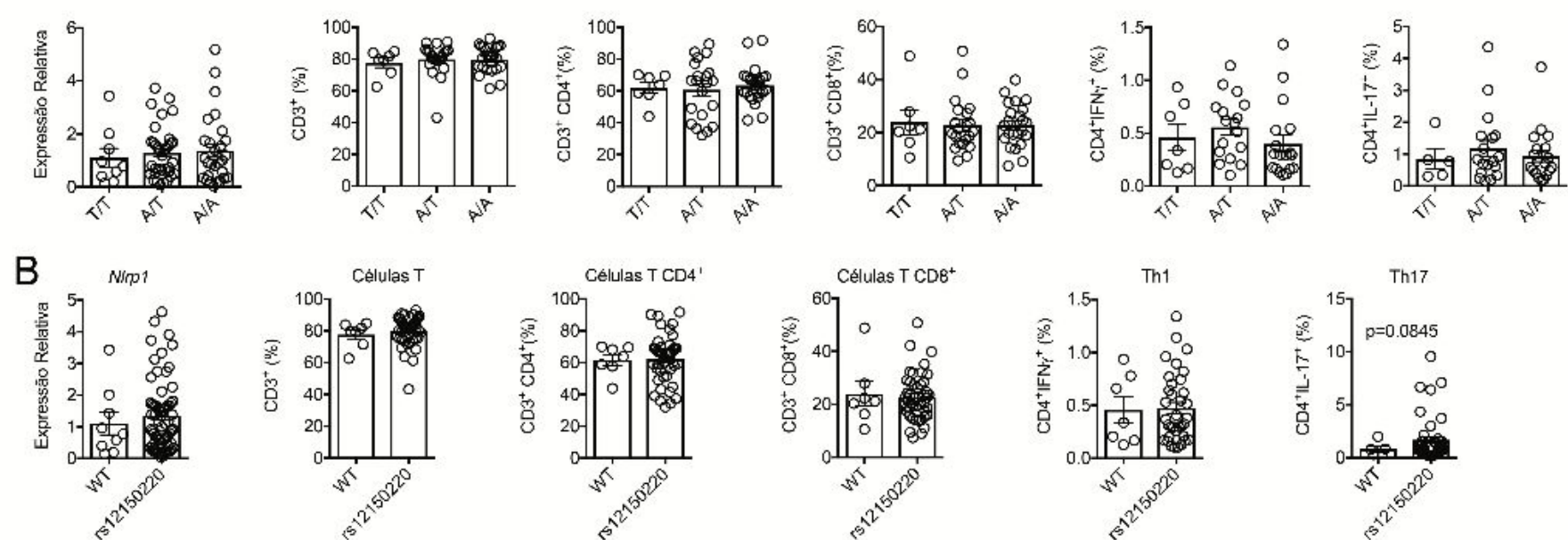

Figura 18: Fenotipagem dos pacientes com DM1 com e sem polimorfismos em NLRP1. Pacientes com DM1 foram divididos em três (A) ou dois (B) grupos, baseados no seu genótipo. Em (A) os indivíduos foram separados em três grupos (T/T: homozigoto para timina; A/T heterozigotos e A/A: homozigotos para adenina). Em (B) os indivíduos foram separados em dois grupos (WT: indivíduos controle, sem o SNP rs12150220, o que corresponde ao grupo T/T, e rs12150220: indivíduos que possuem pelo menos uma adenina em um de seus alelos, sendo correspondente, portanto, aos grupos A/T e A/A). Nesses indivíduos, foram avaliadas a expressão gênica de Nlrp1 as frequências de células T $\left(\mathrm{CD} 3^{+}\right), \mathrm{T}_{\mathrm{CD}}{ }^{+}$ $\left(\mathrm{CD}^{+}{ }^{+} \mathrm{CD} 4^{+}\right), \mathrm{T} \mathrm{CD} 8^{+}\left(\mathrm{CD}^{+}{ }^{+} \mathrm{CD} 8^{+}\right), \mathrm{Th} 1\left(\mathrm{CD}^{+} \mathrm{CD}^{+} \mathrm{IFN}-\gamma^{+}\right)$e Th17 $\left(\mathrm{CD}^{+}{ }^{+} \mathrm{CD} 4^{+} \mathrm{IL}-17^{+}\right)$em PBMCs isoladas. 

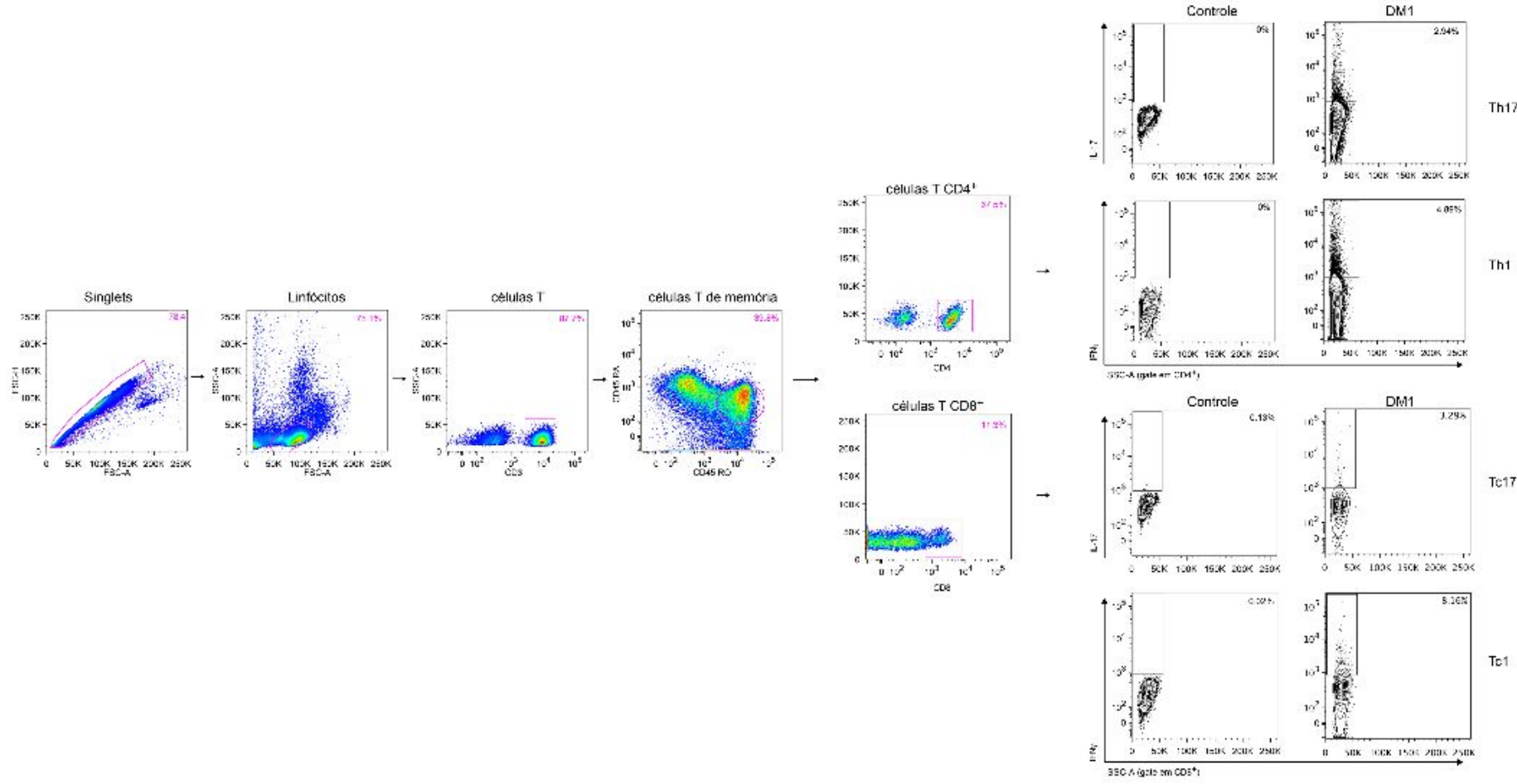

Figura 19: Estratégia de gate para a análise de linfócitos presentes no compartimento de memória. Pacientes com DM1 tiveram o sangue coletado para o isolamento de PBMCs. Posteriormente, essas células foram analisadas pela técnica de citometria de fluxo, onde analisamos a presença de células T de memória produtoras de IFN- $\gamma$ (Th1 e Tc1) e de IL-17 (Th17 e Tc17). Após a exclusão dos doublets, fizemos uma gate em células com características de linfócitos, baseado em seu tamanho e granulosidade (FSC/SSC). Posteriormente, realizamos uma sequência de gates: células T (CD3 $\left.{ }^{+}\right)$, células

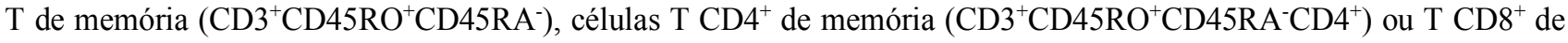
memória $\left(\mathrm{CD}^{+}{ }^{+} \mathrm{CD} 45 \mathrm{RO}^{+} \mathrm{CD} 45 \mathrm{RA}^{-} \mathrm{CD} 8^{+}\right)$e, por fim, células produtoras de IFN- $\gamma\left(\mathrm{Th} 1-\mathrm{CD}^{+} \mathrm{CD}^{4} 5 \mathrm{RO}^{+} \mathrm{CD}^{-} \mathrm{RA}^{-}\right.$

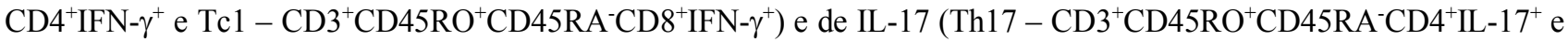
$\left.\mathrm{Tc} 17-\mathrm{CD}^{+} \mathrm{CD} 45 \mathrm{RO}^{+} \mathrm{CD} 45 \mathrm{RA}^{-} \mathrm{CD} 8^{+} \mathrm{IL}-17^{+}\right)$. 

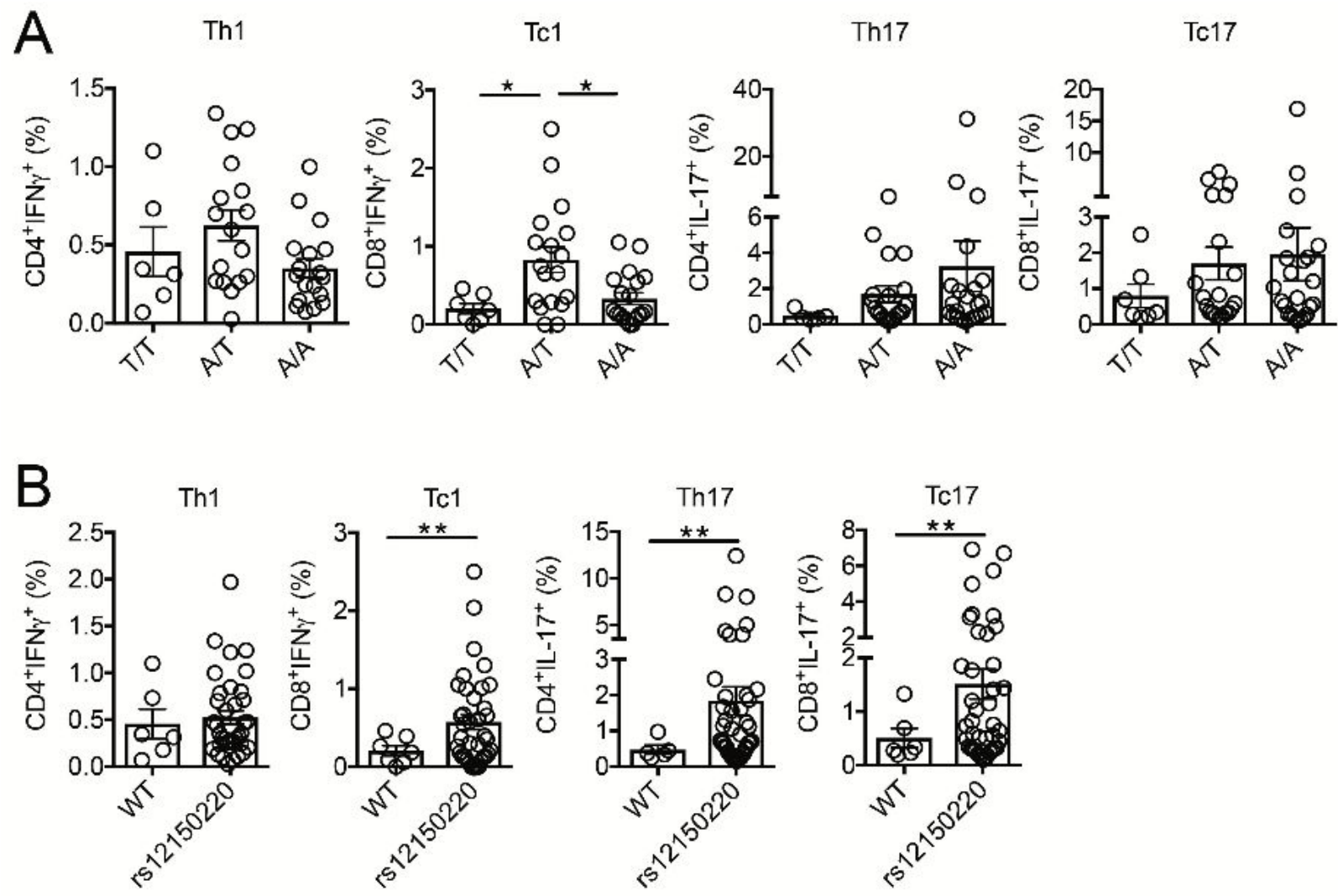

Figura 20: Células produtoras de IL-17 estão aumentadas em pacientes com polimorfismos em NLRP1. Pacientes com DM1 tiveram o sangue coletado para o isolamento de PBMCs. Posteriormente, essas células foram analisadas pela técnica de citometria de fluxo, onde analisamos a presença de células T de memória produtoras de IFN- $\gamma(\mathrm{Th} 1 \mathrm{e}$ Tc1) e de IL-17 (Th17 e Tc17), conforme descrito na legenda da Figura 15. Esses pacientes foram divididos em três (A) ou dois (B) grupos, baseados no seu genótipo. Em (A) os indivíduos foram separados em três grupos (T/T: homozigoto para timina; A/T heterozigotos e A/A: homozigotos para adenina). Em (B) os indivíduos foram separados em dois grupos (WT: indivíduos controle, sem o SNP rs12150220, o que corresponde ao grupo T/T, e rs12150220: indivíduos que possuem pelo menos uma adenina em um de seus alelos, sendo correspondente, portanto, aos grupos $\mathrm{A} / \mathrm{T}$ e $\mathrm{A} / \mathrm{A}$ ). Os resultados foram expressos em Média \pm Erro Padrão da Média. $\mathrm{P} \leq 0.05$ foi considerado estatisticamente significativo. 

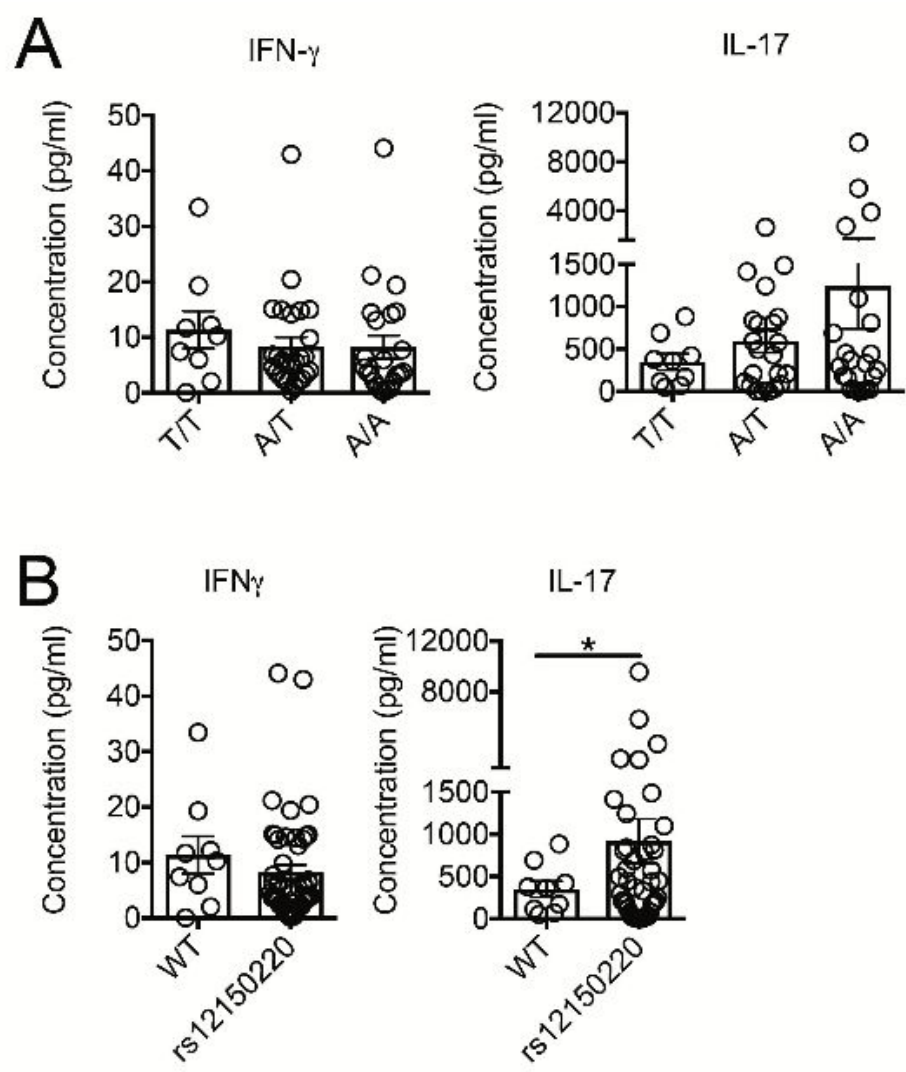

Figura 21: IL-17 está aumentada no soro de pacientes com polimorfismos em NLRP1. Pacientes com DM1 tiveram o sangue coletado para o isolamento soro. Posteriormente, esses pacientes foram divididos em três (A) ou dois (B) grupos, baseados no seu genótipo. Em (A) os indivíduos foram separados em três grupos (T/T: homozigoto para timina; A/T heterozigotos e A/A: homozigotos para adenina). Em (B) os indivíduos foram separados em dois grupos (WT: indivíduos controle, sem o SNP rs12150220, o que corresponde ao grupo T/T, e rs12150220: indivíduos que possuem pelo menos uma adenina em um de seus alelos, sendo correspondente, portanto, aos grupos A/T e A/A). A análise da produção das citocinas IFN- $\gamma$ e IL-17 foi realizada pela técnica de ELISA. Os resultados foram expressos em Média \pm Erro Padrão da Média. $\mathrm{P} \leq 0.05$ foi considerado estatisticamente significativo. 


\section{Discussão}


O sistema imunológico se depara a todo momento com uma infinidade de estímulos antigênicos, sejam eles próprios (auto-antígenos) ou não próprios ao hospedeiro, como antígenos da dieta, bactérias (microbiota), fungos (micobiota), vírus (viroma) comensais e/ou patógenos. Nesta interação, ele deve ser capaz de discernir o que é prejudicial ou não ao hospedeiro, induzindo tolerância ao próprio e a microorganismos comensais, ou ativando uma cascata pró-inflamatória contra antígenos patogênicos. No entanto, quando esses mecanismos de auto tolerância (central e periférica) falham, dá-se início a uma resposta autoimune que irá culminar em última instância na destruição de tecidos do próprio indivíduo. Portanto, entender os mecanismos envolvidos no desenvolvimento do DM1, uma doença autoimune onde o pâncreas é atacado pela resposta auto-reativa, é de suma importância a fim de se encontrar novas abordagens terapêuticas, buscando a melhora e/ou cura do quadro clínico dos pacientes acometidos por essa doença.

Neste sentido, demonstramos que o sensor da imunidade inata NLRP1 possui um papel protetor no DM1 experimental, inibindo um perfil de resposta Th17 em estágios iniciais da doença. Além disso, demonstramos que NLRP1 também parece possuir um papel na integridade da barreira epitelial intestinal, uma vez que na ausência do receptor, houve um robusto aumento na translocação de bactérias para os LNPs de animais injetados com STZ. Posteriormente, confirmamos nossos achados em outro modelo de DM1, o camundongo NOD, demonstrando um aumento na expressão de NLRP1, o que coincidiu com a redução da expressão gênica e proteica de IL-17 no pâncreas desses animais. Por fim, utilizamos um polimorfismo em NLRP1, o rs12150220, que já foi descrito na literatura como estando relacionado ao aumento da suscetibilidade ao DM1 humano, para investigar o possível papel desse receptor na doença. Observamos que, de fato, pacientes com DM1 que possuem polimorfismos em NLRP1 apresentam um proeminente aumento na produção de células produtoras de IL-17, Th17 e Tc1. No entanto, este aumento só foi observado em células $\mathrm{T}$ de memória, demonstrando a necessidade de um estímulo prévio por parte desses linfócitos. De forma geral, nossos dados indicam um papel protetor de NLRP1 no DM1 experimental, além de estar associado a uma resposta Th17 em pacientes com DM1.

Diversos estudos têm demonstrado o papel patogênico de células T no DM1 (revisado em WALKER, 2015). A partir desta constatação, diversos ensaios clínicos surgiram a fim de bloquear a resposta imune adaptativa em humanos com DM1 (PESCOVITZ et al., 
2009; HEROLD et al., 2013). No entanto, todas as abordagens testadas até o momento que tinham como alvo a resposta imune adaptativa falharam quando testadas em humanos (REED; HEROLD, 2015), apesar dos resultados animadores em modelos experimentais. Portanto, deu-se início à procura de possíveis novas abordagens terapêuticas para o DM1. Neste contexto, a imunidade inata tem se tornado um importante alvo de investigação da comunidade científica, uma vez que pouco ainda se sabe sobre o seu papel no desenvolvimento da doença. Neste sentido, foi demonstrado em modelos experimentais, por exemplo, que camundongos deficientes para TLR2 no background do NOD são resistentes ao desenvolvimento do DM1 (KIM et al., 2007), embora no modelo do STZ tal evidência não tenha sido encontrada (DEVARAJ et al., 2011). Além disso, nosso grupo de pesquisa recentemente demonstrou que os sensores da imunidade inata NLRP3 (CARLOS et al., 2017) e NOD2 (COSTA et al., 2016) apresentam um papel patogênico no desenvolvimento de DM1 induzido por STZ, o que foi confirmado no modelo do NOD (HU et al., 2015b; LI et al., 2017), embora atuem de maneira distinta nos dois modelos. Na presente tese, nós reportamos que o sensor da imunidade inata NLRP1 possui um papel protetor em modelos experimentais de DM1, uma vez que na ausência desse receptor, animais injetados com STZ se tornaram mais suscetíveis à doença, apresentando um maior infiltrado inflamatório nas ilhotas pancreáticas, o que foi correlacionado a um aumento na resposta imune adaptativa, com um aumento robusto de células produtoras de IL-17 nos LNPs, além do aumento de IL-17 no pâncreas de animais que se tornaram diabéticos.

Conforme discutido na introdução, alguns trabalhos apontam o IFN- $\gamma$ como uma citocina patogênica no contexto do DM1, enquanto outros artigos falharam em encontrar uma relação entre a produção dessa citocina e o aumento na suscetibilidade à doença. Neste contexto, o papel da IL-17 no DM1 também é controverso. Em camundongos, já foi demonstrado que o silenciamento de IL-17 em camundongos NOD não foi capaz de proteger esses animais do desenvolvimento da doença (JOSEPH et al., 2012a). Em contrapartida, outros trabalhos demonstram um papel patogênico desta citocina na doença. Por exemplo, o bloqueio de células Th17 com um anticorpo monoclonal anti-IL-17 na fase efetora da doença (10 semanas de idade) foi mostrado como sendo capaz de prevenir o desenvolvimento de DM1 em camundongos NOD (EMAMAULLEE et al., 2009b). No modelo do STZ, IL-17 também parece ter um papel patogênico (YAOCHITE et al., 2012; COSTA et 
al., 2016). Já em humanos, há o aumento de IL-17 no soro (HONKANEN et al., 2010) e linfonodos pancreáticos (FERRARO et al., 2011) de pacientes com DM1, corroborando para um papel patogênico da citocina na progressão da doença. Nossos resultados estão de acordo com os dados do modelo das injeções de STZ e em humanos, onde demonstramos que o aumento de IL-17 nas fases iniciais da doença está intimamente correlacionado a um aumento na suscetibilidade à doença. De forma interessante, observamos que em um mesmo grupo de animais (NLRP1 ${ }^{-/}$injetados com STZ) aqueles que estavam com hiperglicemia possuíam maiores níveis de IL-17, enquanto que os camundongos que ainda não haviam desenvolvido a doença produziam níveis basais da citocina. Ademais, demonstramos que o aumento de células produtoras de IL-17 (Th17 e Tc17) nos LNPs estava relacionado ao aumento no infiltrado inflamatório e a elevados níveis de glicemia nesses animais.

Nosso próximo passo foi investigar o que estaria levando a esse aumento de IL-17 na ausência do receptor NLRP1. Já está bem estabelecido a importância da citocina IL-6 que, juntamente ao TGF- $\beta$, é imprescindível para a geração de uma resposta Th17 (BETTELLI et al., 2006). Dessa forma, resolvemos investigar se NLRP1 poderia agir como um possível regulador negativo da citocina IL-6, o que explicaria o aumento dessa citocina e consequentemente de células Th17 na ausência do receptor. De fato, observamos que na ausência de NLRP1, células dendríticas (DCs) passam a produzir mais IL-6. Para confirmar essa hipótese, fizemos uma transferência adotiva de DCs de animais NLRP1 ${ }^{-/}$para camundongos WT, fazendo com que as únicas células que não expressassem NLRP1 nesses animais fossem as DCs. Esta abordagem tem sido amplamente utilizada em estudos sobre o papel específico de DCs, tanto no contexto da autoimunidade (SAUMA et al., 2017), como também em infecções (PONCE et al., 2005). Posteriormente, injetamos as 5 doses de STZ necessárias para o desenvolvimento da doença e observamos o fenótipo desses animais. Contrariando a nossa hipótese inicial, a ausência de NLRP1 em DCs não foi suficiente para induzir um aumento na produção de IL-6 por essas células, indicando que algum outro fator que não a ausência de NLRP1 na célula em questão seria o responsável pelo aumento da produção de IL-6 em DCs. Nosso grupo recentemente estabeleceu um importante papel da microbiota intestinal no desenvolvimento do DM1 induzido por STZ. Observamos que a microbiota intestinal é capaz de translocar para os LNPs, ativar células mielóides via 
NOD2 e induzir uma resposta pró-inflamatória, com a produção de citocinas como IL-6 e IL-12 que, em último grau, levam ao aumento de células T efetoras (Th1 e Th17, respectivamente) no órgão alvo da doença, o pâncreas (COSTA et al., 2016). Portanto, decidimos avaliar se a microbiota intestinal seria a responsável pela indução de uma resposta Th17 em animais NLRP1 ${ }^{-/}$.

A fim de analisar o papel da microbiota intestinal no aumento de células Th17 e consequente aumento na suscetibilidade ao DM1 induzido por STZ, realizamos primeiramente um ensaio de translocação bacteriana. De forma interessante, observamos um aumento na translocação de bactérias para os linfonodos pancreáticos em animais deficientes para NLRP1. Além disso, observamos bactérias (aeróbicas e anaeróbicas) até mesmo em animais $\mathrm{NLRP}^{-/-}$naive, sem qualquer tratamento, sugerindo um possível papel do receptor na manutenção da barreira epitelial intestinal. Outros receptores da família NLR, como NLRP6 e NLRP12 já foram descritos como tendo um papel importante na composição da microbiota e integridade da barreira intestinal (ELINAV et al., 2011; CHEN, 2014; WLODARSKA et al., 2014). Ademais, já foi demonstrado um aumento de NLRP1 no cólon de biópsias de pacientes com colite ulcerativa (WILLIAMS et al., 2015), corroborando para um papel do receptor no intestino. De forma interessante, também observamos que em animais WT diabéticos houve um aumento da expressão de Nlrpla, mas não Nlrplb no íleo desses animais, indicando possíveis funções distintas para os genes parálogos, sendo Nlrp la importante, portanto, como um possível gene envolvido na manutenção da barreira epitelial intestinal. Com relação aos diferentes papéis dos genes parálogos de NLRP1, já foi reportado que Nlrplb parece estar envolvido no reconhecimento de patógenos, como Toxoplasma gondii (EWALD; CHAVARRIA-SMITH; JOHN, 2014), Bacillus anthracis (SASTALLA; LEPPLA; MOAYERI, 2012), além de estar envolvido em doenças como colite ulcerativa (WILLIAMS et al., 2015), sendo que uma das principais funções atribuídas para esse gene até o momento seja a ativação da maquinaria do inflamassoma, via ativação de caspase-1 (VAN OPDENBOSCH et al., 2014). Já foi demonstrado que Nlrp1b é extremamente polimórfico em camundongos, apresentando cinco alelos polimórficos em 18 linhagens analisadas (BOYDEN; DIETRICH, 2006). Baseado nesses alelos, os autores foram capazes de dividir essas linhagens murinas em camundongos que possuem macrófagos suscetíveis à toxina letal (LeTx) do B.anthracis (Nlrplb ativa caspase-1, levando à 
morte celular); e camundongos com macrófagos resistentes à LeTx (Nlrplb não ativa caspase-1 e os macrófagos permanecem viáveis - BOYDEN; DIETRICH, 2006). Já com relação à Nlrpla, um trabalho recente descobriu uma mutação capaz de ativar constitutivamente Nlrpla, fazendo com que os animais com tais alterações desenvolvessem uma inflamação neutrofílica em diversos órgãos (MASTERS et al., 2012b). Com relação ao mecanismo, foi descoberto que Nlrpla ativado inibe a diferenciação de células progenitoras da medula óssea para sua forma madura, através da piroptose dependente de caspase-1, mas não de ASC. Além disso, um outro trabalho demonstrou um possível ativador de Nlrpla, o fator de transcrição SREBP-1a (do inglês, sterol regulatory element binding protein-1a IM et al., 2012). Neste trabalho, foi demonstrado que camundongos deficientes para SREBP-1a, um fator de transcrição intimamente relacionado ao metabolismo dos lipídeos, são resistentes ao choque séptico causado pelo modelo experimental de sepse induzido por ligadura e perfuração do ceco (do inglês, cecal ligation and puncture - CLP). Eles atribuíram essa resistência à falha desses animais em ativar Nlrpla, o que por sua vez inibiu a ativação de caspase-1, diminuindo assim os níveis de IL-1 $\beta$, tornando-os resistente à síndrome da resposta inflamatória sistêmica (IM et al., 2012). Já Nlrplc é diferente de Nlrpla e Nlrplb no sentido em que ele é um gene truncado após o exon 8, não sendo capaz de expressar os domínios FIIND e CARD, sendo considerado, portanto, um pseudogene (SASTALLA et al., 2013).

Confirmado o papel de NLRP1 na integridade da barreira intestinal, nosso próximo passo foi avaliar se a translocação bacteriana para os LNPs de animais NLRP1 ${ }^{-/-}$estava correlacionada ao aumento de células Th17 nesses animais. Surpreendentemente, nós observamos que mesmo com o coquetel de antibióticos para depletar a microbiota intestinal, esses animais ainda possuíam níveis elevados de Th17 nos LNPs. Estudos recentes têm apontado para o papel de receptores da imunidade inata, como TLR2, NOD2 e NLRP3 diretamente em linfócitos, possuindo papel proeminente na diferenciação dessas células para células Th (do inglês, T helper - CHEN et al., 2009; BRUCHARD et al., 2015; ARBORE et al., 2016). Dessa forma, nós supusemos que talvez NLRP1 também tivesse um papel em células linfóides. Portanto, decidimos avaliar a expressão de Nlrpla e Nlrplb em células linfóides e mielóides. De forma interessante, observamos que no decorrer do desenvolvimento do DM1 induzido por STZ, houve um aumento de Nlrp1b, mas não 
Nlrpla tanto em células linfóides, como em mielóides. Esse resultado sugere um possível papel de Nlrplb tanto na ativação da maquinaria do inflamassoma em células mielóides, como também na diferenciação de linfócitos.

A fim de se analisar o papel de NLRP1 como um ativador do inflamassoma, analisamos a produção de citocinas que necessitam ou não da clivagem pela caspase-1 para se encontrarem em seu estado ativo (IL-1 $\beta$ e IL-18; e IL-1 $\alpha$, respectivamente) no pâncreas de animais WT ou deficientes para NLRP1, ambos injetados com STZ. De fato, na ausência de NLRP1 houve uma diminuição de IL-1 $\beta$ e IL-18 no décimo dia após a primeira dose de STZ, o que coincidiu com o pico de expressão de Nlrp $1 b$ em células mielóides. Além disso, observamos que assim que a expressão de Nlrplb retornou aos níveis basais, o que ocorre com 15 dias após as doses de STZ, a diferença estatística na produção de citocinas que necessitam da maquinaria do inflamassoma para clivar sua pró-forma em forma ativa é perdida entre os grupos. Esses resultados indicam a ativação do inflamassoma de NLRP1 no DM1, possivelmente via Nlrp1b em células mielóides. Posteriormente, injetamos STZ em camundongos deficientes para diversas moléculas envolvidas na via de sinalização do inflamassoma, como caspase-1, ASC e IL-1R a fim de se analisar a contribuição dessa via no fenótipo de suscetibilidade encontrado em animais NLRP1 ${ }^{-/}$. Escolhemos tais moléculas uma vez que já foi demonstrada a importância de caspase-1 na piroptose e produção de IL-1 $\beta$ dependente de Nlrp $1 b$. Já com relação à ASC, já foi estabelecido que ela é importante para autoproteólise da caspase-1 mediada por Nlrp1b, embora seja dispensável para a piroptose e produção de IL-1 $\beta$ (VAN OPDENBOSCH et al., 2014). De forma interessante, observamos que na ausência de moléculas importantes para a maquinaria do inflamassoma, os animais se tornam resistentes à indução de DM1 por STZ, ao contrário do que ocorre com animais NLRP1 ${ }^{-/}$. Esses dados sugerem que o papel protetor de NLRP1 no DM1 induzido por STZ independe da ativação da maquinaria do inflamassoma.

Nosso próximo passo foi avaliar o possível papel de NLRP1 diretamente em células linfóides, como um potencial regulador negativo da diferenciação de células Th17, o que explicaria o aumento dessa subpopulação na ausência do receptor. Portanto, realizamos uma transferência adotiva de células T naive de camundongos WT ou NLRP1 ${ }^{-/}$para animais Rag $1^{-/}$, que por sua vez foram injetados com STZ. Surpreendentemente, observamos que houve um aumento na diferenciação para o perfil Th17 in vivo de células $\mathrm{T}$ naive 
oriundas de animais deficientes para NLRP1, quando comparado ao controle. Esses resultados sugerem um possível papel de NLRP1 na diferenciação de células Th17.

Conforme mencionado anteriormente, os genes parálogos, especialmente Nlrplb, são extremamente polimórficos em linhagens isogênicas distintas. Por exemplo, em macrófagos da linhagem 129S1, apenas o parálogo Nlrplb é expresso (BOYDEN; DIETRICH, 2006). Em camundongos NOD/LtJ, a expressão de Nlrplc em macrófagos é praticamente nula (SASTALLA et al., 2013). Dessa forma, faz-se necessário a análise do papel de NLRP1 no DM1 em outros modelos experimentais, a fim de se investigar se os resultados obtidos são exclusivos de uma linhagem, ou refletem, de fato, o papel do receptor na patogênese da doença. Portanto, fizemos uma cinética da expressão de Nlrpla e Nlrplb no pâncreas de camundongos NOD durante a progressão do DM1. De forma interessante, ao contrário do que observamos no modelo de DM1 induzido por STZ, onde apenas Nlrplb foi expresso, em camundongos NOD observamos o aumento tanto de Nlrpla, como de Nlrp1b. Com relação ao papel de NLRP1 neste modelo, existe apenas um relato na literatura sugerindo um possível papel de Nlrplb no desenvolvimento da doença (MOTTA et al., 2015). Neste estudo, foi demonstrado que camundongos NOD que expressam o locus Idd4 de camundongos NOR (do inglês, nonobese resistant - são camundongos com o mesmo haplótipo de MHC-II de camundongos NOD, o I-A(g7), que, porém, não desenvolvem DM1) se tornam resistentes ao desenvolvimento espontâneo de DM1. Ao sequenciar a região e a comparar com o locus Idd4 de camundongos NOD, os autores observaram diversos polimorfismos em Nlrplb de camundongos NOR, comparado aos NOD, tornando-o um possível gene envolvido na resistência observada em camundongos NOR. De forma interessante, foi observado que Nlrplb de camundongos NOR produz uma proteína truncada, sem o domínio CARD, tornando-o incapaz de produzir IL-1 $\beta$ em sua forma madura, o que poderia estar relacionado à resistência observada nesses animais (MOTTA et al., 2015).

Por fim, avaliamos o papel de NLRP1 em humanos com DM1. Para isso, utilizamos um polimorfismo em NLRP1 (SNP rs12150220), que já foi amplamente reportado na literatura como sendo capaz de aumentar a suscetibilidade ao DM1 (MAGITTA et al., 2009; TANG et al., 2013). Ao correlacionar a expressão de Nlrpl com um dos três genótipos possíveis do $\operatorname{rs} 12150220$ (T/T, A/T ou A/A) não encontramos nenhuma diferença, 
indicando que tal polimorfismo não é capaz de alterar os níveis de mRNA do receptor. Todavia, já foi demonstrado que monócitos de indivíduos que carregam mutações específicas em Nlrpl (sendo uma delas o SNP rs12150220) são capazes de processar mais IL-1 $\beta$ em sua forma ativa, apesar de apresentarem os mesmos níveis de expressão gênica e proteica de NLRP1 (LEVANDOWSKI et al., 2013). Portanto, o SNP rs12150220 aparenta ser uma mutação com ganho de função, fazendo com que células mielóides de indivíduos que o possuem sejam capazes de produzir mais IL-1 $\beta$ madura. De forma interessante, observamos que pacientes com DM1 que possuem a mutação rs12150220 possuem mais células produtoras de IL-17 (Th17 e Tc17) comparado a indivíduos sem o polimorfismo. Considerando o papel imprescindível de IL-1 $\beta$ para a indução de células Th17 (SIMS; SMITH, 2010), acreditamos que o aumento de IL-17 em pacientes com o rs12150220 possa estar relacionado a um aumento na produção de IL-1 $\beta$ pelos monócitos desses pacientes. Por conseguinte, é importante destacar que NLRP1 humano parece possuir uma função oposta ao NLRP1 de camundongos. No modelo de DM1 induzido por STZ, NLRP1 parece ser importante em células linfóides, inibindo a diferenciação de células Th17. Já, em humanos, NLRP1 também está relacionado a células Th17, porém de maneira diferente: o ganho de função de NLRP1 (rs12150220), faz com que os monócitos sejam capazes de processar mais IL-1 $\beta$ (LEVANDOWSKI et al., 2013), o que está diretamente relacionado ao aumento de células produtoras de IL-17, bem como ao aumento de IL-17 no soro de pacientes com tal polimorfismo.

Em suma, no presente trabalho elucidamos o papel do receptor NLRP1 em modelos experimentais e humanos com DM1. Nossos dados indicam que NLRP1, que é altamente polimórfico entre linhagens isogênicas distintas, é diferencialmente expresso em modelos de DM1 espontâneo (NOD) e induzido por droga (STZ), sendo protetor neste modelo, além de possuir um papel deletério em pacientes com DM1. Nossos achados são de extrema importância, pois contribuem para um melhor entendimento acerca das complexas interações envolvidas na resposta imune inata e adaptativa durante o desenvolvimento do DM1, oferecendo suporte para novas abordagens terapêuticas que poderão ser utilizadas futuramente no tratamento de pacientes diabéticos. 
Sumário 
Os dados gerados na presente tese demonstram que:

- NLRP1 é protetor no DM1 induzido por STZ;

- NLRP1 inibe a diferenciação de células Th17 em estágios iniciais do DM1 induzido por STZ;

- NLRP1 inibe a produção de IL-6 por células dendríticas durante o desenvolvimento do DM1 induzido por STZ;

- NLRP1 inibe a translocação de bactérias da microbiota intestinal para os linfonodos pancreáticos;

- O tratamento com antibióticos é capaz de reverter o fenótipo de suscetibilidade de animais NLRP1 $1^{-/}$injetados com STZ;

- A quantidade, mas não a qualidade de bactérias parece estar envolvida no aumento da suscetibilidade de animais NLRP1 ${ }^{-/-}$ao DM1 induzido por STZ;

- Nlrp1a, mas não Nlrp1b parece estar envolvido no papel de NLRP1 em manter a barreira epitelial intestinal;

- O efeito protetor de NLRP1 no DM1 induzido por STZ independe da ativação da maquinaria do inflamassoma;

- Nlrplb é expresso em células linfóides durante o desenvolvimento do DM1 induzido por STZ

- NLRP1 é um regulador negativo da diferenciação de células Th17 in vivo

- Nlrpla e Nlrp1b são expressos em estágios tardios do desenvolvimento do DM1 no modelo do NOD

- A expressão de Nlrpla e Nlrp1b no modelo do NOD coincide com a diminuição da expressão gênica e proteica de IL-17

- Pacientes com DM1 que possuem o SNP rs12150220 apresentam maiores números de células produtoras de IL-17 no compartimento de memória, o que foi correlacionado ao aumento de IL-17 no soro;

- Considerando que o SNP rs12150220 corresponde a uma mutação com ganho de função, NLRP1 em humanos parece possuir um papel oposto ao NLRP1 de camundongos C57BL/6, induzindo a diferenciação de células Th17, enquanto no modelo murino ele parece inibir a diferenciação das mesmas. 
Conclusão 
Nlrpl é um gene bastante polimórfico não só entre linhagens isogênicas distintas de camundongos, como também entre camundongos e humanos. Enquanto NLRP1 parece ter um papel protetor no DM1 induzido por STZ, inibindo a translocação de bactérias para os LNPs, a diferenciação de células Th17 e, em última instância, o infiltrado inflamatório nas ilhotas pancreáticas; ele aparenta ter um papel patogênico no DM1 em humanos, favorecendo a diferenciação do perfil Th17 em indivíduos que possuem polimorfismos com ganho de função no receptor. 


\section{Referências bibliográficas}


ADA. STANDARDS OF MEDICAL CARE IN DIABETES - 2017 Standards of Medical Care in Diabetes d 2017. v. 40, n. January, 2017.

ALKANANI, A. K.; HARA, N.; GOTTLIEB, P. A.; IR, D.; ROBERTSON, C. E.; WAGNER, B. D.; FRANK, D. N.; ZIPRIS, D. Alterations in Intestinal Microbiota Correlate with Susceptibility to Type 1 Diabetes. Diabetes, p. db14-1847-, 2015. Disponível em: $<$ http://diabetes.diabetesjournals.org/content/early/2015/06/17/db14-1847.abstract $>$.

ALLAM, R.; LAWLOR, K. E.; YU, E. C.-W.; MILDENHALL, A. L.; MOUJALLED, D. M.; LEWIS, R. S.; KE, F.; MASON, K. D.; WHITE, M. J.; STACEY, K. J.; STRASSER, A.; O'REILlY, L. A.; ALEXANDER, W.; KILE, B. T.; VAUX, D. L.; VINCE, J. E. Mitochondrial apoptosis is dispensable for NLRP3 inflammasome activation but nonapoptotic caspase-8 is required for inflammasome priming. EMBO reports, v. 15, n. 9, p. 982-990, 2014. Disponível em: $<$ http://embor.embopress.org/cgi/doi/10.15252/embr.201438463>.

ANDERSON, M. S.; BLUESTONE, J. A. The NOD mouse: a model of immune dysregulation. Annual review of immunology, v. 23, p. 447-485, 2005.

ANDERSON, O. A.; FINKELSTEIN, A.; SHIMA, D. T. A2E Induces IL-1?? Production in Retinal Pigment Epithelial Cells via the NLRP3 Inflammasome. PLoS ONE, v. 8, n. 6, 2013.

ARBORE, G.; WEST, E. E.; SPOLSKI, R.; ROBERTSON, A. A. B.; KLOS, A.; RHEINHEIMER, C.; DUTOW, P.; WOODRUFF, T. M.; YU, Z. X.; ONEILL, L. A.; COLL, R. C.; SHER, A.; LEONARD, W. J.; KOHL, J.; MONK, P.; COOPER, M. A.; ARNO, M.; AFZALI, B.; LACHMANN, H. J.; COPE, A. P.; MAYER-BARBER, K. D.; KEMPER, C. T helper 1 immunity requires complement-driven NLRP3 inflammasome activity in CD4+ T cells. Science, v. 352, n. 6292, p. aad1210-aad1210, 2016. Disponível em: <http://www.sciencemag.org/cgi/doi/10.1126/science.aad1210>.

ARIF, S.; MOORE, F.; MARKS, K.; BOUCKENOOGHE, T.; DAYAN, C. M.; PLANAS, R.; VIVES-PI, M.; POWRIE, J.; TREE, T.; MARCHETTI, P.; HUANG, G. C.; GURZOV, E. N.; PUJOL-BORRELL, R.; EIZIRIK, D. L.; PEAKMAN, M. Peripheral and islet interleukin-17 pathway activation characterizes human autoimmune diabetes and promotes cytokine-mediated $\beta$-cell death. Diabetes, v. 60, p. 2112-2119, 2011.

ARNUSH, M.; SCARIM, A. L.; HEITMEIER, M. R.; KELLY, C. B.; CORBETT, J. A. Potential role of resident islet macrophage activation in the initiation of autoimmune diabetes. Journal of immunology (Baltimore, Md. : 1950), v. 160, n. 6, p. 2684-2691, 1998. Disponível em: <http://www.jimmunol.org/content/160/6/2684.short>.

ATKINSON, M. a. The pathogenesis and natural history of type 1 diabetes. Cold Spring Harb Perspect Med, v. 2, n. 11, p. a007641, 2012. Disponível em: $<$ http://www.ncbi.nlm.nih.gov/pubmed/23125199>.

ATKINSON, M. A.; EISENBARTH, G. S.; MICHELS, A. W. Type 1 diabetes. Lancet, v. 383, n. 9911, p. 69-82, 2014. 
BACH, J.-F. The effect of infections on susceptibility to autoimmune and allergic diseases. v. 347, n. 12, p. 911-920, 2002.

$\mathrm{BACH}$, J. F. Insulin-dependent diabetes mellitus as an autoimmune disease. Endocrine reviews, v. 15, n. 4, p. 516-542, 1994.

BANATVALA, J. E.; SCHERNTHANER, G.; SCHOBER, E.; DE SILVA, L. M.; BRYANT, J.; BORKENSTEIN, M.; BROWN, D.; MENSER, M. A.; SILINK, M. COXSACKIE B, MUMPS, RUBELLA, AND CYTOMEGALOVIRUS SPECIFIC IgM RESPONSES IN PATIENTS WITH JUVENILE-ONSET INSULIN-DEPENDENT DIABETES MELLITUS IN BRITAIN, AUSTRIA, AND AUSTRALIA. The Lancet, v. 325, n. 8443, p. 1409-1412, 1985.

BENDELAC, B. Y. A.; CARNAUD, C.; BOITARD, C.; BACH, J. F. Syngeneic Transfer of Autoimmune Diabetes from diabetic NOD mice to healthy neonates: Requirement for Both L3T4' and Lyt-2 + T Cells. J. Exp. MED, v. 166, n. October, p. 823-832, 1987.

BENDING, D.; DE LA PEÑA, H.; VELDHOEN, M.; PHILLIPS, J. M.; UYTTENHOVE, C.; STOCKINGER, B.; COOKE, A. Highly purified Th17 cells from BDC2.5NOD mice convert into Th1-like cells in NOD/SCID recipient mice. The Journal of clinical investigation, v. 119, p. 565-572, 2009.

BETTELLI, E.; CARRIER, Y.; GAO, W.; KORN, T.; STROM, T. B.; OUKKA, M.; WEINER, H. L.; KUCHROO, V. K. Reciprocal developmental pathways for the generation of pathogenic effector TH17 and regulatory T cells. Nature, v. 441, p. 235-238, 2006.

BEYERLEIN, A.; CHMIEL, R.; HUMMEL, S.; WINKLER, C.; BONIFACIO, E.; ZIEGLER, A. G. Timing of gluten introduction and islet autoimmunity in young children: Updated results from the Babydiet studyDiabetes Care, 2014. .

BOSI, E.; MOLTENI, L.; RADAELLI, M. G.; FOLINI, L.; FERMO, I.; BAZZIGALUPPI, E.; PIEMONTI, L.; PASTORE, M. R.; PARONI, R. Increased intestinal permeability precedes clinical onset of type 1 diabetes. Diabetologia, v. 49, p. 2824-2827, 2006.

BOYDEN, E. D.; DIETRICH, W. F. Nalp1b controls mouse macrophage susceptibility to anthrax lethal toxin. Nature genetics, v. 38, p. 240-244, 2006.

BLISS, M. The discovery of insulin. Chicago: The University of Chicago Press, Chicago, 2007. 310p.

BRAUNER, H.; ELEMANS, M.; LEMOS, S.; BROBERGER, C.; HOLMBERG, D.; FLODSTRÖM-TULLBERG, M.; KÄRRE, K.; HÖGLUND, P. Distinct Phenotype and Function of NK Cells in the Pancreas of Nonobese Diabetic Mice. The Journal of Immunology, v. 184, n. 5, p. 2272-2280, 2010. Disponível em: $<$ http://www.jimmunol.org/lookup/doi/10.4049/jimmunol.0804358>.

BRESTOFF, J. R.; ARTIS, D. Commensal bacteria at the interface of host metabolism and the 
immune system. Nature immunology, v. 14, n. 7, p. 676-84, 2013. Disponível em: $<$ http://www.nature.com/doifinder/10.1038/ni.2640\%5Cnhttp://www.nature.com/ni/journ al/v14/n7/fig_tab/ni.2640_F1.html>.

BRUCHARD, M.; REBÉ, C.; DERANGÈRE, V.; TOGBÉ, D.; RYFFEL, B.; BOIDOT, R.; HUMBLIN, E.; HAMMAN, A.; CHALMIN, F.; BERGER, H.; CHEVRIAUX, A.; LIMAGNE, E.; APETOH, L.; VÉGRAN, F.; GHIRINGHELLI, F. The receptor NLRP3 is a transcriptional regulator of TH2 differentiation. Nature Immunology, v. 16, n. 8, p. 859870, 2015. Disponível em: <http://www.nature.com/doifinder/10.1038/ni.3202>.

BRUGMAN, S.; KLATTER, F. A.; VISSER, J. T. J.; WILDEBOER-VELOO, A. C. M.; HARMSEN, H. J. M.; ROZING, J.; BOS, N. A. Antibiotic treatment partially protects against type 1 diabetes in the Bio-Breeding diabetes-prone rat. Is the gut flora involved in the development of type 1 diabetes? Diabetologia, v. 49, p. 2105-2108, 2006.

CAETANO, B. C.; BISWAS, A.; LIMA, D. S.; BENEVIDES, L.; MINEO, T. W. P.; HORTA, C. V; LEE, K.-H.; SILVA, J. S.; GAZZINELLI, R. T.; ZAMBONI, D. S.; KOBAYASHI, $\mathrm{K}$. S. Intrinsic expression of Nod2 in CD4+ T lymphocytes is not necessary for the development of cell-mediated immunity and host resistance to Toxoplasma gondii. European journal of immunology, v. 41, n. 12, p. 3627-31, dez. 2011. Disponível em: $<$ http://www.pubmedcentral.nih.gov/articlerender.fcgi?artid=3241608\&tool=pmcentrez\& rendertype=abstract $>$. Acesso em: 18 fev. 2014.

CARDWELL, C. R.; CARSON, D. J.; PATTERSON, C. C. No association between routinely recorded infections in early life and subsequent risk of childhood-onset Type 1 diabetes: A matched case-control study using the UK General Practice Research Database. Diabetic Medicine, v. 25, n. 3, p. 261-267, 2008.

CARlOS, D.; COSTA, F. R. C.; PEREIRA, C. A.; ROCHA, F. A.; YAOCHITE, J. N. U.; OLIVEIRA, G. G.; CARNEIRO, F. S.; TOSTES, R. C.; RAMOS, S. G.; ZAMBONI, D. S.; CAMARA, N. O. S.; RYFFEL, B.; SILVA, J. S. Mitochondrial DNA activates the NLRP3 inflammasome and predisposes to type 1 diabetes in murine model. Frontiers in Immunology, v. 8, n. FEB, 2017.

CHATZIGEORGIOU, A.; HAROKOPOS, V.; MYLONA-KARAGIANNI, C.; TSOUVALAS, E.; AIDINIS, V.; KAMPER, E. The pattern of inflammatory/antiinflammatory cytokines and chemokines in type 1 diabetic patients over time. Annals of Medicine, v. 42, n. 6, p. 426-438, 2010.

CHEN, G.; SHAW, M. H.; KIM, Y.-G.; NUÑEZ, G. NOD-like receptors: role in innate immunity and inflammatory disease. Annual review of pathology: Mechanisms of Disease, $\quad$ v. $4, \quad$ p. 365-98, 2009. Disponível em: $<$ http://www.ncbi.nlm.nih.gov/pubmed/18928408>.

CHEN, G. Y. Role of Nlrp6 and Nlrp12 in the maintenance of intestinal homeostasis. European Journal of Immunology, v. 44, n. 2, p. 321-327, 2014.

COLE, D. K.; BULEK, A. M.; DOLTON, G.; SCHAUENBERG, A. J.; SZOMOLAY, B.; 
RITTASE, M.; TRIMBY, A.; JOTHIKUMAR, P.; FULLER, A.; SKOWERA, A.; ROSSJOHN, J.; ZHU, C.; MILES, J. J.; PEAKMAN, M.; RIZKALLAH, P. J.; SEWELL, A. K. Hotspot autoimmune T-cell receptor binding to pathogen and insulin peptides e. The Journal of clinical investigation, v. In press., n. 6, p. 2191-2204, 2016.

CONCANNON, P.; RICH, S. S.; NEPOM, G. T. Genetics of Type 1A Diabetes. New England Journal of Medicine, v. 360, n. 16, p. 1646-1654, 2009. Disponível em: $<$ http://www.nejm.org/doi/abs/10.1056/NEJMra0808284>.

COOPER, J. D.; SMYTH, D. J.; SMILES, A. M.; PLAGNOL, V.; WALKER, N. M.; ALLEN, J. E.; DOWNES, K.; BARRETT, J. C.; HEALY, B. C.; MYCHALECKYJ, J. C.; WARRAM, J. H.; TODD, J. A. Meta-analysis of genome-wide association study data identifies additional type 1 diabetes risk loci. Nature Genetics, v. 40, n. 12, p. 1399-1401, 2008.

COPPIETERS, K. T.; WIBERG, A.; TRACY, S. M.; VON HERRATH, M. G. Immunology in the clinic review series: Focus on type 1 diabetes and viruses: The role of viruses in type 1 diabetes: A difficult dilemmaClinical and Experimental Immunology, 2012. .

COSTA, F. R. C.; FRANÇOZO, M. C. S.; DE OLIVEIRA, G. G.; IGNACIO, A.; CASTOLDI, A.; ZAMBONI, D. S.; RAMOS, S. G.; CÂMARA, N. O.; DE ZOETE, M. R.; PALM, N. W.; FLAVELL, R. A.; SILVA, J. S.; CARLOS, D. Gut microbiota translocation to the pancreatic lymph nodes triggers NOD2 activation and contributes to T1D onset. The Journal of Experimental Medicine, p. jem.20150744, 2016. Disponível em: $<$ http://www.jem.org/lookup/doi/10.1084/jem.20150744>.

COUTINHO, W. F.; SANTANA, W.; JÚNIOR, S. Diabetes Care in Brazil. Annals of Global Health, v. 81, n. 6, p. 735-741, 2015. Disponível em: $<$ http://dx.doi.org/10.1016/j.aogh.2015.12.010>.

DAHLÉN, E.; DAWE, K.; OHLSSON, L.; HEDLUND, G. Dendritic cells and macrophages are the first and major producers of TNF-alpha in pancreatic islets in the nonobese diabetic mouse. Journal of immunology (Baltimore, Md. : 1950), v. 160, p. 3585-3593, 1998.

DAVID, L. A.; MAURICE, C. F.; CARMODY, R. N.; GOOTENBERG, D. B.; BUTTON, J. E.; WOLFE, B. E.; LING, A. V; DEVLIN, A. S.; VARMA, Y.; FISCHBACH, M. A.; BIDDINGER, S. B.; DUTTON, R. J.; TURNBAUGH, P. J. Diet rapidly and reproducibly alters the human gut microbiome. Nature, v. 505, n. 7484, p. 559-63, 2014. Disponível em:

$<$ http://www.pubmedcentral.nih.gov/articlerender.fcgi?artid=3957428\&tool=pmcentrez\& rendertype $=$ abstract $>$.

DEVARAJ, S.; TOBIAS, P.; KASINATH, B. S.; RAMSAMOOJ, R.; AFIFY, A.; JIALAL, I. Knockout of toll-like receptor-2 attenuates both the proinflammatory state of diabetes and incipient diabetic nephropathy. Arteriosclerosis, Thrombosis, and Vascular Biology, v. 31, n. 8, p. 1796-1804, 2011.

DIAZ-VALENCIA, P. A.; BOUGNÈRES, P.; VALLERON, A.-J. Global epidemiology of type 
1 diabetes in young adults and adults: a systematic review. BMC Public Health, v. 15, n. 1, p. 255, 2015. 2 Disponível $<\mathrm{http}: / /$ bmcpublichealth.biomedcentral.com/articles/10.1186/s12889-015-1591-y>.

DIPPE, S. E.; MILLER, M.; BENNETT, P. H.; MAYNARD, J. E.; BERQUIST, K. R. LACK OF CAUSAL ASSOCIATION BETWEEN COXSACKIE B4 VIRUS INFECTION AND DIABETES. The Lancet, v. 305, n. 7920, p. 1314-1317, 1975.

DOLAN, M. E. Inhibition of DNA repair as a means of increasing the antitumor activity of DNA reactive agentsAdvanced Drug Delivery Reviews, 1997. .

DOTTA, F.; CENSINI, S.; VAN HALTEREN, A. G. S.; MARSELLI, L.; MASINI, M.; DIONISI, S.; MOSCA, F.; BOGGI, U.; MUDA, A. O.; DEL PRATO, S.; ELLIOTT, J. F.; COVACCI, A.; RAPPUOLI, R.; ROEP, B. O.; MARCHETTI, P. Coxsackie B4 virus infection of $\beta$ cells and natural killer cell insulitis in recent-onset type 1 diabetic patients. Proceedings of the National Academy of Sciences of the United States of America, v. 104, n. 12, p. 5115-5120, 2007.

ELEAZU, C. O.; ELEAZU, K. C.; CHUKWUMA, S.; ESSIEN, U. N. Review of the mechanism of cell death resulting from streptozotocin challenge in experimental animals, its practical use and potential risk to humans. p. 1-7, 2013.

ELINAV, E.; STROWIG, T.; KAU, A. L.; HENAO-MEJIA, J.; THAISS, C. A.; BOOTH, C. J.; PEAPER, D. R.; BERTIN, J.; EISENBARTH, S. C.; GORDON, J. I.; FLAVELL, R. A. NLRP6 inflammasome regulates colonic microbial ecology and risk for colitis. Cell, v. 145 , n. 5, p. 745-757, 2011.

EMAMAULLEE, J. A.; DAVIS, J.; MERANI, S.; TOSO, C.; ELLIOTT, J. F.; THIESEN, A.; SHAPIRO, A. M. Inhibition of Th17 Cells Regulates Autoimmune Diabetes in NOD Mice. Diabetes, v. 58, n. 6, p. 1302-1311, 2009a. Disponível em: $<$ http://www.ncbi.nlm.nih.gov/pubmed/19289457>.

EMAMAULLEE, J. A.; DAVIS, J.; MERANI, S.; TOSO, C.; ELLIOTT, J. F.; THIESEN, A.; SHAPIRO, A. M. J. Inhibition of Th17 cells regulates autoimmune diabetes in NOD mice. Diabetes, v. 58, p. 1302-1311, $2009 \mathrm{~b}$.

ERLICH, H. A.; VALDES, A. M.; MCDEVITT, S. L.; SIMEN, B. B.; BLAKE, L. A.; MCGOWAN, K. R.; TODD, J. A.; RICH, S. S.; NOBLE, J. A. Next generation sequencing reveals the association of DRB3*02:02 with type 1 diabetes. Diabetes, v. 62, n. 7, p. $2618-$ $2622,2013$.

EWALD, S. E.; CHAVARRIA-SMITH, J.; JOHN, C. NLRP1 Is an Inflammasome Sensor for Toxoplasma gondii. v. 82, n. 1, 2014.

FAUSTIN, B.; LARTIGUE, L.; BRUEY, J.-M.; LUCIANO, F.; SERGIENKO, E.; BAILLYMAITRE, B.; VOLKMANN, N.; HANEIN, D.; ROUILLER, I.; REED, J. C. Reconstituted NALP1 inflammasome reveals two-step mechanism of caspase-1 activation. Molecular cell, v. 25, p. 713-724, 2007. 
FAUSTMAN, D. L.; STEINMAN, R. M.; GEBEL, H. M.; HAUPTFELD, V.; DAVIE, J. M.; LACY, P. E. Prevention of rejection of murine islet allografts by pretreatment with antidendritic cell antibody. Proceedings of the National Academy of Sciences of the United States of America, v. 81, n. 12, p. 3864-8, 1984. Disponível em: $<$ http://www.pubmedcentral.nih.gov/articlerender.fcgi?artid=345322\&tool=pmcentrez\&r endertype $=$ abstract $>$.

FERON, V. J.; WOUTERSEN, R. A.; VAN GARDEREN-HOETMER, A.; DREEF-VAN DER MEULEN, H. C. Upper respiratory tract tumors in Cpb:WU (Wistar random) rats. In: Environmental Health Perspectives, Anais...1990.

FERRARO, A.; SOCCI, C.; STABILINI, A.; VALLE, A.; MONTI, P.; PIEMONTI, L.; NANO, R.; OLEK, S.; MAFFI, P.; SCAVINI, M.; SECCHI, A.; STAUDACHER, C.; BONIFACIO, E.; BATTAGLIA, M. Expansion of Th17 cells and functional defects in T regulatory cells are key features of the pancreatic lymph nodes in patients with type 1 diabetes. Diabetes, v. 60, n. 11, p. 2903-2913, 2011.

FILIPPI, C. M.; VON HERRATH, M. G. Viral trigger for type 1 diabetes: pros and cons. Diabetes, v. 57, n. 11, p. 2863-71, nov. 2008. Disponível em: $<$ http://www.pubmedcentral.nih.gov/articlerender.fcgi?artid $=2570378 \&$ tool=pmcentrez\& rendertype $=$ abstract $>$. Acesso em: 30 out. 2013.

FOUSTERI, G.; DAVE, A.; BOT, A.; JUNTTI, T.; OMID, S.; VON HERRATH, M. Subcutaneous insulin B:9-23/IFA immunisation induces Tregs that control late-stage prediabetes in NOD mice through IL-10 and IFN $\gamma$. Diabetologia, v. 53, n. 9, p. 1958-1970, 2010 .

GAMBLE, D. R.; FITZGERALD, M. G.; BOLTON, R.; TAYLOR, K. W.; KINSLEY, M. L. Viral Antibodies in Diabetes Mellitus. British Medical Journal, v. 3, n. 5671, p. 627-630, 1969.

GANESAN, S.; RATHINAM, V. A. K.; BOSSALLER, L.; ARMY, K.; KAISER, W. J.; MOCARSKI, E. S.; DILLON, C. P.; GREEN, D. R.; MAYADAS, T. N.; LEVITZ, S. M.; HISE, A. G.; SILVERMAN, N.; FITZGERALD, K. A. Caspase-8 Modulates Dectin-1 and Complement Receptor 3-Driven IL-1 $\beta$ Production in Response to $\beta$-Glucans and the Fungal Pathogen, Candida albicans. The Journal of Immunology, v. 193, n. 5, p. 2519 2530, 2014. Disponível em: $<$ http://www.jimmunol.org/lookup/doi/10.4049/jimmunol.1400276>.

GRAHAM, J.; HAGOPIAN, W. A.; KOCKUM, I.; LI, L. S.; SANJEEVI, C. B.; LOWE, R. M.; SCHAEFER, J. B.; ZARGHAMI, M.; DAY, H. L.; LANDIN-OLSSON, M.; PALMER, J. P.; JANER-VILLANUEVA, M.; HOOD, L.; SUNDKVIST, G.; LERNMARK, Å.; BRESLOW, N.; DAHLQUIST, G.; BLOHMÉ, G. Genetic effects on age-dependent onset and islet cell autoantibody markers in type 1 diabetes. Diabetes, $v$. 51, n. 5, p. 1346-1355, 2002.

GREINER, T. U.; HY??TYL??INEN, T.; KNIP, M.; B??CKHED, F.; ORE??I??, M. The gut microbiota modulates glycaemic control and serum metabolite profiles in non-obese 
diabetic mice. PLoS ONE, v. 9, n. 11, 2014.

GUNDERSEN, E. Is diabetes of infectious origin? Journal of Infectious Diseases, v. 41, n. 3, p. 197-202, 1927.

GUO, H.; CALLAWAY, J. B.; TING, J. P. Inflammasomes : mechanism of action, role in disease, and therapeutics. v. 21, n. 7, p. 677-687, 2015.

GUR, C.; PORGADOR, A.; ELBOIM, M.; GAZIT, R.; MIZRAHI, S.; STERN-GINOSSAR, N.; ACHDOUT, H.; GHADIALLY, H.; DOR, Y.; NIR, T.; DOVINER, V.; HERSHKOVITZ, O.; MENDELSON, M.; NAPARSTEK, Y.; MANDELBOIM, O. The activating receptor NKp46 is essential for the development of type 1 diabetes. Nature Immunology, v. 11, n. 2, p. 121-128, 2010.

GURUNG, P.; ANAND, P. K.; MALIREDDI, R. K. S.; VANDE WALLE, L.; VAN OPDENBOSCH, N.; DILLON, C. P.; WEINLICH, R.; GREEN, D. R.; LAMKANFI, M.; KANNEGANTI, T.-D. FADD and Caspase- 8 Mediate Priming and Activation of the Canonical and Noncanonical Nlrp3 Inflammasomes. The Journal of Immunology, v. 192, n. $4, \quad$ p. 1835-1846, 2014. Disponível em: $<$ http://www.jimmunol.org/cgi/doi/10.4049/jimmunol.1302839>.

HAMALAINEN, A.-M.; KNIP, M. Autoimmunity and familial risk of type 1 diabetes. Current diabetes reports, v. 2, n. 4, p. 347-353, 2002.

HAN, D.; LEYVA, C. a; MATHESON, D.; MINEO, D.; MESSINGER, S.; BLOMBERG, B. B.; HERNANDEZ, A.; MENEGHINI, L. F.; ALLENDE, G.; SKYLER, J. S.; ALEJANDRO, R.; PUGLIESE, A.; KENYON, N. S. Immune profiling by multiple gene expression analysis in patients at-risk and with type 1 diabetes. Clinical immunology (Orlando, Fla.), v. 139, n. 3, p. 290-301, 2011.

HARRINGTON, L. E.; HATTON, R. D.; MANGAN, P. R.; TURNER, H.; MURPHY, T. L.; MURPHY, K. M.; WEAVER, C. T. Interleukin 17-producing CD4+ effector T cells develop via a lineage distinct from the $\mathrm{T}$ helper type 1 and 2 lineages. Nature Immunology, v. 6, n. 11, p. 1123-1132, 2005.

HEROLD, K. C.; GITELMAN, S. E.; WILLI, S. M.; GOTTLIEB, P. a.; WALDRON-LYNCH, F.; DEVINE, L.; SHERR, J.; ROSENTHAL, S. M.; ADI, S.; JALALUDIN, M. Y.; MICHELS, a. W.; DZIURA, J.; BLUESTONE, J. a. Teplizumab treatment may improve $\mathrm{C}$-peptide responses in participants with type 1 diabetes after the new-onset period: A randomised controlled trial. Diabetologia, v. 56, n. 2, p. 391-400, 2013.

HILDEBRANDT, M. A.; HOFFMANN, C.; SHERRILL-MIX, S. A.; KEILBAUGH, S. A.; HAMADY, M.; CHEN, Y. Y.; KNIGHT, R.; AHIMA, R. S.; BUSHMAN, F.; WU, G. D. High-Fat Diet Determines the Composition of the Murine Gut Microbiome Independently of Obesity. Gastroenterology, v. 137, n. 5, 2009.

HOLMES, E.; LI, J. V.; MARCHESI, J. R.; NICHOLSON, J. K. Gut microbiota composition and activity in relation to host metabolic phenotype and disease riskCell Metabolism, 
2012. .

HONKANEN, J.; NIEMINEN, J. K.; GAO, R.; LUOPAJARVI, K.; SALO, H. M.; ILONEN, J.; KNIP, M.; OTONKOSKI, T.; VAARALA, O. IL-17 immunity in human type 1 diabetes. Journal of immunology (Baltimore, Md. : 1950), v. 185, n. 3, p. 1959-1967, 2010 .

HSU, L.-C.; ALI, S. R.; MCGILLIVRAY, S.; TSENG, P.-H.; MARIATHASAN, S.; HUMKE, E. W.; ECKMANN, L.; POWELL, J. J.; NIZET, V.; DIXIT, V. M.; KARIN, M. A NOD2NALP1 complex mediates caspase-1-dependent IL-1beta secretion in response to Bacillus anthracis infection and muramyl dipeptide. Proceedings of the National Academy of Sciences of the United States of America, v. 105, p. 7803-7808, 2008.

HU, C.; DING, H.; LI, Y.; PEARSON, J. a.; ZHANG, X.; FLAVELL, R. a.; WONG, F. S.; WEN, L. NLRP3 deficiency protects from type 1 diabetes through the regulation of chemotaxis into the pancreatic islets. Proceedings of the National Academy of Sciences, v. 112, n. 36, p. 11318-11323, 2015a. Disponível em: $<$ http://www.pnas.org/lookup/doi/10.1073/pnas.1513509112>.

HU, C.; DING, H.; LI, Y.; PEARSON, J. A.; ZHANG, X.; FLAVELL, R. A.; WONG, F. S.; WEN, L. NLRP3 deficiency protects from type 1 diabetes through the regulation of chemotaxis into the pancreatic islets. Proceedings of the National Academy of Sciences, v. 112, n. 36, p. 11318-11323, 2015b. Disponível em: $<$ http://www.pnas.org/lookup/doi/10.1073/pnas.1513509112>.

HULTGREN, B.; HUANG, X.; DYBDAL, N.; STEWART, T. A. Genetic absence of gammainterferon delays but does not prevent diabetes in NOD mice. Diabetes, v. 45, n. 6, p. $812-$ 817, 1996. Disponível em: <http://www.ncbi.nlm.nih.gov/pubmed/8635658>.

HUTCHINGS, P.; ROSEN, H.; O'REILLY, L.; SIMPSON, E.; GORDON, S.; COOKE, A. Transfer of diabetes in mice prevented by blockade of adhesion-promoting receptor on macrophages. Nature, v. 348, n. 6302, p. 639-642, 1990.

ILONEN, J.; HAMMAIS, A.; LAINE, A. P.; LEMPAINEN, J.; VAARALA, O.; VEIJOLA, R.; SIMELL, O.; KNIP, M. Patterns of beta-cell autoantibody appearance and genetic associations during the first years of life. Diabetes, v. 62, n. 10, p. 3636-3640, 2013.

IM, S.; YOUSEF, L.; BLASCHITZ, C.; LIU, J. Z.; EDWARDS, R. A.; YOUNG, S. G.; RAFFATELLU, M.; OSBORNE, T. F. Linking Lipid Metabolism to the Innate Immune Response in Macrophages through Sterol Regulatory Element Binding Protein -1a. Cell metabolism, v. 13, n. 5, p. 540-549, 2012.

IMAGAWA, A.; HANAFUSA, T.; MIYAGAWA, J.; MATSUZAWA, Y. A Novel Subtype of Type 1 Diabetes Mellitus Characterized by a Rapid Onset and an Absence of DiabetesRelated Antibodies. New England Journal of Medicine, v. 342, n. 5, p. 301-307, 2000. Disponível em: <http://www.nejm.org/doi/abs/10.1056/NEJM200002033420501>.

JAIN, R.; TARTAR, D. M.; GREGG, R. K.; DIVEKAR, R. D.; BELL, J. J.; LEE, H.-H.; YU, 
P.; ELLIS, J. S.; HOEMAN, C. M.; FRANKLIN, C. L.; ZAGHOUANI, H. Innocuous IFN $\gamma$ induced by adjuvant-free antigen restores normoglycemia in NOD mice through inhibition of IL-17 production. The Journal of Experimental Medicine, v. 205, n. 1, p. 207-218, 2008. Disponível em: <http://www.jem.org/lookup/doi/10.1084/jem.20071878>.

JOSEPH, J.; BITTNER, S.; KAISER, F. M. P.; WIENDL, H.; KISSLER, S. IL-17 Silencing Does Not Protect Nonobese Diabetic Mice from Autoimmune Diabetes. The Journal of Immunology, v. 188, n. 1, p. 216-221, 2012a. Disponível em: $<$ http://www.jimmunol.org/cgi/doi/10.4049/jimmunol.1101215>.

JOSEPH, J.; BITTNER, S.; KAISER, F. M. P.; WIENDL, H.; KISSLER, S. IL-17 silencing does not protect nonobese diabetic mice from autoimmune diabetes. Journal of immunology (Baltimore, Md. : 1950), v. 188, n. 1, p. 216-21, 1 jan. 2012b. Disponível em: <http://www.ncbi.nlm.nih.gov/pubmed/22116823>. Acesso em: 3 jul. 2014.

KANAGAWA, O.; XU, G.; TEVAARWERK, A.; VAUPEL, B. A. Protection of Nonobese Diabetic Mice from Diabetes by Gene(s) Closely Linked to IFN- Receptor Loci. The Journal of Immunology, v. 164, n. 7, p. 3919-3923, 2000. Disponível em: $<$ http://www.jimmunol.org/content/164/7/3919.full $>$.

KATSAROU, A.; GUDBJÖRNSDOTTIR, S.; RAWSHANI, A.; DABELEA, D.; BONIFACIO, E.; ANDERSON, B. J.; JACOBSEN, L. M.; SCHATZ, D. A.; LERNMARK, Å. Type 1 diabetes mellitus. Nature Publishing Group, v. 3, p. 1-18, 2017. Disponível em: <http://dx.doi.org/10.1038/nrdp.2017.16>.

KATZ, J. D.; BENOIST, C.; MATHIS, D. T helper cell subsets in insulin-dependent diabetes. Science, v. 268, n. 5214, p. 1185-1188, 1995.

KENT, S. C.; CHEN, Y.; BREGOLI, L.; CLEMMINGS, S. M.; KENYON, N. S.; RICORDI, C.; HERING, B. J.; HAFLER, D. A. Expanded T cells from pancreatic lymph nodes of type 1 diabetic subjects recognize an insulin epitope. Nature, v. 435, n. 7039, p. 224-228, 2005.

KIKUTANI, H.; MAKINO, S. The murine autoimmune diabetes model: NOD and related strains. Advances in immunology, v. 51, p. 285-322, 1992. Disponível em: $<$ http://www.ncbi.nlm.nih.gov/pubmed/1323922>.

KIM, H. S.; HAN, M. S.; CHUNG, K. W.; KIM, S.; KIM, E.; KIM, M. J.; JANG, E.; LEE, H. A.; YOUN, J.; AKIRA, S.; LEE, M. S. Toll-like Receptor 2 Senses Beta-Cell Death and Contributes to the Initiation of Autoimmune Diabetes. Immunity, v. 27, n. 2, p. 321-333, 2007. Disponível em: <http://www.ncbi.nlm.nih.gov/pubmed/17707128>.

KITABACHI, A. E.; UMPIERREZ, G. E.; MURPHY, M. B.; KRESBERG, R. A. Hyperglycemic Crises in Adult Patients. v. 29, n. 12, 2006.

KNIP, M.; KUKKO, M.; KULMALA, P.; VEIJOLA, R.; SIMELL, O.; ??KERBLOM, H. K.; ILONEN, J. Humoral beta-cell autoimmunity in relation to HLA-defined disease susceptibility in preclinical and clinical type 1 diabetesAmerican Journal of Medical 
Genetics - Seminars in Medical Genetics, 2002. .

KOVAROVA, M.; HESKER, P. R.; JANIA, L.; NGUYEN, M.; SNOUWAERT, J. N.; XIANG, Z.; LOMMATZSCH, S. E.; HUANG, M. T.; TING, J. P.-Y.; KOLLER, B. H. NLRP1-dependent pyroptosis leads to acute lung injury and morbidity in mice. Journal of immunology (Baltimore, Md. : 1950), v. 189, n. 4, p. 2006-16, 15 ago. 2012. Disponível em:

$<$ http://www.pubmedcentral.nih.gov/articlerender.fcgi?artid=3635067\&tool=pmcentrez\& rendertype $=$ abstract $>$. Acesso em: 4 nov. 2013.

KRISCHER, J. P.; LYNCH, K. F.; SCHATZ, D. A.; ILONEN, J.; LERNMARK, Å.; HAGOPIAN, W. A.; REWERS, M. J.; SHE, J. X.; SIMELL, O. G.; TOPPARI, J.; ZIEGLER, A. G.; AKOLKAR, B.; BONIFACIO, E. The 6 year incidence of diabetesassociated autoantibodies in genetically at-risk children: the TEDDY study. Diabetologia, v. 58, n. 5 , p. $980-987,2015$.

KROGVOLD, L.; EDWIN, B.; BUANES, T.; FRISK, G.; SKOG, O.; ANAGANDULA, M.; KORSGREN, O.; UNDLIEN, D.; EIKE, M. C.; RICHARDSON, S. J.; LEETE, P.; MORGAN, N. G.; OIKARINEN, S.; OIKARINEN, M.; LAIHO, J. E.; HYÖTY, H.; LUDVIGSSON, J.; HANSSEN, K. F.; DAHL-JØRGENSEN, K. Detection of a low-grade enteroviral infection in the islets of langerhans of living patients newly diagnosed with type 1 diabetes. Diabetes, v. 64, n. 5, p. 1682-7, 2015. Disponível em: $<$ http://www.ncbi.nlm.nih.gov/pubmed/25422108>.

KYVIK, K. O.; GREEN, A.; BECK-NIELSEN, H. Concordance rates of insulin dependent diabetes mellitus: a population based study of young Danish twins. BMJ, v. 311, p. 913917, 1995.

LACEY, P. E.; DAVIE, J. M.; FINKE, E. H. Prolongation of Islet Allograft Survival Following in vitro Culture ( $24^{\circ}$ C ) and a Single Injection of ALS. Science, v. 204, n. April, p. 312$313,1979$.

LAMKANFI, M.; DIXIT, V. M. Mechanisms and functions of inflammasomes. Cell, v. 157, n. 5, p. 1013-1022, 2014. Disponível em: <http://dx.doi.org/10.1016/j.cell.2014.04.007>.

LAMKANFI, M.; DIXIT, V. M. The inflammasome turns 15. Nature, v. 548, 2017.

LEHUEN, A.; DIANA, J.; ZACCONE, P.; COOKE, A. Immune cell crosstalk in type 1 diabetes. Nat Rev Immunol, v. 10, p. 501-513, 2010. Disponível em: $<$ http://www.ncbi.nlm.nih.gov/entrez/query.fcgi? $\mathrm{cmd}=$ Retrieve \&db=PubMed\&dopt=Cita tion\&list_uids=20577267\%5Cnpapers2://publication/doi/10.1038/nri2787>.

LESLIE, R. D. G.; KOLB, H.; SCHLOOT, N. C.; BUZZETTI, R.; SARTI, K. Y. C.; THIVOLET, C.; HADDEN, D.; HUNTER, S. Diabetes classification : grey zones, sound and smoke: Action LADA 1. n. March, p. 511-519, 2008.

LEVANDOWSKI, C. B.; MAILLOUX, C. M.; FERRARA, T. M.; GOWAN, K.; BEN, S.; JIN, Y.; MCFANN, K. K.; HOLLAND, P. J.; FAIN, P. R.; DINARELLO, C. A.; SPRITZ, R. 
A. NLRP1 haplotypes associated with vitiligo and autoimmunity increase interleukin1 processing via the NLRP1 inflammasome. Proceedings of the National Academy of Sciences, v. 110, n. 8, p. 2952-2956, 2013. Disponível em: $<$ http://www.pnas.org/cgi/doi/10.1073/pnas.1222808110>.

LEY, R. E.; PETERSON, D. A.; GORDON, J. I. Ecological and evolutionary forces shaping microbial diversity in the human intestineCell, 2006.

LI, Y. yang; PEARSON, J. A.; CHAO, C.; PENG, J.; ZHANG, X.; ZHOU, Z.; LIU, Y.; WONG, F. S.; WEN, L. Nucleotide-binding oligomerization domain-containing protein 2 (Nod2) modulates T1DM susceptibility by gut microbiota. Journal of Autoimmunity, v. 82, p. 85-95, 2017. Disponível em: <http://dx.doi.org/10.1016/j.jaut.2017.05.007>.

LIKE, A. A.; ROSSINI, A. A. Streptozotocin-induced pancreatic insulitis: new model of diabetes mellitus. Science (New York, N.Y.), v. 193, p. 415-417, 1976.

LISBÔA, H. R.; GRAEBIN, R.; BUTZKE, L.; RODRIGUES, C. S. Incidence of type 1 diabetes mellitus in Passo Fundo, RS, Brazil. Brazilian journal of medical and biological research $=$ Revista brasileira de pesquisas médicas e biológicas / Sociedade Brasileira de Biofísica ... [et al.], v. 31, n. 12, p. 1553-6, 1998. Disponível em: $<$ http://www.ncbi.nlm.nih.gov/pubmed/9951551>.

MAGITTA, N. F.; BØE WOLFF, A. S.; JOHANSSON, S.; SKINNINGSRUD, B.; LIE, B. A.; MYHR, K.-M.; UNDLIEN, D. E.; JONER, G.; NJØLSTAD, P. R.; KVIEN, T. K.; FØRRE, Ø.; KNAPPSKOG, P. M.; HUSEBYE, E. S. A coding polymorphism in NALP1 confers risk for autoimmune Addison's disease and type 1 diabetes. Genes and immunity, v. 10, p. 120-124, 2009.

MAKINO, S.; KUNIMOTO, K.; MURAOKA, Y.; MIZUSHIMA, Y.; KATAGIRI, K.; TOCHINO, Y. Breeding of a non-obese, diabetic strain of mice. Jikken dobutsu. Experimental animals, v. 29, n. 1, p. 1-13, 1980. Disponível em: $<$ http://europepmc.org/abstract/MED/6995140\%5Cnhttp://www.ncbi.nlm.nih.gov/pubme $\mathrm{d} / 6995140>$.

MARLEAU, A. M.; SUMMERS, K. L.; SINGH, B. Differential contributions of APC subsets to $\mathrm{T}$ cell activation in nonobese diabetic mice. Journal of immunology (Baltimore, Md. : 1950), v. 180, n. 8, p. 5235-49, 2008. Disponível em: $<$ http://www.ncbi.nlm.nih.gov/pubmed/18390704>.

MARTIN-OROZCO, N.; CHUNG, Y.; CHANG, S. H.; WANG, Y.-H.; DONG, C. Th17 cells promote pancreatic inflammation but only induce diabetes efficiently in lymphopenic hosts after conversion into Th1 cells. European journal of immunology, v. 39, p. 216-224, 2009.

MARTINON, F.; BURNS, K.; TSCHOPP, J. The inflammasome: a molecular platform triggering activation of inflammatory caspases and processing of proIL-beta. Molecular cell, v. 10, p. 417-426, 2002. 
MASTERS, S. L.; GERLIC, M.; METCALF, D.; PRESTON, S.; PELLEGRINI, M.; DONNELL, J. A. O.; MCARTHUR, K.; BALDWIN, T. M.; CHEVRIER, S.; NOWELL, C. J.; CENGIA, L. H.; HENLEY, K. J.; COLlinge, J. E.; KASTNER, D. L.; FEIGENBAUM, L.; HILTON, D. J.; ALEXANDER, W. S.; KILE, B. T.; CROKER, B. A. Article NLRP1 Inflammasome Activation Induces Pyroptosis of Hematopoietic Progenitor Cells. Immunity, v. 37, n. 6, p. 1009-1023, 2012a. Disponível em: $<$ http://dx.doi.org/10.1016/j.immuni.2012.08.027>.

MASTERS, S. L.; GERLIC, M.; METCALF, D.; PRESTON, S.; PELLEGRINI, M.; O’DONNELL, J. a; MCARTHUR, K.; BALDWIN, T. M.; CHEVRIER, S.; NOWELL, C. J.; CENGIA, L. H.; HENLEY, K. J.; COLLINGE, J. E.; KASTNER, D. L.; FEIGENBAUM, L.; HILTON, D. J.; ALEXANDER, W. S.; KILE, B. T.; CROKER, B. a. NLRP1 inflammasome activation induces pyroptosis of hematopoietic progenitor cells. Immunity, v. 37, p. 1009-23, 2012b. Disponível em: $<$ http://www.ncbi.nlm.nih.gov/pubmed/23219391>.

MATZINGER, P. Tolerance, Danger, and the Extended Family. Annual Review of Immunology, v. 12, n. 1, p. 991-1045, 1994. Disponível em: $<$ http://www.annualreviews.org/doi/10.1146/annurev.iy.12.040194.005015>.

MEDVEI, VC - a. The Greco - Roman period. In: MEDVEI, VC (Ed). The history of clinical endocrinology: a comprehensive account of endocrinology from earliest times to the present day. Nova Iorque: Parthenon Publishing, 1993. p.34, 37.

MEDVEI, VC - b. Mediaeval scene. In: MEDVEI, VC (Ed). The history of clinical endocrinology: a comprehensive account of endocrinology from earliest times to the present day. Nova Iorque: Parthenon Publishing, 1993. p. 46, 49.

MEDVEI, VC - c. The 16th century and the Renaissance. In: MEDVEI, VC (Ed). The history of clinical endocrinology: a comprehensive account of endocrinology from earliest times to the present day. Nova Iorque: Parthenon Publishing, 1993. p. 55- 56.

MEDVEI VC - d. Story o f Insulin. In: MEDVEI, VC (Ed). The history of clinical endocrinology: a comprehensive account of endocrinology from earliest times to the present day. Nova Iorque: Parthenon Publishing, 1993. p.249-251, 253-256.

MEDVEI, VC - e. The birth of endocrinology. In: MEDVEI, VC (Ed). The history of clinical endocrinology: a comprehensive account of endocrinology from earliest times to the present day. Nova Iorque: Parthenon Publishing, 1993. p. 151.

MELANITOU, E.; FAIN, P.; EISENBARTH, G. S. Genetics of type 1A (immune mediated) diabetesJournal of Autoimmunity, 2003. .

MENSAH-BROWN, E. P. K.; SHAHIN, A.; AL-SHAMISI, M.; WEI, X.; LUKIC, M. L. IL23 leads to diabetes induction after subdiabetogenic treatment with multiple low doses of 
streptozotocin. European Journal of Immunology, v. 36, p. 216-223, 2006.

MORGAN, X. C.; TICKLE, T. L.; SOKOL, H.; GEVERS, D.; DEVANEY, K. L.; WARD, D. V; REYES, J. a; SHAH, S. a; LELEIKO, N.; SNAPPER, S. B.; BOUSVAROS, A.; KORZENIK, J.; SANDS, B. E.; XAVIER, R. J.; HUTTENHOWER, C. Dysfunction of the intestinal microbiome in inflammatory bowel disease and treatment. Genome biology, v. 13, n. 9, p. R79, 2012. Disponível em: $<$ http://www.pubmedcentral.nih.gov/articlerender.fcgi?artid=3506950\&tool=pmcentrez\& rendertype $=$ abstract $>$.

MOTTA, V. N.; MARKLE, J. G. M.; GULBAN, O.; MORTIN-TOTH, S.; LIAO, K.-C.; MOGRIDGE, J.; STEWARD, C. A.; DANSKA, J. S. Identification of the Inflammasome Nlrplb as the Candidate Gene Conferring Diabetes Risk at the Idd4.1 Locus in the Nonobese Diabetic Mouse. The Journal of Immunology, p. 1400913+, 2015. Disponível em: <http://dx.doi.org/10.4049/jimmunol.1400913>.

MOWAT, A. M.; AGACE, W. W. Regional specialization within the intestinal immune system. Nat Rev Immunol, v. 14, n. 10, p. 667-685, 2014. Disponível em: $<$ http://www.ncbi.nlm.nih.gov/pubmed/25234148>.

NEEDELL, J. C.; ZIPRIS, D. The Role of the Intestinal Microbiome in Type 1 Diabetes Pathogenesis. Current Diabetes Reports, v. 16, n. 10, p. 89, 2016. Disponível em: $<\mathrm{http}$ //link.springer.com/10.1007/s11892-016-0781-z>.

OILINKI, T.; OTONKOSKI, T.; ILONEN, J.; KNIP, M.; MIETTINEN, P. Prevalence and characteristics of diabetes among Somali children and adolescents living in Helsinki, Finland. Pediatric Diabetes, v. 13, n. 2, p. 176-180, 2012.

PAIK, S. G.; FLEISCHER, N.; SHIN, S. I. Insulin-Dependent Diabetes Mellitus Induced by Subdiabetogenic Doses of Streptozotocin: Obligatory Role of Cell-Mediated Autoimmune Processes. Proceedings of the National Academy of Sciences of the United States of America, v. 77, n. 10, p. 6129-6133, 1980. Disponível em: $<$ http://www.ncbi.nlm.nih.gov/pubmed/6449703>.

PAPASPYROS, NS. The history of diabetes. In: VERLAG, GT. (Ed.). The history of diabetes mellitus. Stuttgart: Thieme, 1964, p. 4.

PALMER, J. P.; HAMPE, C. S.; CHIU, H.; GOEL, A.; BROOKS-WORRELL, B. M. Is latent autoimmune diabetes in adults distinct from type 1 diabetes or just type 1 diabetes at an older age? Diabetes, v. 54, n. SUPPL. 2, 2005.

PARK, H.; LI, Z.; YANG, X. O.; CHANG, S. H.; NURIEVA, R.; WANG, Y. H.; WANG, Y.; HOOD, L.; ZHU, Z.; TIAN, Q.; DONG, C. A distinct lineage of CD4 T cells regulates tissue inflammation by producing interleukin 17. Nature Immunology, v. 6, n. 11, p. 1133-1141, 2005. 
PATTERSON, C. C.; DAHLQUiST, G. G.; GYÜRÜS, E.; GREEN, A.; SOLTÉSZ, G. Incidence trends for childhood type 1 diabetes in Europe during 1989-2003 and predicted new cases 2005-20: a multicentre prospective registration study. Lancet, v. 373, p. $2027-$ 2033, 2009.

PESCOVITZ, M. D.; GREENBAUM, C. J.; KRAUSE-STEINRAUF, H.; BECKER, D. J.; GITELMAN, S. E.; GOLAND, R.; GOTTLIEB, P. A.; MARKS, J. B.; MCGEE, P. F.; MORAN, A. M.; RASKIN, P.; RODRIGUEZ, H.; SCHATZ, D. A.; WHERRETT, D.; WILSON, D. M.; LACHIN, J. M.; SKYLER, J. S. Rituximab, B-Lymphocyte Depletion, and Preservation of Beta-Cell Function. New England Journal of Medicine, v. 361, n. 22, p. 2143-2152, 2009. Disponível em: $<$ http://www.nejm.org/doi/abs/10.1056/NEJMoa0904452>.

PETRICH DE MARQUESINI, L. G.; FU, J.; CONNOR, K. J.; BISHOP, a J.; MCLINTOCK, N. E.; POPE, C.; WONG, F. S.; DAYAN, C. M. IFN-gamma and IL-10 islet-antigenspecific $\mathrm{T}$ cell responses in autoantibody-negative first-degree relatives of patients with type 1 diabetes. Diabetologia, v. 53, n. 7, p. 1451-60, 2010. Disponível em: $<$ http://www.ncbi.nlm.nih.gov/pubmed/20369219>.

POCIOT, F.; AKOLKAR, B.; CONCANNON, P.; ERLICH, H. A.; JULIER, C.; MORAHAN, G.; NIERRAS, C. R.; TODD, J. A.; RICH, S. S.; NERUP, J. Genetics of type 1 diabetes: What's next?Diabetes, 2010. .

POCIOT, F.; LERNMARK, Å. Genetic risk factors for type 1 diabetes. The Lancet, v. 387, n. 10035, p. 2331-2339, 2016. Disponível em: <http://dx.doi.org/10.1016/S01406736(16)30582-7>.

POIROT, L.; BENOIST, C.; MATHIS, D. Natural killer cells distinguish innocuous and destructive forms of pancreatic islet autoimmunity. Proceedings of the National Academy of Sciences of the United States of America, v. 101, n. 21, p. 8102-7, 2004. Disponível em: $<$ http://www.pubmedcentral.nih.gov/articlerender.fcgi?artid=419564\&tool=pmcentrez\&r endertype $=$ abstract $>$.

POLIGONE, B.; WEAVER, D. J.; SEN, P.; BALDWIN, A. S.; TISCH, R. Elevated NF-kappaB activation in nonobese diabetic mouse dendritic cells results in enhanced APC function. Journal of immunology (Baltimore, Md. : 1950), v. 168, n. 1, p. 188-196, 2002.

PONCE, L. V.; CORADO, J.; DÍAZ, N. L.; TAPIA, F. J. Adoptive transfer of dendritic cells modulates immunogenesis and tolerogenesis in a neonatal model of murine cutaneous leishmaniasis. Kinetoplastid Biology and Disease, v. 4, 2005.

PONTILLO, A.; BRANDAO, L.; GUIMARAES, R.; SEGAT, L.; ARAUJO, J.; CROVELLA, S. Two SNPs in NLRP3 Gene Are Involved in the Predisposition to Type-1 Diabetes and Celiac Disease in a Pediatric Population from Northeast Brazil. Autoimmunity, v. 43, n. 8, p. 583-589, 2010. Disponível em: <http://www.ncbi.nlm.nih.gov/pubmed/20370570>.

PORETSKY et al. The Main Events in the History of Diabetes Mellitus. In: PORETSKY, L 
(Ed). Principles of Diabetes Mellitus. Nova Iorque: Springer Science+Business Media, 2004. p.19-37.

RABINOVITCH, A. Immunoregulatory and cytokine imbalances in the pathogenesis of IDDM: Therapeutic intervention by immunostimulation?Diabetes, 1994. .

REED, J. C.; HEROLD, K. C. Thinking bedside at the bench: the NOD mouse model of T1DM. Nature reviews. Endocrinology, p. 1-7, 2015. Disponível em: $<$ http://dx.doi.org/10.1038/nrendo.2014.236>.

REWERS, M.; LUDVIGSSON, J. Environmental risk factors for type 1 diabetes. The Lancet, v. 387, n. 10035, p. 2340-2348, 2016. Disponível em: $<$ http://linkinghub.elsevier.com/retrieve/pii/S0140673616305074>.

SALVESEN, G. S.; WALSH, C. M. Functions of caspase 8: The identified and the mysteriousSeminars in Immunology, 2014. .

SASTALLA, I.; CROWN, D.; MASTERS, S. L.; MCKENZIE, A.; LEPPLA, S. H.; MOAYERI, M. Transcriptional analysis of the three Nlrp1 paralogs in mice. BMC Genomics, v. 14, n. 1, p. 1-10, 2013.

SASTALLA, I.; LEPPLA, S. H.; MOAYERI, M. Anthrax and the inflammasomeMicrobes and Infection, 2012. .

SATOH, J.; SEINO, H.; ABO, T.; TANAKA, S.; SHINTANI, S.; OHTA, S.; TAMURA, K.; SAWAI, T.; NOBUNAGA, T.; OTEKI, T. Recombinant human tumor necrosis factor alpha suppresses autoimmune diabetes in nonobese diabetic mice. The Journal of clinical investigation, v. 84, n. 4, p. 1345-8, 1989. Disponível em: <http://www.jci.org.scihub.io/articles/view/114304>.

SAUMA, D.; CRISÓSTOMO, N.; FUENTES, C.; GLEISNER, M. A.; HIDALGO, Y.; FUENZALIDA, M. J.; ROSEMBLATT, M.; BONO, M. R. Adoptive transfer of autoimmune splenic dendritic cells to lupus-prone mice triggers a B lymphocyte humoral response. Immunologic Research, v. 65, n. 4, p. 957-968, 2017.

SAVINOV, A. Y.; WONG, F. S.; CHERVONSKY, A. V. IFN-gamma affects homing of diabetogenic T cells. Journal of immunology (Baltimore, Md. : 1950), v. 167, n. 11, p. 6637-43, 2001. Disponível em: <http:/www.ncbi.nlm.nih.gov/pubmed/11714835>.

SCHRODER, K.; HERTZOG, P. J.; RAVASI, T.; HUME, D. A. Interferon- y : an overview of signals, mechanisms and functions. Journal of leukocyte Biology, v. 75, n. February, p. 163-189, 2004.

SCHRODER, K.; TSCHOPP, J. The Inflammasomes. Cell, v. 140, n. 6, p. 821-832, 2010. Disponível em: <http://www.ncbi.nlm.nih.gov/pubmed/20303873>.

SCHWABE, R. F.; JOBIN, C. The microbiome and cancer. Nature reviews. Cancer, v. 13, n. 11, p. 800-12, 2013. Disponível em: <http://dx.doi.org/10.1038/nrc3610>. 
SERREZE, D. V; POST, C. M.; CHAPMAN, H. D.; JOHNSON, E. A.; LU, B.; ROTHMAN, P. B. Interferon-gamma receptor signaling is dispensable in the development of autoimmune type 1 diabetes in NOD mice. Diabetes, v. 49, n. 12, p. 2007-11, 2000. Disponível em: <http://www.ncbi.nlm.nih.gov/pubmed/11118001>.

SGOUROUDIS, E.; ALBANESE, A.; PICCIRILLO, C. A. Impact of Protective IL-2 Allelic Variants on CD4+ Foxp3+ Regulatory $\mathrm{T}$ Cell Function in Situ and Resistance to Autoimmune Diabetes in NOD Mice. Journal of Immunology, v. 181, n. 9, p. 6283-6292, 2008. Disponível em: <http://www.ncbi.nlm.nih.gov/pubmed/18941219>.

SHAW, M. H.; REIMER, T.; SÁNCHEZ-VALDEPEÑAS, C.; WARNER, N.; KIM, Y.-G.; FRESNO, M.; NUÑEZ, G. T cell-intrinsic role of Nod2 in promoting type 1 immunity to Toxoplasma gondii. Nature Immunology, v. 10, n. 12, p. 1267-1274, 2009. Disponível em: <http://www.nature.com/doifinder/10.1038/ni.1816>.

SIMS, J. E.; SMITH, D. E. The IL-1 Family: Regulators of Immunity. Nat Rev Immunol, v. 10, n. 2, p. 89-102, 2010. Disponível em: $<$ http://www.ncbi.nlm.nih.gov/pubmed/20081871>.

SMITH, P. M.; HOWITT, M. R.; PANIKOV, N.; MICHAUD, M.; GALLINI, C. A.; BOHLOOLY-Y, M.; GLICKMAN, J. N.; GARRETT, W. S. The Microbial Metabolites, Short-Chain Fatty Acids, Regulate Colonic Treg Cell Homeostasis. Science, v. 341, n. 6145, p. 569-573, 2013. Disponível em: $<$ http://www.sciencemag.org/cgi/doi/10.1126/science.1241165>.

SOARES, J. L. S.; FERNANDES, F. P.; PATENTE, T. A.; MONTEIRO, M. B.; PARISI, M. C.; GIANNELLA-NETO, D.; CORRÊA-GIANNELLA, M. L.; PONTILLO, A. Gain-offunction variants in NLRP1 protect against the development of diabetic kidney disease: NLRP1 inflammasome role in metabolic stress sensing? Clinical Immunology, 2017.

SÖDERSTRÖM, U.; AMAN, J.; HJERN, A. Being born in Sweden increases the risk for type 1 diabetes - a study of migration of children to Sweden as a natural experiment. Acta paediatrica (Oslo, Norway: 1992), v. 101, n. 1, p. 73-7, 2012. Disponível em: $<$ http://www.ncbi.nlm.nih.gov/pubmed/21767306>.

SORINI, C.; FALCONE, M. Shaping the (Auto)immune Response in the Gut: The Role of Intestinal Immune Regulation in the Prevention of Type 1 Diabetes. Am J Clin Exp Immunol, v. 2, n. 2, p. 156-171, 2013. Disponível em: $<$ http://www.ncbi.nlm.nih.gov/pubmed/23885333>.

STEINMAN, L. A brief history of TH17, the first major revision in the T H1/TH2 hypothesis of T cell-mediated tissue damageNature Medicine, 2007. .

STENE, L. C.; OIKARINEN, S.; HYÖTY, H.; BARRIGA, K. J.; NORRIS, J. M.; KLINGENSMITH, G.; HUTTON, J. C.; ERLICH, H. A.; EISENBARTH, G. S.; REWERS, M. Enterovirus infection and progression from islet autoimmunity to type 1 diabetes: The Diabetes and Autoimmunity Study in the Young (DAISY). Diabetes, v. 59, n. 12, p. 3174-3180, 2010. 
STENE, L. C.; REWERS, M. Immunology in the clinic review series; focus on type 1 diabetes and viruses: The enterovirus link to type 1 diabetes: Critical review of human studiesClinical and Experimental Immunology, 2012. .

STEPTOE, R. J.; RITCHIE, J. M.; HARRISON, L. C. Increased generation of dendritic cells from myeloid progenitors in autoimmune-prone nonobese diabetic mice. Journal of immunology (Baltimore, Md. : 1950), v. 168, n. 10, p. 5032-41, 2002. Disponível em: $<$ http://www.ncbi.nlm.nih.gov/pubmed/11994455>.

TANG, L.; WANG, L.; LIAO, Q.; WANG, Q.; XU, L.; BU, S.; HUANG, Y.; ZHANG, C.; YE, H.; XU, X.; LIU, Q.; YE, M.; MAI, Y.; DUAN, S. Genetic associations with diabetes: meta-analyses of 10 candidate polymorphisms. PloS one, v. 8, p. e70301, 2013. Disponível em:

$<$ http://www.pubmedcentral.nih.gov/articlerender.fcgi?artid=3726433\&tool=pmcentrez\& rendertype $=$ abstract $>$.

TRACY, S.; DRESCHER, K. M.; CHAPMAN, N. M. Enteroviruses and type 1 diabetes. Diabetes/Metabolism Research and Reviews, v. 27, n. 8, p. 820-823, 2011.

TURLEY, S.; POIROT, L.; HATTORI, M.; BENOIST, C.; MATHIS, D. Physiological beta cell death triggers priming of self-reactive $\mathrm{T}$ cells by dendritic cells in a type-1 diabetes model. The Journal of experimental medicine, v. 198, n. 10, p. 1527-37, 2003. Disponível em: $<$ http://www.jem.org/lookup/doi/10.1084/jem.20030966\%5Cnhttp://www.ncbi.nlm.nih.g ov/pubmed/14623908\%5Cnhttp://www.pubmedcentral.nih.gov/articlerender.fcgi?artid=P MC2194112\%5Cnhttp://www.ncbi.nlm.nih.gov/pubmed/14623908\%5Cnhttp://www.pub medcentral.nih.gov/ar>.

TURNBAUGH, P. J.; BÄCKHED, F.; FULTON, L.; GORDON, J. I. Diet-Induced Obesity Is Linked to Marked but Reversible Alterations in the Mouse Distal Gut Microbiome. Cell Host and Microbe, v. 3, n. 4, p. 213-223, 2008.

TURNBAUGH, P. J.; LEY, R. E.; MAHOWALD, M. a; MAGRINI, V.; MARDIS, E. R.; GORDON, J. I. An obesity-associated gut microbiome with increased capacity for energy harvest. Nature, v. 444, n. 7122, p. 1027-31, 2006. Disponível em: $<$ http://www.ncbi.nlm.nih.gov/pubmed/17183312>.

UNO, S.; IMAGAWA, a; OKITA, K.; SAYAMA, K.; MORIWAKI, M.; IWAHASHI, H.; YAMAGATA, K.; TAMURA, S.; MATSUZAWA, Y.; HANAFUSA, T.; MIYAGAWA, J.; SHIMOMURA, I. Macrophages and dendritic cells infiltrating islets with or without beta cells produce tumour necrosis factor-alpha in patients with recent-onset type 1 diabetes. Diabetologia, v. 50, n. 3, p. 596-601, 2007. Disponível em: $<$ http://www.ncbi.nlm.nih.gov/pubmed/17221211>.

VAARALA, O. Leaking gut in type 1 diabetes. Current opinion in gastroenterology, v. 24, n. 6, p. 701-6, 2008. Disponível em: <http://www.ncbi.nlm.nih.gov/pubmed/19122519>.

VAARALA, O.; ATKINSON, M. A.; NEU, J. The "perfect storm" for type 1 diabetes: the 
complex interplay between intestinal microbiota, gut permeability, and mucosal immunity. Diabetes, v. 57, p. 2555-2562, 2008.

VANAJA, S. K.; RATHINAM, V. A. K.; FITZGERALD, K. A. Mechanisms of inflammasome activation: Recent advances and novel insightsTrends in Cell Biology, 2015. .

VAN OPDENBOSCH, N.; GURUNG, P.; VANDE WALLE, L.; FOSSOUL, A.; KANNEGANTI, T.-D.; LAMKANFI, M. Activation of the NLRP1b inflammasome independently of ASC-mediated caspase-1 autoproteolysis and speck formation. Nature communications, v. 5, p. 3209, jan. 2014. Disponível em: $<$ http://www.pubmedcentral.nih.gov/articlerender.fcgi?artid=3926011\&tool=pmcentrez\& rendertype $=$ abstract $>$. Acesso em: 14 ago. 2014.

VENTURA-SOBREVILLA, J.; BOONE-VILLA, V. D.; AGUILAR, C. N.; ROMÁNRAMOS, R.; VEGA-AVILA, E.; CAMPOS-SEPÚLVEDA, E.; ALARCÓN-AGUILAR, F. Effect of varying dose and administration of streptozotocin on blood sugar in male CD1 mice. Proceedings of the Western Pharmacology Society, v. 54, p. 5-9, 2011. Disponível em: <http:/www.ncbi.nlm.nih.gov/pubmed/22423571>.

VIJAY-KUMAR, M.; AITKEN, J. D.; CARVALHO, F. A.; CULLENDER, T. C.; MWANGI, S.; SRINIVASAN, S.; SITARAMAN, S. V; KNIGHT, R.; LEY, R. E.; GEWIRTZ, A. T. Metabolic Syndrome and Altered Gut Microbiota in Mice Lacking Toll-Like Receptor 5. Science, v. 328, n. 5975, p. 228-231, 2010. Disponível em: $<$ http://www.sciencemag.org/cgi/content/abstract/328/5975/228>.

VON HERRATH, M. G.; OLDSTONE, M. B. Interferon-gamma is essential for destruction of beta cells and development of insulin-dependent diabetes mellitus. The Journal of experimental medicine, v. 185, n. 3, p. 531-9, 1997. Disponível em: $<$ http://www.pubmedcentral.nih.gov/articlerender.fcgi?artid=2196037\&tool=pmcentrez\& rendertype $=$ abstract $>$.

WALKER, L. S. K. CD4 T cell differentiation in type 1 diabetes. v. 1, p. 16-29, 2015.

WANG, B.; ANDRÉ, I.; GONZALEZ, A.; KATZ, J. D.; AGUET, M.; BENOIST, C.; MATHIS, D. Interferon-gamma impacts at multiple points during the progression of autoimmune diabetes. Proceedings of the National Academy of Sciences of the United States of America, v. 94, n. 25, p. 13844-9, 1997. Disponível em: $<$ http://www.pubmedcentral.nih.gov/articlerender.fcgi?artid=28395\&tool=pmcentrez\&re ndertype $=$ abstract $>$.

WEN, H.; MIAO, E. a; TING, J. P.-Y. Mechanisms of NOD-like receptor-associated inflammasome activation. Immunity, v. 39, n. 3, p. 432-41, 19 set. 2013. Disponível em: $<$ http://www.ncbi.nlm.nih.gov/pubmed/24054327>. Acesso em: 4 nov. 2013.

WICKER, L. S.; MILLER, B. J.; MULLEN, Y. Transfer of autoimmune diabetes mellitus with splenocytes from nonobese diabetic (NOD) mice. Diabetes, v. 35, n. 8, p. 855-860, 1986. 
WILLIAMS, T. M.; LEETH, R. A.; ROTHSCHILD, D. E.; COUTERMARSH-OTT, S. L.; MCDANIEL, D. K.; SIMMONS, A. E.; HEID, B.; CECERE, T. E.; ALLEN, I. C. The NLRP1 Inflammasome Attenuates Colitis and Colitis-Associated Tumorigenesis. The Journal of Immunology, v. 194, n. 7, p. 3369-3380, 2015. Disponível em: $<$ http://www.jimmunol.org/lookup/doi/10.4049/jimmunol.1402098>.

WLODARSKA, M.; THAISS, C. a; NOWARSKI, R.; HENAO-MEJIA, J.; ZHANG, J.-P.; BROWN, E. M.; FRANKEL, G.; LEVY, M.; KATZ, M. N.; PHILBRICK, W. M.; ELINAV, E.; FINLAY, B. B.; FLAVELL, R. a. NLRP6 Inflammasome Orchestrates the Colonic Host-Microbial Interface by Regulating Goblet Cell Mucus Secretion. Cell, v. 156, n. 5, p. 1045-59, 27 fev. 2014. Disponível em: $<$ http://www.ncbi.nlm.nih.gov/pubmed/24581500>. Acesso em: 19 mar. 2014.

WU, G. D.; CHEN, J.; HOFFMANN, C.; BITTINGER, K.; CHEN, Y.-Y.; KEILBAUGH, S. A.; BEWTRA, M.; KNIGHTS, D.; WALTERS, W. A.; KNIGHT, R.; SINHA, R.; GILROY, E.; GUPTA, K.; BALDASSANO, R.; NESSEL, L.; LI, H.; BUSHMAN, F. D.; LEWIS, J. D. Linking long-term dietary patterns with gut microbial enterotypes. Science (New York, N.Y.), v. 334, n. 6052, p. 105-8, 2011. Disponível em: $<$ http://www.pubmedcentral.nih.gov/articlerender.fcgi?artid=3368382\& tool=pmcentrez\& rendertype $=$ abstract $>$.

YAOCHITE, J. N. U.; CALIARI-OLIVEIRA, C.; DAVANSO, M. R.; CARLOS, D.; RIBEIRO MALMEGRIM, K. C.; RIBEIRO DE BARROS CARDOSO, C.; RAMALHO, L. N. Z.; PALMA, P. V. B.; SANTANA DA SILVA, J.; CUNHA, F. Q.; COVAS, D. T.; VOLTARELLI, J. C. Dynamic changes of the Th17/Tc17 and regulatory T cell populations interfere in the experimental autoimmune diabetes pathogenesis. Immunobiology, 2012. Disponível em: <http://www.sciencedirect.com/science/article/pii/S0171298512001131>.

YI, Z.; LI, L.; GARLAND, A.; HE, Q.; WANG, H.; KATZ, J. D.; TISCH, R.; WANG, B. IFN$\gamma$ receptor deficiency prevents diabetes induction by diabetogenic $\mathrm{CD} 4+$, but not $\mathrm{CD} 8+, \mathrm{T}$ cells. European Journal of Immunology, v. 42, n. 8, p. 2010-2018, 2012.

YOON, J. W.; AUSTIN, M.; ONODERA, T.; NOTKINS, a L. Isolation of a virus from the pancreas of a child with diabetic ketoacidosis. The New England journal of medicine, $v$. 300, n. 21, p. 1173-9, 1979 . Disponível em: $<$ http://www.ncbi.nlm.nih.gov/pubmed/219345>.

ZIEGLER, A. G.; REWERS, M.; SIMELL, O.; SIMELL, T.; LEMPAINEN, J.; STECK, A.; WINKLER, C.; ILONEN, J.; VEIJOLA, R.; KNIP, M.; BONIFACIO, E.; EISENBARTH, G. S. Seroconversion to multiple islet autoantibodies and risk of progression to diabetes in children. Jama, v. 309, n. 23, p. 2473-9, 2013. Disponível em: $<$ http://www.ncbi.nlm.nih.gov/pubmed/23780460>.

ZIEGLER, R.; ALPER, C. A.; AWDEH, Z. L.; CASTANO, L.; BRINK, S. J.; SOELDNER, J. S.; JACKSON, R. A.; EISENBARTH, G. S. Specific association of HLA-DR4 with increased prevalence and level of insulin autoantibodies in first-degree relatives of patients with type I diabetes. Diabetes, v. 40, n. 6, p. 709-714, 1991. 
Anexos 
ANEXO I - ARTIGO PUBLICADO DURANTE O DOUTORADO. A data de início do doutorado foi dia 28 de fevereiro de 2014. Durante o período de fevereiro de 2014 a maio de 2016 (data do aceite), trabalhei exclusivamente na publicação do artigo (capa em anexo), sendo os resultados apresentados na presente tese oriundos do período de maio de 2016 a fevereiro de 2018. 


\title{
Gut microbiota translocation to the pancreatic lymph nodes triggers NOD2 activation and contributes to T1D onset
}

\author{
Frederico R.C. Costa, ${ }^{1}$ Marcela C.S. Françozo, ${ }^{1}$ Gabriela G. de Oliveira, ${ }^{1}$ Aline Ignacio, ${ }^{4}$ \\ Angela Castoldi, ${ }^{4}$ Dario S. Zamboni, ${ }^{2}$ Simone G. Ramos, ${ }^{3}$ Niels O. Câmara, ${ }^{4}$ Marcel R. de Zoete, ${ }^{5,6,7}$ \\ Noah W. Palm, ${ }^{5}$ Richard A. Flavell, ${ }^{5,6}$ João S. Silva, ${ }^{1}$ and Daniela Carlos ${ }^{1}$ \\ ${ }^{1}$ Department of Biochemistry and Immunology, ${ }^{2}$ Department of Molecular and Cell Biology, and ${ }^{3}$ Department of Pathology, Ribeirão Preto Medical School, \\ University of São Paulo, 14049-900 Ribeirão Preto, São Paulo, Brazil \\ ${ }^{4}$ Department of Immunology, Institute of Biomedical Science (ICB), University of São Paulo, 05508-000 São Paulo, Brazil \\ ${ }^{5}$ Department of Immunobiology, Yale University School of Medicine, The Anlyan Center, New Haven, CT 06519 \\ ${ }^{6}$ Howard Hughes Medical Institute, Yale University, New Haven, CT 06510 \\ ${ }^{7}$ Department of Infectious Diseases and Immunology, Utrecht University, 3584 CL Utrecht, the Netherlands
}

Type 1 diabetes (T1D) is an autoimmune disease that is triggered by both genetic and environmental factors, resulting in the destruction of pancreatic $\beta$ cells. The disruption of the intestinal epithelial barrier and consequent escape of microbial products may be one of these environmental triggers. However, the immune receptors that are activated in this context remain elusive. We show here that during streptozotocin (STZ)-induced T1D, the nucleotide-binding oligomerization domain containing 2 (NOD2), but not NOD1, participates in the pathogenesis of the disease by inducing T helper 1 (Th1) and Th17 cells in the pancreatic LNs (PLNs) and pancreas. Additionally, STZ-injected wild-type (WT) diabetic mice displayed an altered gut microbiota compared with vehicle-injected WT mice, together with the translocation of bacteria to the PLNs. Interestingly, WT mice treated with broad-spectrum antibiotics (Abx) were fully protected from STZ-induced T1D, which correlated with the abrogation of bacterial translocation to the PLNs. Notably, when Abx-treated STZ-injected WT mice received the NOD2 ligand muramyl dipeptide, both hyperglycemia and the proinflammatory immune response were restored. Our results demonstrate that the recognition of bacterial products by NOD2 inside the PLNs contributes to T1D development, establishing a new putative target for intervention during the early stages of the disease.

Type 1 diabetes (T1D) is an autoimmune disease that is triggered when immunological tolerance to self-tissues fails, resulting in the autoimmune destruction of pancreatic $\beta$ cells in genetically predisposed individuals. Although genetic factors play a role in susceptibility to T1D, it is possible that the increase in its prevalence is also a result of environmental factors (Gillespie et al., 2004). In this context, many experimental models have been used to study T1D, such as nonobese diabetic (NOD) mice and biobreeding rats, in which the disease develops spontaneously, and mouse models induced by chemicals, such as streptozotocin (STZ), cyclophosphamide, and alloxan (Rees and Alcolado, 2005; Yaochite et al., 2013).

Although the NOD mouse is the most widely used model to study T1D, it has some limitations that must be considered when translating its results to clinical studies. In comparison to human islets, for example, NOD mice exhibit much stronger insulitis as shown by histopathology, which,

Correspondence to Daniela Carlos: danicar@usp.br

Abbreviations used: Abx, antibiotics; GT, glucose tolerance test; ITT, insulin tolerance test; MDP, muramyl dipeptide; MLN, mesenteric LN; NLR, nucleotide-binding domain and leucine-rich repeat containing receptor; NOD, non-obese diabetic mouse; NOD2, nucleotide-binding oligomerization domain containing 2: NOR, nonobese resistant mouse; PLN, pancreatic LN; STZ, streptozotocin; T1D, type 1 diabetes; Th, T helper; T reg, regulatory T.

The Rockefeller University Press $\$ 30.00$ according to van Belle et al. (2011), is like looking at two different diseases. These differences could help explain why some successful treatments in the NOD mouse model failed to show the same efficacy when used in humans (Gitelman et al., 2013; Moran et al., 2013; Reed and Herold, 2015). Therefore, studying other mouse models of the disease should also be considered, especially because other rodent models have several features, such as phenotype and islet cellular infiltrates, which more closely mimic human disease than the NOD mouse (Reed and Herold, 2015). In this regard, the STZ model appears to be an interesting alternative because, in addition to resembling the disease in humans in various aspects (Like and Rossini, 1976; Leiter, 1982), it also represents an immune-mediated mouse model of the disease. In this context, it was shown that the transfer of splenocytes from STZ-injected mice causes insulin resistance and diabetes upon adoptive transfer (Paik et al., 1980; Arata et al., 2001). Accordingly, it has also been shown that athymic nude $(\mathrm{nu} / \mathrm{nu})$ mice are resistant to STZ-induced diabetes compared with euthymic $(+/ n u)$ mice (Paik et al., 1980).

2016 Costa et al. This article is distributed under the terms of an Attribution-Noncommercial-Shar Alike-No Mirror Sites license for the first six months after the publication date (see http://www.rupress.or Iterms). After six months it is available under a Creative Commons License (Attribution-Noncommercial- 
ANEXO II - REPERCUSSÃO DO ARTIGO NO CENÁRIO NACIONAL E INTERNACIONAL. Anualmente, são despendidos milhões de reais em educação, ciência, tecnologia e inovação. Portanto, é de suma importância darmos um retorno à sociedade, justificando tamanho investimento. Neste sentido, a publicação de entrevistas em revistas para leigos tem função muito importante, diminuindo a distância entre cientistas e a sociedade. Ademais, elas contribuem para um melhor entendimento da população acerca da importância de se investir em ciência, e em como esses investimentos refletem diretamente na qualidade dos trabalhos publicados pela ciência brasileira. Dessa forma, segue em anexo a capa das reportagens, bem como o link para o acesso ao conteúdo completo. 


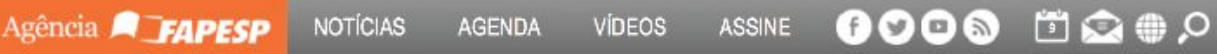

\section{ULTTIMAS NOTICIAS}

\begin{tabular}{l|l|l|l|}
\hline $\begin{array}{l}\text { Parque Tecnológico CT- } \\
\text { Tec abre espaço para } \\
\text { pequenas empresas } \\
\text { as de fevereiro de } 2018\end{array}$ & $\begin{array}{l}\text { Livro investiga rumos do } \\
\text { teatro político paulistano } \\
\text { contemporâneo } \\
07 \text { de fevereiro de } 2018\end{array}$ & $\begin{array}{l}\text { Crise na ciência não se } \\
\text { deve apenas à falta de } \\
\text { recursos, avaliam } \\
\text { clentistas } \\
\text { of de fevereiro de } 2018\end{array}$ & $\begin{array}{l}\text { FAPESP e CSTC (Irã) } \\
\text { abrem nova chamada de } \\
\text { propostas } \\
07 \text { de fevereiro de 2018 }\end{array}$ \\
\hline
\end{tabular}

\section{Bactérias do intestino podem}

ser gatilho para o diabetes tipo 1 20 de julho de 2016

\section{$\oplus 000$} Karina Toledo | Agência FAPESP Estudos recentes têm mostrado que portadores de diabetes

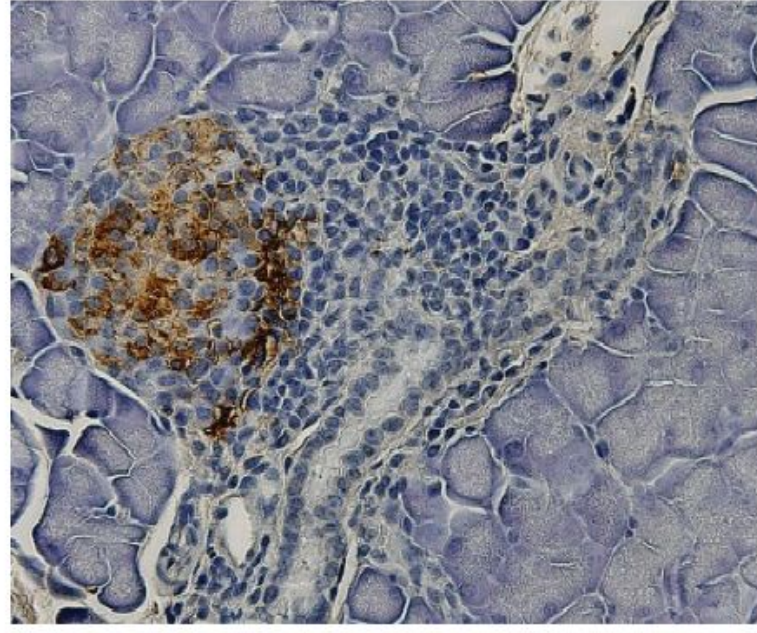

Ilhota pancreática com reduzida marcação de insulina do grupo de roedores tratados com STZ, antibiótico e MDP, mostrando o processo de destruição contra as células beta produtoras de insulina (Imagem: Divulgação)

frequentemente

apresentam um desequilíbrio entre as bactérias benéficas e as patogênicas que compõem a microbiota intestinal - condição conhecida como disbiose, potencialmente maléfica ao organismo. Não está claro, contudo, se isso é uma das causas ou uma consequência dessa doença metabólica.

Novas evidências publicadas por pesquisadores brasileiros no Journal of Experimental Medicine sugerem que, quando bactérias intestinais conseguem escapar para os gânglios linfáticos localizados próximos ao pâncreas - devido a alterações de permeabilidade da parede do intestino causadas pelo processo de disbiose -, elas podem ativar certos receptores existentes em células do sistema imune inato (primeira linha de defesa do organismo), particularmente nos

Link:http://agencia.fapesp.br/bacterias_do_intestino_podem_ser_gatilho_para_o_diabetes_tipo_1/23601/ (acessado em: 09/02/2018) 


\title{
Jornal da USP
}

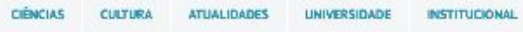

$*$

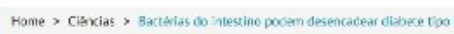

Ciências $-08 / 07 / 2016$

\section{Bactérias do intestino podem desencadear diabete tipo 1}

Descobertas inéditas foram publicadas na revista "The Journal of Experimental

Medicine $^{n}$ e podem abrir caminhos para tratamentos da doença

Por Redaçâo - Editorias: Ciências, Ciências Biológicas

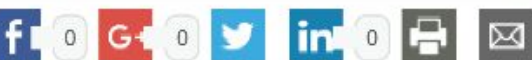

Cientistas do Laboratório de Imunoparasitologia da Faculdade de Medicina de Ribeirāo Preto (FMRP) da USP desvendam mecanismo capaz de dar início ao diabete tipo 1, doença autoimune que impede o pâncreas de produzir insulina e responde por $10 \%$ de todos os casos de diabete.

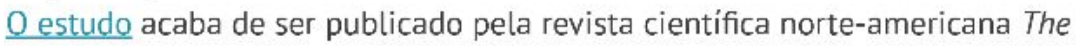
Journal of Experimental Medicine. Os pesquisadores brasileiros verificaram que bactérias são capazes de extravasar a parede do intestino e chegar ao pâncreas, contribuindo com o desencadeamento da doença.

Segundo Frederico Ribeiro Campos Costa, integrante da equipe e primeiro autor do estudo, pesquisas recentes têm relacionado a microbiota intestinal (popularmente conhecida como flora intestinal) com o diabete tipo 1 e revelam composição diferente de bactérias no intestino de pessoas predispostas a essa doença. No entanto, uma pergunta intrigava a comunidade científica: como uma bactéria que está no nosso intestino pode levar à destruição de uma célula que está no pâncreas? Instigados pelo enigma, Costa, com seu grupo de pesquisa, se puseram a investigar.

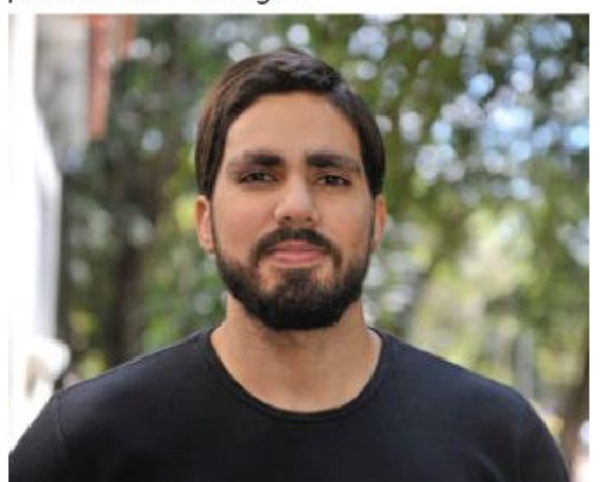

O diabete tipo 1 é uma doença autoimune que se caracteriza pelo

\section{Link: http://jornal.usp.br/ciencias/bacterias-do-intestino-podem-desencadear-diabe- tes-tipo-1/ \\ (acessado em: 09/02/2018)}




\section{Estudo da USP aponta que bactérias do intestino provocam diabetes tipo 1}

Micro-organismos se deslocam para o pâncreas e causam inflamação local. Ainda em fase de testes em animais, pesquisa busca prevenção da doença.

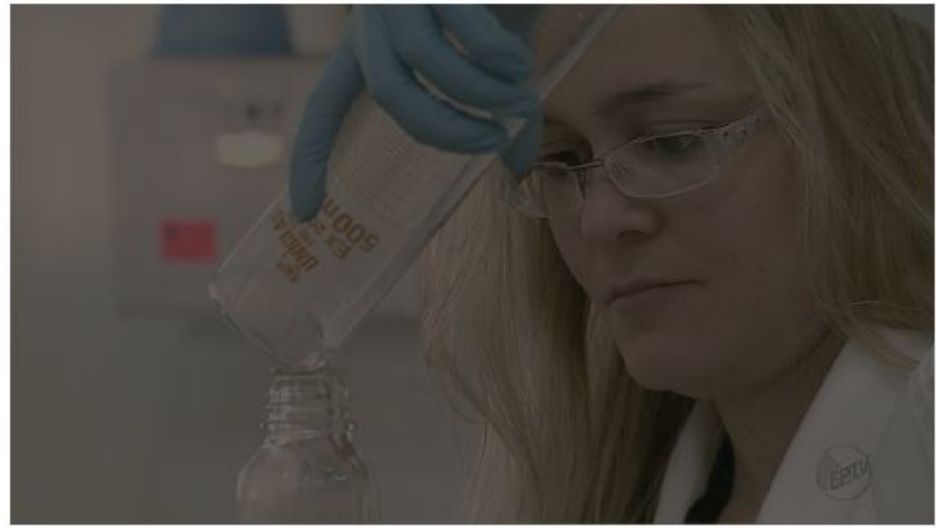

Pesquisadores da Faculdade $\mathrm{d}$ Medicina da USP em Ribeirão Preto (SP) descobriram que bactérias da flora intestinal podem ser responsáveis pelo desenvolvimento do diabetes ti $1 \mathrm{em}$ pessoas com predisposição à doença.

Ainda em fase de testes em animais, o estudo leva esperança aos pacientes, uma vez que a doença autoimune $n$ tem cura e o único tratamento disponível é o uso diário de insulina, hormônio responsável pelo controle de açúcar no sangue.

O pesquisador Frederico Campos Costa explica estudos anteriores já haviam identificado que pessoas com predisposição genética para diabetes possuem a flora intestinal alterada. Entretanto, ainda não havia sido comprovada a relação entre essa alteração e a doença.

Costa diz que o ser humano tem entre 30 e 40 trilhões de bactérias no organismo, sendo a maioria no intestino. Ocorre que nesses individuos, algumas delas conseguem escapar da barreira intestinc e se instalam nos linfonodos pancreáticos, estrutura ao redor do pâncreas.

"Ali, elas vão ser reconhecidas pelo sistema de defesa e isso vai gerar uma inflamação local. Então nosso grupo acredita que essa inflamação possa contribuir para o desenvolvimento da doença em indivíduos que possuem pré-disposição genética para o diabetes", diz.

Link:http://g1.globo.com/sp/ribeirao-preto-franca/noticia/2016/07/estudo-da-uspaponta-que-bacterias-do-intestino-provocam-diabetes-tipo-1.html

(acessado em: 09/02/2018) 


\section{Inflammation memory}

Contact sensitizers elicit a population of natural killer (NK) cells with memory-like functions that reside in the liver. In Immunity, Hornung and colleagues use a model of contact hypersensitivity to show that the establishment of NK cell memory is dependent on the NLRP3 inflammasome. The application of monobenzone onto the skin drives an NK cell-mediated cytotoxic immune response to melanocytes. The hapten-induced NK cells reside in the liver and can transfer long-term monobenzene-specific responses to naive mice. Monobenzone induces the infiltration of macrophages into the skin as well as the recruitment of macrophages with a tissue-resident phenotype to the lymph nodes, and the infiltration of macrophages and NK cells into the skin is dependent on NLRP3 and interleukin 18. Activation of inflammasomes in tissue-resident macrophages is required for both the priming phase and the recall phase of monobenzone-induced memory NK cell responses.

Immunity (7 June 2016) doi:10.1016/j.immuni.2016.05.008

\section{Mind over tumor}

Environmental stress can influence anti-tumor immune responses. n Cancer Immunology Research, Xiao et al. identify a positive role for the neuropeptide BDNF in eliciting enhanced cytotoxic CD8 ${ }^{+} \mathrm{T}$ cell directed against melanoma tumors. Mice living in socially stimulating environments express more BDNF. Both the sympathetic nervous system and the hypothalamic-pituitary-adrenal axis contribute to the effects mediated by BDNF. Enhanced hypothalamic expression of BDNF increases the frequency of anti-tumor $\mathrm{CD}^{+} \mathrm{T}$ cells in lymph nodes and diminishes the tumor burden, whereas suppression of BDNF expression produces the opposite effect. These findings indicate a role for neuralimmunological communication that can lead to better control of tumor progression.

Cancer Immunol. Res. 4, 488-497 (2016)

\section{Dengue suppresses MAVS}

Viral infection triggers the production of interferons; however, dengue virus can suppress this antiviral response. In the Journal of Virology, He et al. show that the dengue virus non-structural protein NS4a subverts induction of the production of type I interferons by interfering with the RIG-I-MAVS activation pathway. The recognition of viral RNA by the RNA helicase RIG-I triggers interactions between the caspase-recruitment domains of RIG-I and those of the signaling adaptor MAVS that lead to activation of kinase TBK 1 and the expression of genes encoding antiviral products, including Ifnb, mediated by the transcription factor IRF3. NS4a potently disrupts this interaction by binding to the MAVS caspase-recruitment and carboxyl-terminal domains and thereby prevents Ifnb expression. NS4a localizes to the mitochondrial membrane, and the transmembrane domain 3 can mediate inhibition of MAVS. These findings suggest targeting NS4a or its ability to interact with MAVS might enhance innate antiviral responses to dengue.

J. Virol. (1 Jun 2016) doi:10.1128/JVI.00221-16

\section{The protective crypt}

Intestinal epithelial stem cells reside at the base of intestinal crypts. In Cell, Kaiko et al. identify the microbial metabolite butyrate as an inhibitor of intestinal stem-cell proliferation. Butyrate is a product of bacterial fermentation of dietary fiber. At concentrations found in the mouse colon (1-5 mM), butyrate suppresses epithelial-cell proliferation in vitro and in the crypt-less zebrafish colon or after injuryinduced exposure of stem cells in the mouse colon. This inhibitory effect is reversed by culture with differentiated colon epithelial cells, which metabolize butyrate as an energy source. Mice that lack the enzyme that converts butyrate to acetyl-CoA have less proliferation of colonic epithelial cells. Butyrate inhibits histone-deacetylase activity, induces alterations to gene expression and increases binding of the transcription factor Foxo3 to the promoters of the genes encoding the cell-cycle regulators Cdkn1a, Cdk1c and Gadd45b in intestinal stem cells. In vivo, Foxo inhibitors 'rescue' the effect of butyrate on epithelial-cell proliferation.

Cell (2 June 2016) doi:10.1016/j.cell.2016.05.018

\section{Prospecting TCRs for immunotherapy}

The elimination of tumors through vaccination or the adoptive transfer of tumor-specific T cells is an attractive option but is technically challenging because of difficulties in raising robust and appropriate immune responses. In Science, Schumacher and colleagues study patients with melanoma and find that their endogenous anti-tumor responses are poor, most probably due to immunoediting. Therefore, the authors turn to healthy donors as a potential source of reactivity of the T cell antigen receptor to melanoma neoantigens. An HLA-binding screen of potential melanoma neopeptides reveals a much greate number of healthy donor $\mathrm{T}$ cells that recognize melanoma. Many of these donor-derived T cell antigen receptors can be successfully introduced into recipient $T$ cells, which can result in specific recognition of tumor neoantigens. These findings reveal that donors can act as a rich source of neoantigen reactivity, and this could inform their use in adoptive cancer immunotherapy.

Science 352, 1337-1341 (2016)

\section{A Nod to type 1 diabetes}

Type 1 diabetes (T1D) is triggered by both genetic factors and environmental factors, and among the latter, the gut microbiota seems to be important. In the Journal of Experimental Medicine, Carlos and colleagues use a streptozotocin-induced model of T1D to investigate the importance of the gut microbiota. Treatment with streptozotocin leads to the translocation of bacteria to pancreatic lymph nodes and results in the production of inflammatory cytokines by macrophages and dendritic cells. Critically, the induction of these cytokines depends on expression of the intracellular bacterial sensor Nod2. Accordingly, treatment with broad-spectrum antibiotics or Nod2 deficiency in mice results in relative protection from T1D. These data reveal a mechanism by which breakdown of the gut barrier can initiate a cascade that leads to the manifestation of T1D.

J. Exp. Med. (20 June 2016) doi:10.1084/jem.20150744

Link: https://www.nature.com/articles/ni.3530 (acessado em: 09/02/2018) 
ANEXO III - CERTIFICADO DO COMITÊ DE ÉTICA EM EXPERIMENTAÇÃO ANIMAL. 
Certificamos que o Protocolo para Uso de Animais em Experimentação $\mathbf{n}^{0} 139 / 2012$, sobre o projeto intitulado "Papel dos receptores NLRs nos mecanismos de imunoregulação do diabetes do tipo 1 e 2: identificação de novos alvos terapêuticos.", sob a responsabilidade do Professor Doutor João Santana da Silva está de acordo com os Princípios Éticos em Experimentação Animal adotado pelo Conselho Nacional de Controle de Experimentação Animal (CONCEA) e foi APROVADO em reunião de 26 de novembro de 2012.

We certify that the protocol $\mathrm{n}^{\circ} 139 / 2012$, entitled "Papel of $N$ LRs receptors in the immunoregulation mechanisms in type 1 and 2 diabetes: identification of new therapeutic targets", is in accordance with the Ethical Principles in Animal Research adopted by the National Council for the Control of Animal Experimentation (CONCEA) and was approved by the Local Animal Ethical Committee from the School of Medicine of Ribeirão Preto of the University of São Paulo in 11/26/2012.

Ribeirão Preto, 26 de novembro de 2012.

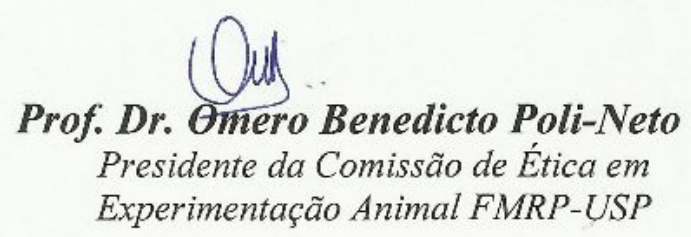




\section{ANEXO IV - GERAÇÃO DE CAMUNDONGOS NOD.NLRP1A ${ }^{-/-}$E NOD.NLRP1B-}

/- PELA TÉCNICA DE CRISPR/CAS9. A figura a seguir demonstra a geração de sgRNAs que serão utilizados para a geração dos animais deficientes para NLRP1a e NLRP1b no background do NOD. Em A é mostrado o plasmídeo px330, amplamente utilizado para a clonagem de sgRNAs. Apresenta como principais características um local de inserção para o sgRNA (sgRNA scaffold), enzima Cas9, que é responsável pela clivagem do DNA alvo, além do gene de resistência para ampicilina, facilitando a seleção de colônias onde a transformação bacteriana ocorreu com êxito. Em B é apresentado o resultado do sequenciamento do DNA da clonagem, demonstrando que o sgRNA foi devidamente clonado no plasmídeo, sem qualquer mutação. Posteriormente, foi realizado o ensaio de transcrição in vitro para a geração do sgRNA puro, que será inoculado juntamente à Cas 9 em embriões de fêmeas NOD grávidas, a fim de se gerar as linhagens de interesse. Acreditamos que até o segundo semestre de 2018 teremos as linhagens prontas para a realização dos experimentos. 
A

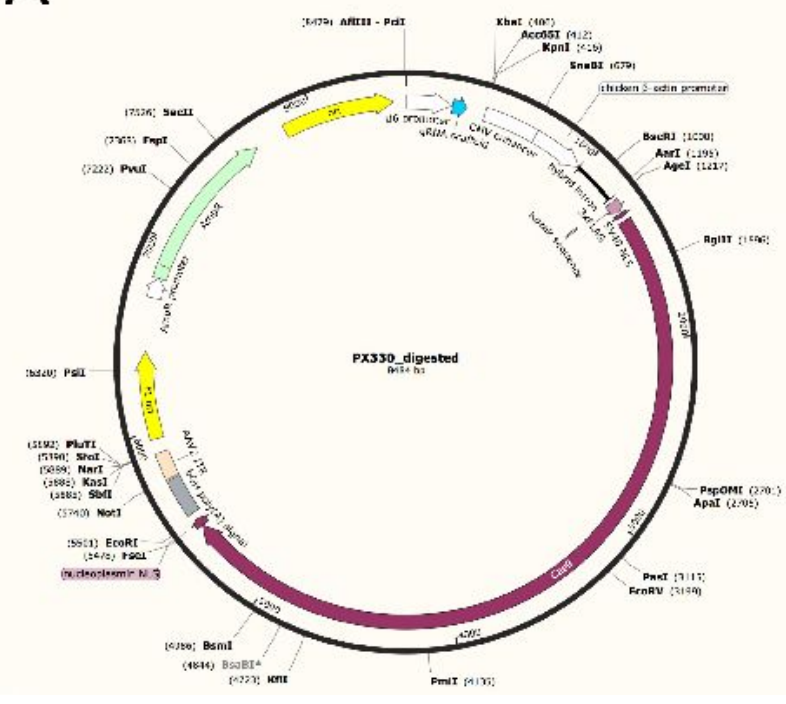

B

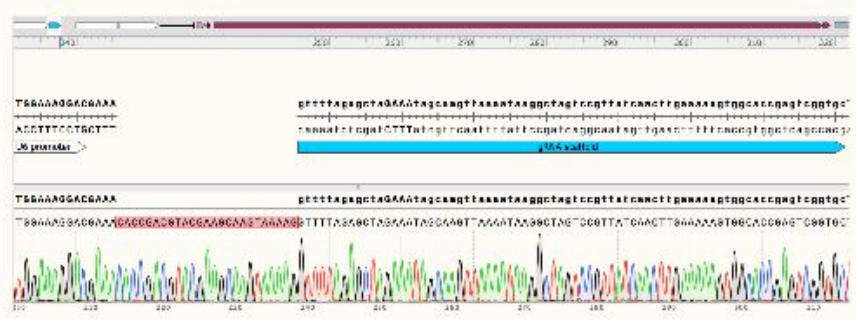


ANEXO V - ACEITE DO COMITÊ DE ÉTICA DO HOSPITAL DAS CLÍNICAS DA FACULDADE DE MEDICINA - USP-RP 


\section{USP - FACULDADE DE
MEDICINA DE RIBEIRÃO
PRP-RIBEIRÃO}

\section{PARECER CONSUBSTANCIADO DO CEP}

\section{DADOS DO PROJETO DE PESQUISA}

Título da Pesquisa: Estudo sobre a ativação e o papel do inflamassoma NLRP1 na resposta imune celular do diabetes tipo 1

Pesquisador: Daniela Carlos Sartori

Área Temática:

Versão: 2

CAAE: 58922416.6 .0000 .5440

Instituição Proponente: Hospital das Clínicas da Faculdade de Medicina de Ribeirão Preto da USP -

Patrocinador Principal: Financiamento Próprio

\section{DADOS DO PARECER}

Número do Parecer: 1.887 .263

\section{Apresentação do Projeto:}

O diabetes do tipo 1 (DM1) é uma doença autoimune e sua etiologia é determinada por fatores genéticos e pela interferência de fatores ambientais. Esta doença caracteriza-se pela disfunção do pâncreas decorrente da destruição seletiva das células presentes nas ilhotas pancreáticas e produtoras de insulina, por linfócitos T autorreativos, levando o indivíduo a um estado de hiperglicemia. Os linfócitos T CD4+ auxiliares (Th) produtores de IFN- (Th1) e CD8 citotóxicos são extremamente importantes na resposta autoimune no DM1, enquanto que linfócitos T reguladores (Treg) participam no controle desta doença. Etudos conduzidos pelo grupo de pesquisa mostraram que o aumento de linfócitos Th17 correlaciona com a progressão do DM1, e que a deficiência do receptor para IL-17 inibe a inflamação tecido-específica no pâncreas. Citocinas como IL -1, IL-6, TGF-, IL-18 e IL-23 participam da geração/expansão de linfócitos Th17, sendo que são secretadas em sua forma biologicamente ativa, com exceção da IL-1 e IL-18. Tais citocinas, por sua vez, se tornam ativas somente após clivagem proteolítica pela caspase-1 decorrente da formação do inflamassoma. Este consiste de uma plataforma molecular, que engloba membros da família dos receptores citosólicos, que incluem o NLRP1, NLRP3, NLRP6 e NLRC4. Apesar de estudos constatarem a presença de polimorfismos no gene NIrp1 em pacientes diabéticos, não há relatos

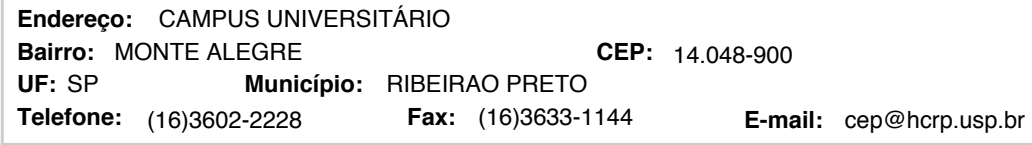




\section{USP - FACULDADE DE
MEDICINA DE RIBEIRÃO
PRETO DA USP}

Continuação do Parecer: 1.887.263

sobre a função deste receptor no DM1. Sendo assim, o projeto visa investigar o papel do inflamassoma NLRP1 na regulação da resposta celular específica e na plasticidade de linfócitos Treg/Th1/Th17 no DM1.

\section{Objetivo da Pesquisa:}

O projeto tem como principal objetivo investigar o papel funcional do inflamassoma NLRP1 na modulação da resposta imune celular no DM1, assim como os fatores que contribuem para sua ativação e as vias de sinalização intracelulares envolvidas. Especificamente, o projeto propõe:

1. Correlacionar a expressão gênica e proteica de NLRP1 e das vias de sinalização downstream com fatores de transcrição envolvidos ao padrão de resposta Treg/Th17/Th1 em células mononucleares de sangue periférico (PBMCs) de pacientes com DM1.

2. Caracterizar a população de células mielóides que expressam o receptor NLRP1, caspase-1 ativa e produzem IL-1 e/ou IL-18 em PBMCs;

3. Determinar o exato papel do inflamassoma NLRP1 na suscetibilidade/resistência ao DM1.

4. Elucidar se a ativação do inflamassoma NLRP1 e citocinas produzidas em decorrência da sua ativação (IL -1 e IL-18) interferem na estabilidade/plasticidade dos linfócitos Treg;

\section{Avaliação dos Riscos e Benefícios:}

Riscos: A pessoa que participar desta pesquisa deverá doar $40 \mathrm{~mL}$ de sangue. Esta quantidade de sangue retirada não será prejudicial à saúde. A coleta de sangue será realizada no braço, com seringas e agulhas descartáveis por um profissional capacitado, podendo levar a um leve desconforto passageiro. Além do desconforto da picada da agulha no momento da coleta de sangue, outros riscos que podem ocorrer são: formação de hematomas no local da punção venosa, dor e mais raramente, infecção no local da punção. Benefícios: A execução desse projeto será de grande relevância, uma vez que a identificação de alvos moleculares associados à imunopatogenia do DM1 poderá contribuir para a implementação e validação de terapias que poderão ser usadas futuramente no tratamento de pacientes diabéticos.

\section{Comentários e Considerações sobre a Pesquisa:}

O projeto propõe a investigação do receptor NLRP1, que apresenta um importante papel patogênico e está relacionado com morte celular induzida por piroptose, porém de forma independente das citocinas IL-1 e IL1R. Entretanto, os mecanismos precisos da via de sinalização que envolvem esse processo de piroptose ainda não foram elucidados. Com relação ao papel do receptor NLRP1 no DM1, existem apenas relatos na literatura sobre a presença de polimorfismos no gene NIrp1 em pacientes diabéticos, entretanto, a importância deste receptor assim como das

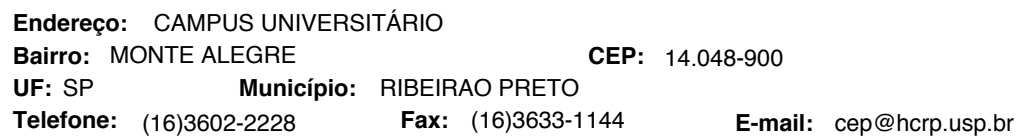




USP - FACULDADE DE
MEDICINA DE RIBEIRÃO
PSP-RIBEIRĀO

Continuação do Parecer: 1.887.263

citocinas produzidas em decorrência da sua ativação na indução da resposta inflamatória e polarização da resposta imune celular no modelo de DM1 ainda não foi investigada. Portanto, iremos avaliar o papel do receptor NLRP1, na patogênese do DM1, com ênfase na regulação da resposta mediada por linfócitos Treg/Th17/Th1 e na plasticidade destes subtipos celulares. A execução desse projeto poderá identificar alvos moleculares associados à imunopatogenia do DM1 e poderá contribuir para a implementação e validação de terapias que poderão ser usadas futuramente no tratamento de pacientes diabéticos.

\section{Considerações sobre os Termos de apresentação obrigatória:}

Os termos obrigatórios foram apresentados. A Pesquisadora responsável atendeu adequadamente as recomendações solicitadas no parecer anterior.

\section{Recomendações:}

Deve-se formatar / Configurar o termo de Consentimento Livre e Esclarecido (TCLE) de forma que a os locais destinados as assinaturas do sujeito e do pesquisador (DECLARAÇÃO DE ASSENTIMENTO DO SUJEITO DA PESQUISA) não fiquem em folhas separadas (desmembradas) do corpo do texto.

\section{Conclusões ou Pendências e Lista de Inadequações:}

Diante do exposto e à luz da Resolução CNS 466/2012, o projeto de pesquisa versão 2 Data: 18/11/16, assim como o Termo de Consentimento Livre e Esclarecido Versão 02 Data: 18/11/16, podem ser enquadrados na categoria APROVADO.

\section{Considerações Finais a critério do CEP:}

Projeto Aprovado: Tendo em vista a legislação vigente, devem ser encaminhados ao CEP, relatórios parciais anuais referentes ao andamento da pesquisa e relatório final ao término do trabalho. Qualquer modificação do projeto original deve ser apresentada a este CEP em nova versão, de forma objetiva e com justificativas, para nova apreciação.

Este parecer foi elaborado baseado nos documentos abaixo relacionados:

\begin{tabular}{|l|l|c|l|c|}
\hline Tipo Documento & \multicolumn{1}{|c|}{ Arquivo } & Postagem & Autor & Situação \\
\hline $\begin{array}{l}\text { Informações Básicas } \\
\text { do Projeto }\end{array}$ & PB_INFORMAÇÕES_BÁSICAS_DO_P & $18 / 11 / 2016$ & & Aceito \\
\hline Outros & ROJETO_425809.pdf & $10: 56: 27$ & & \\
& & & $18 / 11 / 2016$ \\
Projeto Detalhado / & projeto_detalhado_versao_02.pdf & $10: 55: 24$ & $\begin{array}{l}\text { Daniela Carlos } \\
\text { Sartori }\end{array}$ & Aceito \\
Brochura & & $10: 54: 31$ & $\begin{array}{l}\text { Daniela Carlos } \\
\text { Sartori }\end{array}$ & Aceito \\
\hline
\end{tabular}

Endereço: CAMPUS UNIVERSITÁRIO

Bairro: MONTE ALEGRE CEP: $14.048-900$

UF: SP Município: RIBEIRAO PRETO

Telefone: (16)3602-2228 Fax: (16)3633-1144 E-mail: cep@hcrp.usp.br 


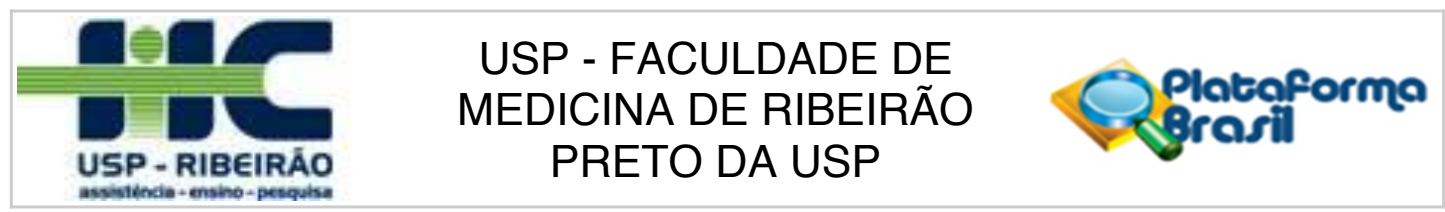

Continuação do Parecer: 1.887.263

\begin{tabular}{|l|l|c|l|c|}
\hline Investigador & projeto_detalhado_versao_02.pdf & $\begin{array}{c}18 / 11 / 2016 \\
10: 54: 31\end{array}$ & $\begin{array}{l}\text { Daniela Carlos } \\
\text { Sartori }\end{array}$ & Aceito \\
\hline TCLE / Termos de & TCLE_DM1_versao_02.pdf & $18 / 11 / 2016$ & $10: 53: 52$ \\
Assentimento / & & Daniela Carlos & Sartori \\
Justificativa de & & $19 / 08 / 2016$ & Aceito \\
Ausência & & $16: 10: 32$ & Daniela Carlos \\
Sartori & Aceito \\
\hline Outros & folha_UPC_rev.jpg & $14: 12: 57$ & Daniela Carlos & Aceito \\
\hline Projeto Detalhado / & projeto_detalhado_com_cronograma_re & $01 / 08 / 2016$ & \\
Brochura & v.docx & $01 / 08 / 2016$ & Daniela Carlos & Aceito \\
Investigador & & $14: 10: 57$ & & \\
\hline TCLE / Termos de & TCLE_DM1_rev.docx & & & Aceito \\
Assentimento / & & $28 / 07 / 2016$ \\
Justificativa de & & $28: 11: 45$ & Daniela Carlos & Aceito \\
Ausência & & $16: 00: 57$ & Daniela Carlos & for \\
\hline Folha de Rosto & folha_de_rosto.pdf & & & \\
\hline Orçamento & Orcamento_financeiro.docx & & \\
\end{tabular}

Situação do Parecer:

Aprovado

Necessita Apreciação da CONEP:

Não

RIBEIRAO PRETO, 13 de Dezembro de 2016

Assinado por:
MARCIA GUIMARÃES VILLANOVA

(Coordenador)

Endereço: CAMPUS UNIVERSITÁRIO

Bairro: MONTE ALEGRE

CEP: $14.048-900$

UF: SP Município: RIBEIRAO PRETO

Telefone: (16)3602-2228 Fax: (16)3633-1144 E-mail: cep@hcrp.usp.br 
ANEXO VI - TERMO DE CONSENTIMENTO LIVRE E ESCLARECIDO ENTREGUE AOS PACIENTES NO ATO DA COLETA DE SANGUE 
HOSPITAL DAS CLÍNICAS - FACULDADE DE MEDICINA DE RIBEIRÃO PRETO - UNIVERSIDADE DE SÃO

PAULO

\title{
TERMO DE CONSENTIMENTO LIVRE E ESCLARECIDO
}

\author{
Título do Projeto: \\ "Estudo sobre a ativação e o papel do inflamassoma NLRP1 na resposta imune \\ celular do diabetes tipo 1".
}

\section{Pesquisadores responsáveis:}

Frederico Ribeiro Campos Costa/ Dra. Maria Cristina Foss de Freitas / Dra. Kelen Cristina Ribeirão Malmegrim de Farias/ Dra. Diane Meyre Rassi / Dra. Daniela Carlos

\section{Prezado voluntário (a),}

Gostaríamos de convidá-lo (a) a participar deste projeto de pesquisa. Este projeto faz parte de uma linha de pesquisa que vem sendo desenvolvida pelo corpo clínico do Hospital das Clínicas da FMRP-USP em conjunto com os pesquisadores do Departamento de Bioquímica e Imunologia da FMRP-USP, com o objetivo de entender melhor porque nosso sistema de defesa ataca e destrói as células produtoras de insulina, levando ao aparecimento do diabetes tipo 1 . A sua participação é voluntária. Para participar, é necessário ler atentamente este documento e ouvir nossas explicações em caso de dúvidas. Se estiver interessado em participar, solicitaremos que assine este documento.

\section{Como será feita esta pesquisa?}

Após ter concordado em participar do estudo e ter assinado este termo de consentimento, a coleta de sangue será feita com o auxílio de agulhas e seringas descartáveis, pela equipe do ambulatório do Hospital das Clínicas da Faculdade de Medicina de Ribeirão Preto. A partir do sangue coletado, serão isoladas diversas células do sistema de defesa e serão realizadas várias análises laboratoriais a fim de se entender melhor os mecanismos imunológicos envolvidos no diabetes tipo 1.

\section{O que será feito com o material remanescente a este estudo?}

As células remanescentes a esta pesquisa serão conservadas no biorepositório de AMOSTRAS DE SANGUE DM1 - FMRP - USP para análises futuras, com finalidade científica. $O$ armazenamento do material também é opcional, não havendo nenhum prejuízo ou represálias caso você opte por não permitir o armazenamento do material.

\section{Como você vai participar da pesquisa, quais são os riscos que podem ocorrer?}

A pessoa que participar desta pesquisa deverá doar $40 \mathrm{~mL}$ (aproximadamente 8 colheres de chá) de sangue. Esta quantidade de sangue retirada não será prejudicial à saúde. A coleta de sangue será realizada no braço, com seringas e agulhas descartáveis por um profissional capacitado, podendo levar a um leve desconforto passageiro. Além do desconforto da picada 
HOSPITAL DAS CLÍNICAS - FACULDADE DE MEDICINA DE RIBEIRÃO PRETO - UNIVERSIDADE DE SÃO

PAULO

da agulha no momento da coleta de sangue, outros riscos que podem ocorrer são: formação de hematomas no local, dor e mais raramente, infecção no local da punção.

O que acontece se eu não aceitar em participar?

Sua participação é voluntária e caso você opte por não participar, não terá nenhum prejuízo ou represálias.

\section{Haverá alguma despesa ou benefício com este estudo?}

Não haverá nenhuma despesa e nenhum ganho em dinheiro. O único benefício será o de auxiliar-nos a tentar melhorar no futuro o tratamento de pessoas com diabetes tipo 1. Afirmamos que os dados obtidos serão guardados de maneira sigilosa e que os nomes dos participantes não serão divulgados em nenhum momento.

Caso você se sinta prejudicado por esta pesquisa, terá direito a indenização conforme as leis vigentes no pais.

Garantimos o direito de receber respostas e esclarecimentos de quaisquer dúvidas a respeito dos procedimentos, riscos, benefícios e de outras situações relacionadas com a pesquisa, bem como a liberdade de retirar o seu consentimento e deixar de participar do estudo, a qualquer momento, sem que isso lhe traga qualquer prejuízo.

Estamos à disposição para esclarecer qualquer dúvida sobre esta pesquisa. Neste caso, favor entrar em contato com Frederico Ribeiro Campos Costa pelo telefone 3315-3231 (ramal 3231). Você poderá também contatar o comitê de Ética em Pesquisa do Hospital das Clínicas da Faculdade de Medicina de Ribeirão Preto no telefone 01636022228 para dúvidas éticas.

Eu receberei uma cópia assinada e datada deste Documento

\section{DECLARACC̃̃O DE ASSENTIMENTO DO SUJEITO DA PESQUISA:}

Eu li e discuti com o investigador responsável pelo presente estudo os detalhes descritos neste documento. Entendo que eu sou livre para aceitar ou recusar, e que posso interromper a minha participação a qualquer momento sem dar uma razão. Eu concordo que os dados coletados para o estudo sejam usados para o propósito acima descrito e que as células remanescentes sejam armazenadas para projetos científicos futuros.

Eu entendi a informação apresentada neste TERMO DE ASSENTIMENTO. Eu tive a oportunidade para fazer perguntas e todas as minhas perguntas foram respondidas.

Eu receberei uma cópia assinada e datada deste Documento DE ASSENTIMENTO INFORMADO.

NOME DO DOADOR

ASSINATURA

DATA

NOME DO INVESTIGADOR

ASSINATURA

DATA 